Tiago Januário da Costa

\title{
TESTOSTERONA ABOLE OS EFEITOS \\ VASCULOPROTETORES DO TRATAMENTO COM CONJUGADO ESTROGÊNIO EQUINO (PREMARIN®) \\ EM RATAS ESPONTANEAMENTE HIPERTENSAS OVARIECTOMIZADAS
}

Dissertação apresentada ao

Programa de Pós-graduação em Farmacologia do Instituto de Ciências Biomédicas da Universidade de São Paulo para obtenção do título de Mestre em Ciências. 
Tiago Januário da Costa

\title{
TESTOTERONA ABOLE OS EFEITOS \\ VASCULOPROTETORES NO TRATAMENTO COM \\ CONJUGADO ESTROGÊNIO EQUINO (PREMARIN囚) EM \\ RATAS ESPONTANEAMENTE HIPERTENSAS \\ OVARIECTOMIZADAS
}

\begin{abstract}
Dissertação apresentada ao
Programa de Pós-graduação em

Farmacologia do Instituto de Ciências

Biomédicas da Universidade de São

Paulo para obtenção do título de Mestre em Ciências.

Área de Concentração: Farmacologia

Orientadora: $\operatorname{Prof}^{\mathrm{a}} \mathrm{Dr}^{\mathrm{a}}$ Maria Helena Catelli de Carvalho

Versão corrigida. A versão original eletrônica encontra-se disponível tanto na Biblioteca do ICB quanto na Biblioteca Digital de Teses e Dissertações da USP (BDTD).
\end{abstract}


DADOS DE CATALOGAÇÃO NA PUBLICAÇÃO (CIP)

Serviço de Biblioteca e Informação Biomédica do

Instituto de Ciências Biomédicas da Universidade de São Paulo

reprodução não autorizada pelo autor

Costa, Tiago Januário.

Testosterona abole os efeitos vasculoprotetores do tratamento com conjugado estrogênio equino (PREMARIN $\left.{ }^{\circledR}\right)$ em ratas espontaneamente hipertensas (SHR) ovariectomizadas / Tiago Januário Costa. -- São Paulo, 2012.

Orientador: Profa. Dra. Maria Helena Catelli de Carvalho.

Dissertação (Mestrado) - Universidade de São Paulo. Instituto de Ciências Biomédicas. Departamento de Farmacologia. Área de concentração: Farmacologia. Linha de pesquisa: Hipertensão e terapia de reposição hormonal.

Versão do título para o inglês: The vascular protective effects of conjugated equine estrogen (PREMARIN ${ }^{\circledR}$ ) is blunted by testosterone in ovariectomized spontaneously hypertenssive rats (SHR).

$\begin{array}{llll}\text { 1. Hipertensão } & \text { 2. Estrógeno } & 3 \text {. Testosterona 4. Endotélio vascular }\end{array}$ 5. Ovariectomia 6. Estresse oxidativo I. Carvalho, Profa. Dra. Maria Helena Catelli de II. Universidade de São Paulo. Instituto de Ciências Biomédicas. Programa de Pós-Graduação em Farmacologia III. Título. 
Candidato(a):

Título da Dissertação:

Orientador(a):
Tiago Januário Costa.

Testosterona abole os efeitos vasculoprotetores do tratamento com conjugado estrogênio equino (PREMARIN ${ }^{\circledR}$ ) em ratas espontaneamente hipertensas (SHR) ovariectomizadas.

Profa. Dra. Maria Helena Catelli de Carvalho.

A Comissão Julgadora dos trabalhos de Defesa da Dissertação de Mestrado, em sessão pública realizada a ...
( ) Aprovado(a)
( ) Reprovado(a)

Examinador(a): Assinatura:

Nome:

Instituição:

Examinador(a): Assinatura:

Nome:

Instituição:

Presidente: Assinatura:

Nome:

Instituição: 


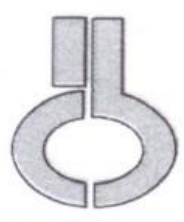

UNIVERSIDADE DE SÃO PAULO INSTITUTO DE CIÊNCIAS BIOMÉDICAS

Cidade Universitária "Armando de Salles Oliveira"

Av. Prof. Lineu Prestes, 2415 - CEP. 05508-000 São Paulo, SP - Brasil

Telefone :(55) (011) 3091.7733 - e-mail: ceparieb, usp.br

\section{Certificado}

Certificamos que o protocolo registrado sob $\mathrm{n}^{\circ} \mathbf{1 4 5}$ nas fls. 95 do livro 02 para uso de animais em experimentaçāo, sob a responsabilidade do $\operatorname{Prof}(a) \operatorname{Dr}(\mathrm{a})$ Maria Helena Catelli de Carvalho, Coordenador(a) da Linha de pesquisa Reatividade de macro e microvasos em patologias experimentais. Papel do endotélio do qual participam o(s) alunos Graziela Scalianti Ceravolo, Rosana Marangoni,Fernando Paranaiba Filgueira, Gisele Facholi Bomfim, Luciana dos Reis Rigueiral Giaquinto, Thiago Januário da Costa, Priscila Xavier de Araujo, Cynthia Echem de Souza Pereira, Murilo Lombardo Lopes Pereira, está de acordo com os Principios Éticos de Experimentação Animal adotado pela Sociedade Brasileira de Ciência de Animais de Laboratório (SBCAL) e foi aprovado pela COMISSĀO DE ÉTICA NO USO DE ANIMAIS (CEUA) em 06.12.2010, com validade de 3 anos.

Sāo Paulo, 08 de dezembro de 2010.
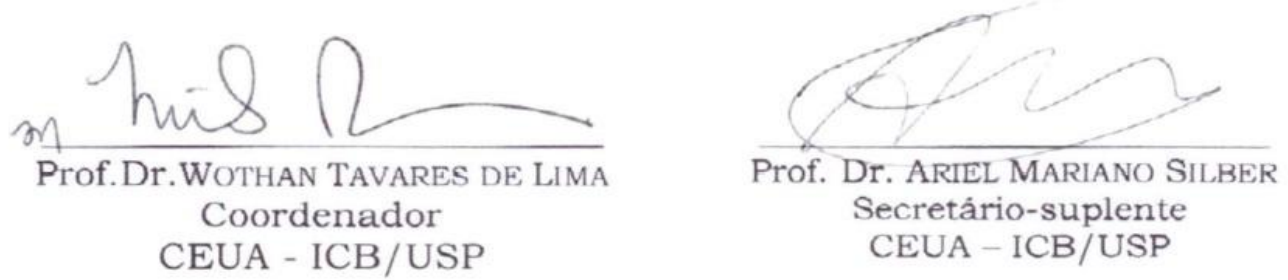
A vocês que fazem parte da minha vida. 


\section{AGRADECIMENTOS}

Á Deus por me agraciar com o dom da vida e, além de agraciar-me, se fazer presente diariamente dando suporte de forma inexplicável a todos os meus passos.

\section{A partir de hoje não sou mais o mesmo, pois, no quebra-cabeça da vida, algumas} pessoas me ajudaram a encaixar mais uma peça.

Prof ${ }^{a}$ Dr $^{\mathrm{a}}$ Maria Helena Catelli de Carvalho (professora Maria Helena) pelo incentivo dado, que começou na iniciação científica, e persistiu até o mestrado. Obrigado pelas conversas enriquecedoras, orientações, incentivos e por me conduzir de uma forma que me faz crescer.

A $\operatorname{Prof}^{a} \mathrm{Dr}^{\mathrm{a}}$ Graziela S. Ceravolo (a Gra) pelo grande apoio dado ao longe desses 4 anos que trabalhamos juntos; somos parceiros! Obrigado pelas dicas, correções e tantos aprendizados. Obrigado por me ouvir e por me orientar nas diversas situações da vida. Meu reconhecimento é eterno.

A Prof ${ }^{a} \operatorname{Dr}^{a}$ Zuleica Bruno Fortes (Professora Zuleica). Tive algumas oportunidades de entrar na sua sala e conversar. Sua experiência, compreensão, dicas e orientações me fez crescer de uma forma inimaginável. A sua conduta científica é admirável.

A Prof ${ }^{a} \operatorname{Dr}^{\mathrm{a}}$ Eliana (a Eli) pelas dicas, ajudas, disponibilização do seu laboratório, do seu tempo e por me ouvir em momentos de loucuras e desespero.

Aos fantásticos amigos de laboratório, o meu muito obrigado, primeiramente, pelo grande suporte técnico, dicas, discussões científicas e ajudas; com vocês torna-se mais fácil. Segundo, pela imensa amizade, bate-papos (cassação de assunto), opiniões, ajudas pessoais, risadas, imitações, cafés (chás), florais e lanches que tornaram nossa convivência mais harmoniosa. Sou de fã de cada um de vocês:

Priscila Xavier (a Pri), Cinthya Echem (a Ci), Beatriz F. Ponzio (a Bia), Simone Marcielle Sartoretto (a Mone), Vanessa Oliveira (a Van), Gisele F. Bomfim (a Gi), Eveline Fonseca (a Eve), Graziele Neves (a NH), Maria Aparecida de Oliveria (a Cidora), Sônia Leite (a Bá), Marta Rodrigues (a Marta Gata), Ana Rita Araújo (a Ritinha), Antônio Garcia (o Tonho), Rosangela Eicheler (a Rosa), Caroline Midori (a Carol), Paula Honda (a Paulinha), Clara Martins (a Clara), Verônica (a Verônica), Alice Araújo (a tia Alice), Manuel Rocha (o Manecas), Fernanda Giachini (a Fê), Fernando Carneiro (o Fernando), Núbia Lobato (a Núbia), Fernando Filgueira (o Fernandinho).

Agradeço a meninas da secretária Camila, Mônica, Selma e Julieta pela imensa colaboração dada e amizade.

Obrigado a Beatriz Felice Ponzio (a Bia) pela pergunta que iniciou tudo isso: $\mathrm{Ti}$, vocë quer fazer um estágio?

Obrigado a Simone Marciele Sartoretto (a Mone, Mone do Pai, Sartoretto, Si, Representante de discente) pelo imenso companheirismo político, por me defender, pela amizade e por 
tantos momentos de conversa e desabafos onde surgiram tantas teorias malucas. $V_{1}$ iluminada, acredite nisso.

A Luciana Giaquinto (a Lu) pela grande amizade, conversas, longos bate-papos (com diversas análises) e parcerias jornalísticas (eae Lu belê?).

Obrigado Maria Aparecida de Oliveira (a Cidora) pelas caronas que não era apenas caronas, mas um momento de boas conversas, aprendizado e troca de experiências. Pelas ajudas e dicas que muito me acrescentaram, o meu reconhecimento. Sou seu fã Cidora.

Obrigado Rosangela Eichler (a Rosa) pelo grandioso suporte, amizade e broncas que foram essências para o aprendizado. Agradeço também a sua fantástica família, o Marcio, o Otto e o Erik que me receberam em sua casa como se eu fosse parte dela e na alegria e inocência da infância me fizeram acreditar que o mundo ainda é belo. Sou fã de vocês!

Obrigado Sônia Leite (a Bá) e Marta Rodrigues (a Marta Gata) por, literalmente, pegarem na minha mão e me conduzirem nos experimentos. A qualidade dos experimentos com vocês é indiscutível.

A Ana Rita Arújo (a Ritinha: "detesto") que me concedeu a liberdade de uma grande amizade. Os momentos de comida baiana e conversas (sobre o nazismo e o governo brasileiro) foram muito importantes. E, como você diria: "Não vou mais agradecer porque eu detesto, essa droga...é tudo engano essa dissertação”.

\section{O que seria de mim sem minha família}

Obrigado família! Vocês trabalham no anonimato, mas tudo o que eu sou hoje é o reflexo de cada um de vocês. Ao meu pai Oripes Januário da Costa, minha mãe Alaíde Célia Pereira da Costa e minha irmã Beatriz Pereira da Costa, o meu eterno obrigado, amo vocês. Obrigado também aos "Januário da Costa" e os "Pereira" vocês realmente acreditam no meu trabalho e me incentivam.

\section{E o que seria da vida sem o convívio com diferentes ideias, ideologias, crenças e opiniões. Amigos, sem vocês não tem graça.}

Erika Freitas (a Erika), Silvana Oliveira (a Si), Natália Fontenelle (a Naty), Maria de Lourdes Reis (a Lourdes), Guilherme Sendas (o Gui), Leandro Rezende (o Lê), Laurindo Vanícola (o seu Laurindo), Sônia Sales (a Soninha), Sidney Vitorino (o Sidney), Ivanildo Barbosa (o Bola), Natália Yara (a Nathy), Bernadete Morisco (a Bê), Willian Fahl ( o W.), Cristina Horii (a Leika), Rafaela Batalhote (a Rafa), Zilma Silva (a Zilmaaa), Isabel Araújo (a Bel), José Perez (o Perez), Otávio Araújo (o Otávio), Pe. Otacílio Lacerda (o Pá tácilio), Pe. Paulo Afonso Sobrinho (o Pe. Paulo), Wilma Filocreão B. Cunha (a Wilma), Valdete Ceolin (a Val), Luzia Chacin (a Lu), Ana Alice Dias (a gatinha), Andrea Bordenali (a Andrea), Mauro Terralavoro (o anjão), Adriano Orlando (o Dri). 
Aos professores que participaram da minha formação o meu reconhecimento e gratidão: Rita Tostes, Luciana Rossoni, Lucia Lopes, Antônio Carlos de Oliveira, Kátia de Angelis, Gilberto de Nucci, Silvia Lachinni, Maria Lúcia Abib, José Guilherme Chaui Berlinck, Szulin Ber Zinguer.

Agradeço a Fundação de Amparo a Pesquisa do Estado de São Paulo (FAPESP) e Coordenadoria de Aperfeiçoamento de Pessoal de Nível Superior (CAPES) pelo suporte financeiro para o desenvolvimento desta pesquisa. 
Sem arriscar, não vivemos a esperança.

(Dom Hélder Câmara) 


\section{RESUMO}

Costa TJ. Testosterona abole os efeitos vasculoprotetores do tratamento com conjugado estrogênio equino (Premarin ${ }^{\circledR}$ ) em ratas espontaneamente hipertensas ovariectomizadas. [Dissertação (Mestrado em Ciências)]. São Paulo: Instituto de Ciências Biomédicas da Universidade de São Paulo; 2012.

Os efeitos vasculares do tratamento hormonal com estrogênios associados à testosterona, utilizado para tratamento do distúrbio do desejo sexual hipoativo na pós-menopausa, ainda não estão completamente elucidados. Diante disso, o objetivo do presente trabalho foi avaliar os efeitos do tratamento de ratas espontaneamente hipertensas (SHR) ovariectomizadas (OVX) com um conjugado estrogênio equino (CEE) associado à cipionato de testosterona sobre a reatividade de anéis de aorta isoladas e sobre a pressão arterial. Para isso, ratas SHR com 12 semanas de idade foram divididas em quatro grupos experimentais: animais controle (sham - ratas em estro-fisiológico), OVX, OVX tratada por 15 dias com CEE $(9,6 \mu \mathrm{g} / \mathrm{Kg} / \mathrm{dia}$, gavagem) e OVX tratada com CEE associado ao cipionato de testosterona (2,85 $\mathrm{mg} / \mathrm{kg} / \mathrm{semana}$,im). Foi demonstrado que o tratamento de ratas OVX com CEE corrige a hiperreatividade dos anéis de aorta com endotélio a agentes vasoconstritores: angiotensina II (ANGII) e Fenilefrina (FE). Além disso, o CEE também aumenta a resposta vasodilatadora endotélio-dependente à acetilcolina (ACh) nos anéis de aorta das fêmeas. Estes efeitos benéficos do CEE parecem estar relacionados com a redução da expressão de subunidades da enzima NADPH oxidase e aumento na expressão de enzimas antioxidantes o que resultou em correção da marcação para espécies reativas de oxigênio (EROs) na aorta. Por outro lado, quando a testosterona foi associada ao CEE os benefícios promovidos pelos estrogênios na aorta das ratas SHR-OVX foram abolidos. Dessa forma, os anéis de aorta com endotélio de ratas OVX tratadas com testosterona associada a CEE foram hiperreativos a ANG II e FE, ao passo que a resposta vasodilatadora induzida pela ACh foi diminuída em comparação com as ratas controle e OVX tratadas apenas com CEE. Este comprometimento do efeito protetor do CEE pela associação com testosterona parece depender da maior geração de EROs induzidas pela ativação de 
receptores AT1 de ANG II, por ação do metabólito 20-HETE e ainda pela ativação da NADPH oxidase. Portanto, a associação de CEE e testosterona abole os efeitos vasculoprotetores do CEE, agravando a disfunção endotelial de fêmeas SHR-OVX.

Palavras-chave: Hipertensão. Estrógeno. Testosterona. Endotélio Vascular. Ovariectomia. Estresse oxidativo. 


\begin{abstract}
Costa TJ. The vascular protective effects of conjugated equine estrogen (Premarin $\AA$ ) is blunted by testosterone in ovariectomized SHR. [Masters thesis (Pharmacology]. São Paulo: Instituto de Ciências Biomédicas da Universidade de São Paulo; 2012.
\end{abstract}

The vascular effects of estrogens and testosterone association, used hypoactive sexual desire disorder in postmenopausal women, have not been elucidated. The aim of this study was to evaluate the vascular effects of ovariectomized spontaneously hypertensive rats (OVX-SHR) with a conjugated equine estrogen (CEE) associated or not with testosterone cypionate on reactivity of isolated aortic rings and in blood pressure. For this purpose, 12 week-old SHR were divided into four groups: control (estrus), OVX treated and untreated. The treated OVX groups received either CEE for 15 days $(9.6 \mu \mathrm{g} / \mathrm{kg} /$ day gavage) or CEE associated or testosterone cypionate $(2.85 \mathrm{mg} / \mathrm{kg} /$ week, im). Treatment of OVX rats with CEE corrected the hyperreactivity to vasoconstrictor agents: angiotensin II (ANGII) and phenylephrine (PE). Furthermore, the CEE treatment also increased the endothelium-dependent vasodilator response to acetylcholine (ACh) from OVX rats. These beneficial effects of CEE appear to be related with increased expression of antioxidant enzymes; a reduction in NADPH oxidase subunits expression and reactive oxygen species (ROS) generation. On the other hand, the testosterone association blunted the vascular benefits provided by CEE in SHR-OVX. Thus, aortic rings with endothelium from OVX rats treated with testosterone and CEE were hyperresponsive to vasoconstrictors and exhibited impaired vasodilator responses to Ach, compared to aortas from control and CEE rats. The inhibition of CEE protective effect in aorta by testosterone seems to be related with increased ROS generation through a mechanism that involves ANG II AT1 receptors activation, increased responses to in metabolite 20-HETE and NADPH oxidase activation.

Key words: Hypertension. Estrogen. Testosterone. Vascular endothelium. Ovariectomy. Oxidative stress. 


\section{LISTA DE FIGURAS}

Figura 1 - Esquema representativo da cascata de reações do sistema renina-angiotensina e as ações hormonais (estrógeno e testosterona) sobre a produção de angiotensinogênio e renina e na expressão da ECA e receptor AT1 endoteliais.

Figura 2 - Efeito da ovariectomia e dos tratamentos hormonais (CEE e CEE+T) sobre a resposta vasoconstritora a angiotensina II em anéis de aorta com endotélio.

Figura 3 - Efeito da ovariectomia e dos tratamentos hormonais (CEE e CEE+T) sobre a resposta vasoconstritora a angiotensina II em anéis de aorta sem endotélio.

Figura 4 - Efeito da ovariectomia e dos tratamentos hormonais (CEE e CEE+T) sobre a resposta vasodilatadora a ACh em anéis de aorta com endotélio.

Figura 5 - Efeito da ovariectomia e dos tratamentos hormonais (CEE e CEE+T) sobre a resposta máxima vasodilatadora a ACh em anéis de aorta com endotélio.

Figura 6 - Efeito da ovariectomia e dos tratamentos hormonais (CEE e CEE+T) sobre a resposta vasodilatadora ao nitroprussiato de sódio em anéis de aorta com endotélio.

Figura 7 - Efeito da ovariectomia e dos tratamentos hormonais (CEE e CEE+T) sobre a resposta máxima vasodilatadora ao nitroprussiato de sódio em anéis de aorta com endotélio.

Figura 8 - Efeito da ovariectomia e dos tratamentos hormonais (CEE e CEE+T) sobre a resposta vasoconstritora a fenilefrina em anéis de aorta com endotélio.

Figura 9 - Efeito da ovariectomia e dos tratamentos hormonais (CEE e CEE+T) sobre a resposta vasodilatadora a ACh em anéis de aorta, com endotélio, na presença do losartan, antagonista do AT1R.

Figura 10 - Efeito da ovariectomia e dos tratamentos hormonais (CEE e CEE+T) sobre a resposta máxima vasodilatadora a ACh em anéis de aorta, com endotélio, na presença ou não do losartan, antagonista do AT1R.

Figura 11 - Efeito da ovariectomia e dos tratamentos hormonais (CEE e CEE+T) sobre a resposta máxima vasodilatadora a ACh em anéis de aorta, com endotélio, na presença do losartan, antagonista do AT1R.

Figura 12 - Efeito da ovariectomia e dos tratamentos hormonais (CEE e CEE+T) sobre a resposta vasodilatadora a ACh em anéis de aorta, com endotélio, na presença de Apocinina, inibidor da NADPH oxidase.

Figura 13 - Efeito da ovariectomia e dos tratamentos hormonais (CEE e CEE+T) sobre a resposta máxima vasodilatadora a ACh em anéis de aorta, com endotélio, na presença ou não de Apocinina, inibidor da NADHP oxidase. 
Figura 14 - Efeito da ovariectomia e dos tratamentos hormonais (CEE e CEE+T) sobre a resposta máxima vasodilatadora a ACh em anéis de aorta, com endotélio, na presença de Apocinina, inibidor da NADPH oxidase.

Figura 15 - Efeito da ovariectomia e dos tratamentos hormonais (CEE e CEE+T) sobre a resposta vasodilatadora a ACh em anéis de aorta, com endotélio, na presença de L-NAME, inibidor da óxido nítrico sintase.

Figura 16 - Efeito da ovariectomia e dos tratamentos hormonais (CEE e CEE+T) sobre a geração de EROs em anéis de aorta com endotélio.

Figura 17 - Efeito da ovariectomia e dos tratamentos hormonais (CEE e CEE+T) sobre a geração de EROs em anéis de aorta, com endotélio, na presença do losartan, antagonista do AT1R.

Figura 18 - Efeito da ovariectomia e dos tratamentos hormonais (CEE e CEE+T) sobre a geração de EROs em anéis de aorta, com endotélio, na presença de Apocinina, inibidor da NADPH oxidase.

Figura 19 - Efeito da ovariectomia e dos tratamentos hormonais (CEE e CEE+T) sobre a geração de EROs em anéis de aorta, com endotélio, na presença do 0016HET, inibidor do 20-HETE.

Figura 20 - Efeito da ovariectomia e dos tratamentos hormonais (CEE e CEE+T) sobre a expressão proteica da eNOS em anéis de aorta com endotélio.

Figura 21 - Efeito da ovariectomia e dos tratamentos hormonais (CEE e CEE+T) sobre a expressão do RNAm dos receptores AT1 e AT2 de angiotensina II em anéis de aorta com endotélio.

Figura 22 - Efeito da ovariectomia e dos tratamentos hormonais (CEE e CEE+T) sobre a expressão do RNAm das subunidades da NADPH oxidase (gp91 ${ }^{\text {phox }}$, p4 $7^{\text {phox }}$ e p22 $\left.{ }^{\text {phox }}\right) \mathrm{em}$ anéis de aorta com endotélio.

Figura 23 - Efeito da ovariectomia e dos tratamentos hormonais (CEE e CEE+T) sobre a expressão proteica da superóxido dismutase em anéis de aorta com endotélio.

Figura 24 - Efeito da ovariectomia e dos tratamentos hormonais (CEE e CEE+T) sobre a expressão proteica da catalase em anéis de aorta com endotélio.

Figura 25 - Efeito da ovariectomia e dos tratamentos hormonais (CEE e CEE+T) sobre a expressão do RNAm dos receptores de estrógeno $(\alpha$ e $\beta$ ) e andrógeno. 


\section{LISTA DE TABELAS}

Tabela 1 - Afinidade relativa de ligação (RAL) do CEE nos receptores de estrógeno $\alpha$ e $\beta$ (modificado de BHAVNANI, 2002)

Tabela 2 - Oligonucleotídeos dos receptores de AT1 e AT2 (de ANGII), $\alpha$ e $\beta$ (de estrógeno), de andrógeno e das subunidades da NAD(P)H oxidase (gp91phox, p47phox p22phox )

Tabela 3 - Efeito da ovariectomia e dos tratamentos hormonais (CEE e CEE+T) no peso seco e úmido do útero e nos níveis séricos de $17 \beta$-estradiol, progesterona, testosterona e estrona de fêmeas SHR 46

Tabela 4 - Efeito da ovariectomia e dos tratamentos hormonais (CEE e CEE+T) no peso corpóreo $(\mathrm{g})$ de fêmeas

Tabela 5 - Efeito da ovariectomia e dos tratamentos hormonais (CEE e CEE+T) sobre o peso dos músculos e de gordura retroperitonial de fêmeas SHR

Tabela 6 - Efeito da ovariectomia e dos tratamentos hormonais (CEE e CEE+T) sobre a pressão arterial direta das fêmeas SHR 


\section{LISTA DE ABREVIATURAS E SIGLAS}

20-HETE 20-hydroxyeicosatetraenoic acid (20-hidroxi ácido araquidônico)

$\mathrm{ACh}$

Acetilcolina

ANG II

Angiotensina II

ANOVA

Análise de variância

APO

Apocinina

AT1R

Receptor do tipo AT1 de angiotensina II

AT2R

Receptor do tipo AT2 de angiotensina II

CEE

Conjugado Estrogênio Equino

$\mathrm{CEE}+\mathrm{T}$

Conjugado Estrogênio Equino associado à testosterona

eNOS

Sintase de Óxido Nítrico endotelial

EPM

Erro padrão da média

EROs

Espécies reativas de oxigênio

FE

Fenilefrina

LOS

Losartan

$\mathrm{mmHg}$

Milímetro de mercúrio

NOR

Noradrenalina

NOS

Óxido Nítrico Sintase

NPS

Nitroprussiato de sódio

OVX

Ovariectomia

Rmax

Resposta máxima

SRA

Sistema Renina-Angiotensina

$\mathrm{TH}$

Terapia Hormonal 


\section{Sumário}

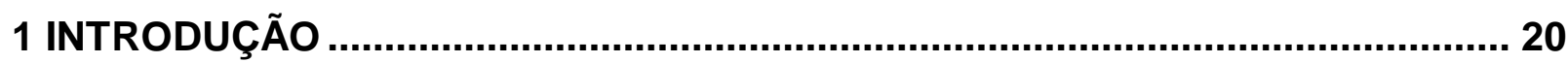

1.1 Pressão arterial, hipertensão arterial e pós-menopausa ...................................20

1.2 Terapia de Reposição Hormonal - TRH ....................................................... 27

1.3 Menopausa, baixo libido e reposição hormonal com testosterona........................ 31

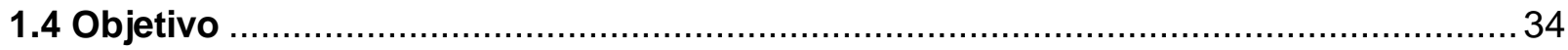

2 MATERIAL E MÉTODOS ........................................................................... 35

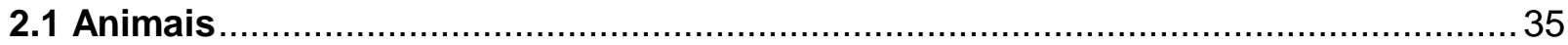

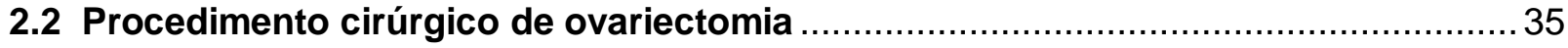

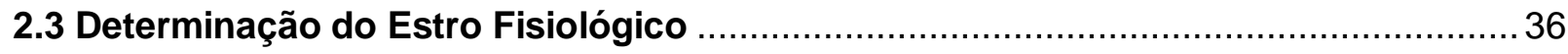

2.4 Tratamento com Conjugado Estrogênio Equino (CEE) ................................... 36

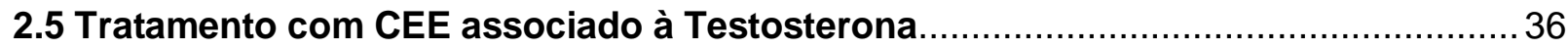

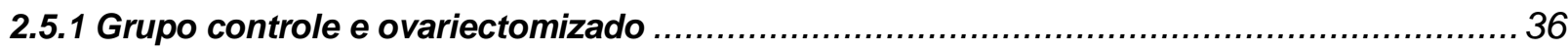

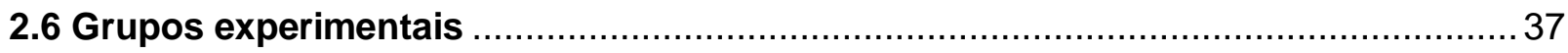

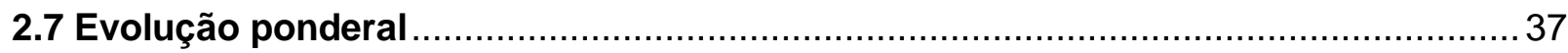

2.8 Determinação da eficácia da ovariectomia e dos tratamentos hormonais ............... 37

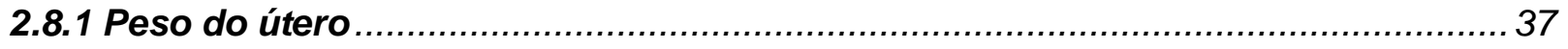

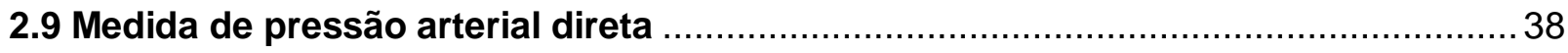

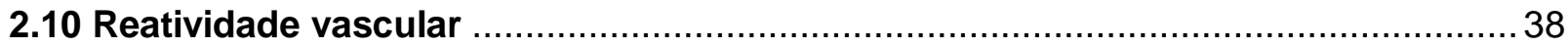

2.11 Expressão do RNAm por Reação em Cadeia da Polimerase (RT-PCR) em tempo real.

2.12 Geração de Espécies Reativas de Oxigênio (EROs) .................................... 41

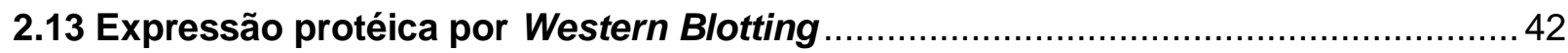

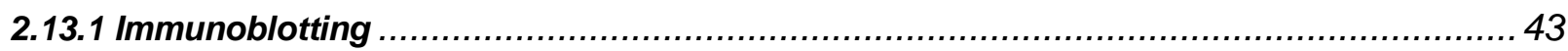

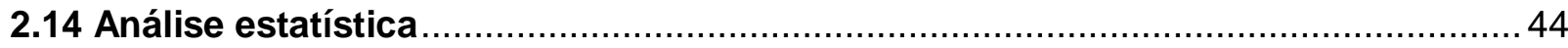

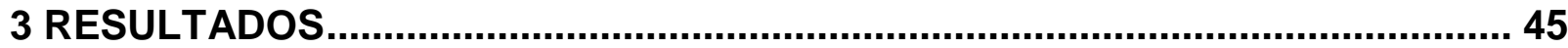


3.1 Caracterização do modelo de ovariectomia

3.1.1 Peso uterino e concentração sérica de 17ß-estradiol, progesterona, testosterona e estrona.

3.1.2 Peso corpóreo (g)

3.1.3 Peso muscular e de gordura retroperitonial.

3.1.4 Avaliação da pressão arterial direta

4 REATIVIDADE VASCULAR

4.1 Avaliação da resposta vasoconstritora à ANG II em anéis de aorta com e sem endotélio, isolados de fêmeas SHR 50

4.2 Avaliação da resposta vasodilatadora à $\mathrm{ACh}$ em anéis de aorta com e sem endotélio , isolados de fêmeas SHR

4.3 Avaliação da resposta vasodilatadora ao NPS em anéis de aorta com endotélio, isolados de fêmeas SHR 56

4.4 Avaliação da resposta vasoconstritora à fenilefrina em anéis de aorta com endotélio, isolados de fêmeas SHR

4.5 Avaliação da resposta vasodilatadora à ACh na presença do antagonista do AT1R de ANG II (losartan) em anéis de aorta isolados de fêmeas SHR.

4.6 Avaliação da resposta vasodilatadora à ACh na presença da apocinina, inibidor da NADPH oxidase.

4.7 Avaliação da resposta vasodilatadora à ACh na presença do inibidor da NOS, LNAME em anéis de aorta de fêmeas SHR.

4.8 Avaliação da geração de espécies reativas de oxigênio (EROs)

4.9 Avaliação da geração de espécies reativas de oxigênio (EROs) na presença do antagonista do AT1R, losartan, em anéis de aorta de fêmeas SHR 71

4.10 Avaliação da geração de espécies reativas de oxigênio (EROs) na presença do inibidor da NADPH oxidase, apocinina, em anéis de aorta de fêmeas SHR 73

4.11 Avaliação da geração de espécies reativas de oxigênio (EROs) no presença do 0016HET, inibidor do 20-HETE, em anéis de aorta de fêmeas SHR. 75

4.12 Análise da expressão protéica da eNOS total em aortas de fêmeas SHR .............77

4.13 Avaliação da expressão do RNAm dos receptores de ANG II (AT1 e AT2) ..............78 
4.14 Expressão do RNAm das subunidades da NAD(P)H oxidase: gp9 $^{\text {phox }}$, p47 ${ }^{\text {phox }}$ e p22 ${ }^{\text {phox }}$

4.15 Análise da expressão protéica das enzimas antioxidantes: $\mathrm{Cu} / \mathrm{Zn}$ Superóxido dismutase (SOD) e Catalase (CAT) ...................................................................... 81

4.16 Expressão do RNAm dos ERa e ERß e de receptor de andrógeno em aortas de fêmeas SHR...

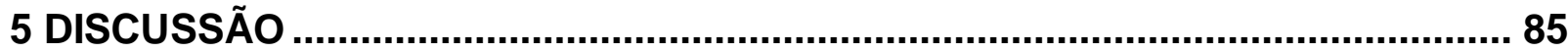

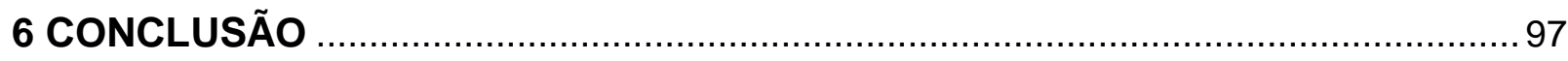

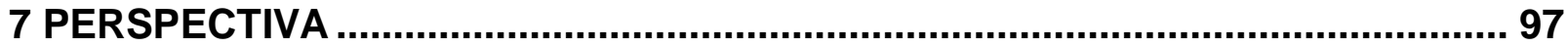

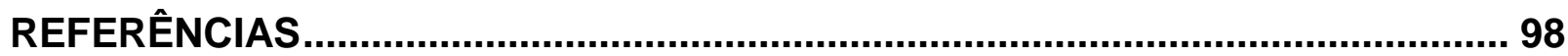




\section{INTRODUÇÃo}

\subsection{Pressão arterial, hipertensão arterial e pós-menopausa}

A principal causa-morte até meados do século XX nos países em desenvolvimento estava relacionada a infecções bacterianas, disenterias ou pestes. Hoje, com o avanço da globalização numa sociedade marcada pelo sedentarismo, má alimentação, obesidade e tabagismo, as doenças cardiovasculares passaram a representar a principal causa-morte no mundo (Roger et al., 2012)

A hipertensão arterial sistêmica representa o principal fator de risco para o desenvolvimento de doenças cardiovasculares. A hipertensão arterial é uma doença crônica-degenerativa, multifatorial e multigênica e ocorre, na maioria dos casos, devido a mudanças nos fatores de controle da pressão arterial (PA). A manutenção da PA ocorre de forma constante devido à força motriz do volume sanguíneo, garantindo irrigação tecidual, o transporte de gases, nutrientes, íons e, assim, a manutenção da vida (Krieger et al., 1996, Krieger et al., 1999). A PA é uma variável física que dependente do volume, do débito cardíaco e da resistência vascular periférica. Quaisquer alterações em uma dessas variáveis, ou em todas, interfere na manutenção dos níveis pressóricos (Krieger et al., 1996, Krieger et al., 1999). A regulação de PA ocorre por fatores locais, neurais e humorais que podem ser regulados a longo ou curto prazo. O controle em curto prazo é importante para rápidas alterações (segundos a minutos), respondendo a necessidade imediata do organismo, como por exemplo, fornecimento de oxigênio $\left(\mathrm{O}_{2}\right)$ ou de nutrientes e remoção de gás carbônico $\left(\mathrm{CO}_{2}\right)$ ou metabólitos celulares. Em longo prazo a regulação da PA estabelece alterações que podem variar de dias a meses e envolve mecanismos de feedback, nos fluídos renais e corporais (equilíbrio entre ingestão/excreção de água e sais) e fatores físicos (rarefação, neoformação de vasos) (Irigoyen et al., 2001).

Dentre os fatores locais do controle da PA destaca-se o papel do tônus miogênico vascular, de fatores metabólicos $\left(\mathrm{O}_{2}\right.$, do $\mathrm{CO}_{2}$, do $\mathrm{pH}$, da osmolaridade) e dos fatores relaxantes, hiperpolarizantes e constritores derivados do endotélio. Entre 
os fatores neurais destaca-se a ação dos mecanos e quimioreceptores e dos fatores humorais a ação das catecolaminas (adrenalina, noradrenalina), do sistema reninaangiotensina-aldosterona (SRA), da vasoprenina, da ocitocina etc. (Mayers, Hughes, 2003)

A hipertensão arterial é caracterizada por níveis elevados e sustentados de pressão arterial (PA), com pressão sistólica acima de $140 \mathrm{mmHg}$ e diastólica acima de $90 \mathrm{mmHg}$, seguindo os padrões de medida estipulados nas Diretrizes Brasileiras de Hipertensão (Diretrizes Brasileira de hipertensão-VI, 2010).

A elevação nos níveis pressóricos é responsável por alterações funcionais e/ou estruturais em órgãos-alvo como coração, cérebro, rins e vasos sanguíneos e alterações metabólicas, contribuindo para o aumento do risco de eventos cardiovasculares que podem ou não ser fatais (Harrap, 1994; Brow, 1996).

No início do século XXI estimou-se que 1 bilhão de adultos fossem hipertensos, sendo que para 2025 a expectativa é que 1,5 bilhão de pessoas sejam hipertensas. Esse aumento ocorre em ambos os sexo, porém, interessantemente, o maior número de indivíduos hipertensos, e consequentemente com doenças cardiovasculares, sé dá em mulheres com idade superior a 49 anos, período esse que coincide com o início do climatério (Roger et al., 2012).

O climatério tem início entre 49 e 55 anos, é um processo lendo e gradual, onde há o declínio da produção e dos níveis endógenos dos hormônios sexuais gonadais, principalmente o estrógeno, devido à cessação da função folicular ovariana, ocasionando a ausência permanente da menstruação, o que é denominado menopausa (Bhavnani et al., 2000; Soules et al., 2001; Fernandes et al., 2008). Após a última menstruação inicia-se o período da pós-menopausa e com o aumento da expectativa de vida feminina no mundo (Diczfalusy et al., 1997) e no Brasil (IBGE, 2010) cerca de um terço das mulheres entrarão na pós-menopausa e permanecerão nesta fase por pelo menos 30 anos (Bhavnani et al., 2003), portanto os estudos científicos básicos e clínicos, nesta faixa etária, são de suma importância para a sociedade.

Em modelos experimentais o envelhecimento também pode aumentar os níveis pressóricos. De fato, ratas SHR velhas apresentam pressão arterial elevada 
quando comparadas a ratas jovens, como acontece na pós-menopausa em mulheres (Reckelhoff, 2004). Não se sabe ao certo a relação entre aumento de pressão arterial e queda dos níveis estrogênicos. Alguns estudos evidenciam que o estrógeno pode regular a pressão arterial, sendo que a ausência desse hormônio aumenta os níveis pressóricos (Dantas et al, 2004). O ciclo estral das ratas começa a se alterar entre 0 décimo e décimo segundo mês de vida, sendo que a partir décimo sexto mês as ratas são consideras velhas, com cessação da função folicular ovariana, queda nos níveis hormonais gonadais e aumento da pressão arterial (Reckelhoff, 2004). Entretanto o procedimento cirúrgico de remoção dos ovários, ovariectomia, é um método classicamente adotado e aceito como modelo para estudo dos efeitos dos baixos níveis hormonais sexuais gonadais, como é observado na pós-menopausa em humanos (Wayntorth et al, 1980).

Os estrógenos são hormônios sexuais com diversas ações fisiológicas nas mulheres e nos homens e sua ação ocorre em tecidos reprodutivos como vagina, endométrio, ovários e em tecidos não-reprodutivos como ossos, sistema nervoso central e sistema cardiovascular. Assim, a ausência desse hormônio no organismo pode levar ao surgimento de sintomas nesses tecidos-alvos (Levin, 2002). As ações clássicas dos estrogênios ocorrem por meio de receptores nucleares denominados alfa (ERa) (Kuiper et al.,1985) e beta (ERß) (Walter et al., 1985) e pelo receptor de membrana acoplado a proteína G denominado GPR30 (G-protein coupled receptor 30) (Revankar et al., 2005).

Os receptores nucleares, ERa e ERß, possuem 44\% de homologia e são expressos em diversos órgãos e tecidos, permitindo, assim, diferentes funções fisiológicas de acordo com o tecido-alvo (Kuiper et al., 1997). O ERa é expresso abundantemente no útero, vagina, ovários, e, em menor proporção, no cérebro, hipotálamo e glândulas mamárias (Kuiper et al., 1997). Por sua vez, o ERß está expresso em ovários, rins, ossos, pulmão e cérebro (Kuiper et al., 1997). No sistema vascular já foi descrito a expressão desses dois receptores no músculo liso (Orimo et al.,1993) e no endotélio (Colburn et al., 1978), o que é de suma importância para o entendimento das ações estrogênicas sobre os vasos sanguíneos. 
Para que atuem em seus receptores intracelulares, os estrógenos penetram nas células por difusão passiva. No citoplasma celular, ligam-se aos receptores, desencadeando ações denominadas genômicas (transcricionais) ou não-genômicas (não-transcricionais). Tanto as ações genômicas quanto as não-genômicas podem estar envolvidas nos efeitos desses hormônios sobre o endotélio e músculo liso vascular (Paech et al., 1997).

Nos vasos, os efeitos não-genômicos ocorrem de maneira rápida em resposta a ligação dos estrógenos aos receptores, independentemente de transcrição gênica e síntese proteica (Farhat et al., 1996), promovendo vasodilatação que envolve a ativação de quinases, fosfatases e de canais iônicos presentes na membrana (Simoncini et al., 2004; Hammes et al., 2007). Especificamente, o 17ß-estradiol, por seus efeitos não-genômicos, vem sendo apontado como um fator importante no controle do tônus vascular por ação no endotélio e no músculo liso vascular (Khalil et al., 2009). Nas células endoteliais, contribui para produção de óxido nítrico (NO), ativando a enzima NO sintase endotelial (eNOS). O NO é um poderoso vasodilatador produzido a partir da transformação da L-arginina em L-citrulina pela NO sintase (NOS). Outro importante mediador das ações estrogênicas é o fator hiperpolarizante derivado do endotélio que atua nos canais iônicos, principalmente ativando os canais de potássio, promovendo hiperpolarização celular (Simoncini et al., 2000; Hisamoto et al., 2001).

Nas células do músculo liso vascular, o estrógeno atua antagonizando os canais de cálcio sensíveis a voltagem, reduzindo a entrada do cálcio para o meio intracelular e a formação do complexo cálcio-calmodulina que ativa a cadeia leve de miosina e leva a contração das células (Prossnitz et al., 2009; Meyer et al., 2009), concomitantemente, com a diminuição da ação de enzimas mediadoras da contração via cálcio, como a PKC e Rho-Kinase (Crews et al., 1999). Além disso, foi demonstrado que ações não-genômicas podem ocorrer via o receptor GPR30, uma vez que a ativação deste por seus agonistas promove vasodilatação em artérias coronárias de porcas (Meyer et al., 2010), por mecanismos ainda não esclarecidos.

$O$ estrógeno atua também em seus receptores intracelulares regulando processos transcricionais que envolvem a translocação nuclear do complexo 
estrógeno-receptor e ligação ao elemento responsivo ao estrógeno (ERE) e a regulação da expressão do gene alvo (Khalil et al., 2009). Nos vasos, a ação estrogênica afeta a expressão de genes envolvidos na síntese de proteínas que alteram o tônus vascular, que participam da resposta a injúria vascular e aterosclerose. Dentre estes genes, o da eNOS (Macritchie et al.,1997; Rubanyi, 1997), da ciclooxigenase-1 (COX1) (Jun et al.,1998), da prostaciclina sintase (Stewart et al., 1999; Khalil et al., 2009) têm sua expressão modulada positivamente, enquanto os genes da endotelina (Akishita et al., 1998) e das MAPKs (mitogenactivated protein kinase) (Dubey et al., 1999) são regulados negativamente.

O SRA é um importante complexo hormonal que atua na regulação da pressão arterial, sais, fluidos corporais e sua ação pode ser regulada por hormônios esteróides (Brosnihan et al.,1999). A formação dos peptídeos do SRA ocorre quando o angiotensinogênio hepático sofre ação da protease renina, formada na células justaglomerulares renais, originando o dectapeitídeo angiotensina I que é clivado pela enzima conversora de angiotensina (ECA), formando o octapepitídeo angiotensina II (ANGII), o principal peptídeo vasoconstritor deste sistema. Alguns orgãos podem sintetizar componentes do SRA, por isso, esse sistema pode ser divido em local ou circulante. Além da cascata clássica de formação de peptídeos, pode-se destacar a produção de outras angiotensinas importantes e com ações específicas, entre elas as angiotensinas III, IV, 1-7 (Rigatto et al., 2004).

A ANGII interage com pelo menos dois receptores acoplados a proteina $G$, denominados AT1 (AT1R) e AT2 (AT2R). Na interação entre ANGll e AT1R as ações fisiológicas observadas são vasoconstrição, estimulação da secreção de aldosterona, retenção de sal e água, crescimento celular e produção de espécies reativas de oxigênio (EROs) (Schiffrin et al., 2002). Os efeitos observados na interação entre ANGII e AT2R são vasodilatação, inibição do crescimento celular, diferenciação celular e apoptose (Ferrario et al., 2006). O AT1R é expresso na maioria das células, incluindo vasos sanguíneos e coração e sua ativação está mais relacionada a alterações cardiovasculares, ao passo que o AT2R é pouco expresso em tecidos adultos, tendo sua maior expressão em tecidos embrionários (Schiffrin et al., 2002). 
Os hormônios esteróides promovem efeitos direitos sobre o SRA (Figura 1). O estrógeno é capaz de aumentar os níveis circulantes de angiotensinogênio, porém promove um efeito inibitório sobre a produção de renina e a expressão de ECA e do AT1R endoteliais (Brosnihan et al.,1999; Fisher et al., 2002; Xue et al., 2007; Yanes et al., 2010). Essas alterações, no SRA, são observadas principalmente na fase folicar do ciclo menstrual, fase essa associada a altos níveis séricos de estrógeno (Brosnihann et al.,1999). Além disso, mulheres que utilizam a Terapia Hormonal (TH) com estrógeno apresentam essas mesmas alterações no SRA (Alhenc-gelas et al., 1986), o que também pode estar relacionado com os altos níveis estrogênicos.

Figura 1 - Esquema representativo da cascata de reações do sistema reninaangiotensina e as ações hormonais (estrógeno e testosterona) sobre a produção de angiotensinogênio e renina e na expressão da ECA e AT1R endoteliais.

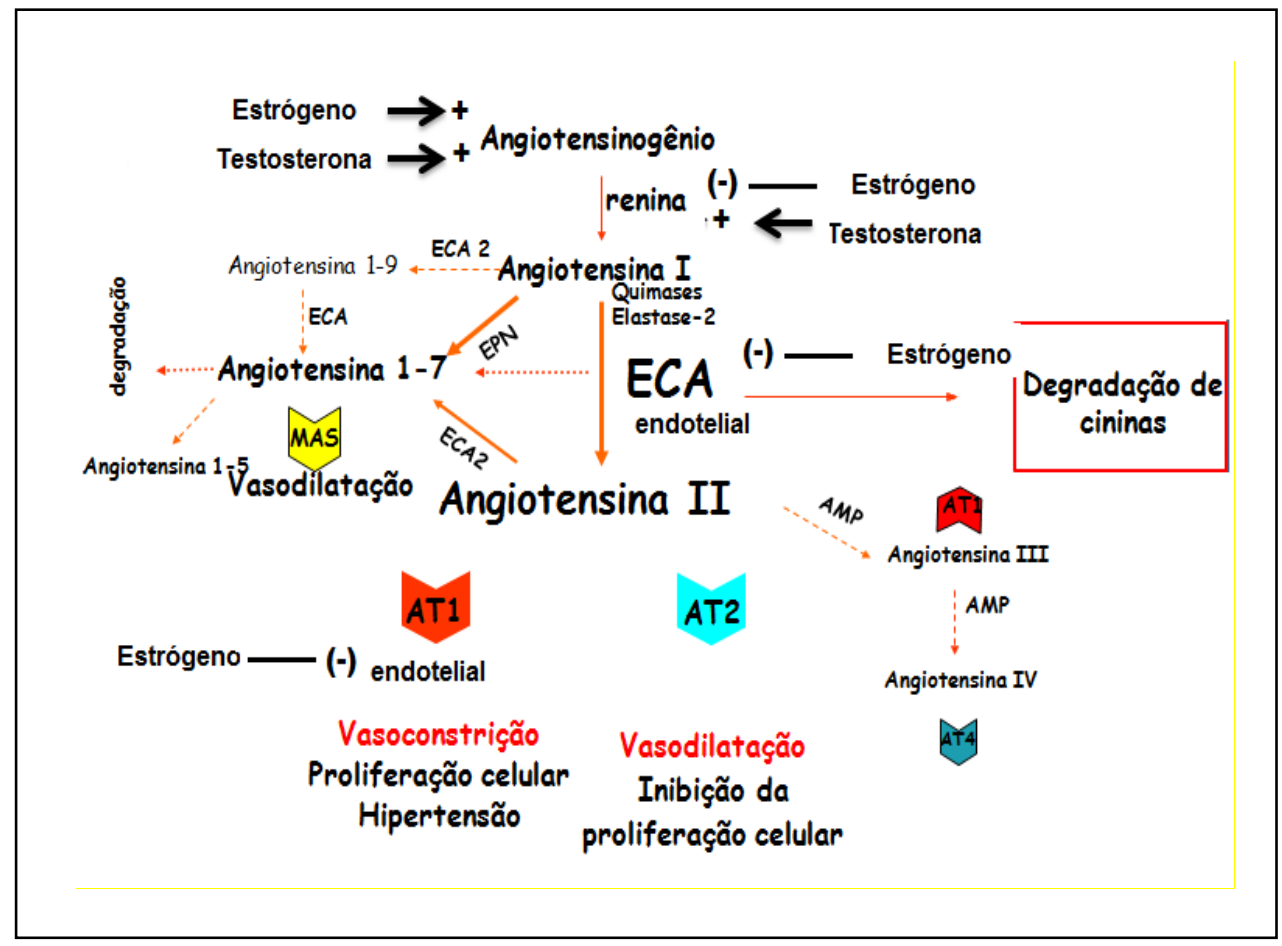

Fonte: Costa, 2012.

Outra importante função atribuída ao SRA refere-se ao seu papel modulador na biodisponibilidade de NO, por meio da produção de EROs, como o ânion superóxido, peróxido nitrito e de hidrogênio, podendo dessa forma participar do desenvolvimento de disfunção endotelial (Touyz et al., 2003). A disfunção endotelial 
caracteriza-se por desequilíbrio na liberação/produção de agentes vasoconstritores e vasodilatadores derivados do endotélio. Dentre os fatores contráteis derivados do endotélio, o ânion superóxido desempenha importante papel na disfunção endotelial por promover oxidação do vasodilatador NO a peroxinitrito, o que leva a diminuição de sua biodisponibilidade. Este desequilíbrio, entre fatores relaxantes e contráteis, pode promover alterações de tônus vascular, favorecer a agregação plaquetária, a proliferação celular, a adesão e migração leucocitária e a fibrinólise. Destaca-se que o NO é um importante agente vasodilatador, antiproliferativo, antiaterogênico e antiinflamatório. Portanto, sua menor biodisponibilidade contribui fortemente para disfunção endotelial (Wajchenberg, 2002)

A produção de EROs na vasculatura pode ter como origem diversas fontes, dentre elas a da ciclooxigenase e da lipoxigenase, do citocromo P450, 0 desacoplamento da NOS e ativação da NADPH oxidase (nicotine adenine dinucleotide phosphate, na forma reduzida) (Cai et al., 2003). Na interação ANGll e AT1R em vasos sanguíneos, tanto no músculo liso como no endotélio, a produção enzimática de EROs se dá principalmente pela ativaçao da NADPH oxidase (Lasségue et al., 2003).

As NADPH oxidases, ou Noxes, são importantes enzimas reguladoras das sinalizações redox e as principais geradoras de ânion superóxido $\left(\mathrm{O}_{2}{ }^{\bullet-}\right)$ do tecido vascular (Park et al., 1997). O protótipo das Noxes, é a enzima presente em células fagocíticas estando intimamente relacionada com a resposta imune inata, por gerar grandes quantidades de ânion superóxido. A atividade da NADPH oxidase requer o recrutamento de subunidades citosólicas ( $\mathrm{p} 40^{\text {phox }}, \mathrm{p} 47^{\text {phox }}$ e $p 67^{\text {phox }}$ ) e sua associação com subunidades de membrana (gp91 ${ }^{\text {phox }}$ e p22 phox ). Alterações na expressão dessas subunidades leva a maior ou menor atividade da enzima e consequentemente na produção de EROs (Price et al., 2002). Foram descritas sete subunidades homólogas a gp9 $1^{\text {phox }}$ denominadas Nox, sendo que quatro delas foram descritas na vasculatura (Nox1, Nox2, Nox4 e Nox5) (Lasségue et al., 2010).

Para controlar a ação oxidante, as células desenvolveram mecanismos antioxidantes. Pela ação da superóxido dismutase (SOD) $0 \mathrm{O}_{2}{ }^{\bullet-}$ é transformado em peróxido de hidrogênio $\left(\mathrm{H}_{2} \mathrm{O}_{2}\right)$. $\mathrm{O} \mathrm{H}_{2} \mathrm{O}_{2}$, por sua vez, sofre ação da enzima catalase 
(CAT), sendo convertido em água $\left(\mathrm{H}_{2} \mathrm{O}\right)$ (Vasconcelos et al., 2007). Esse sistema antioxidante é de suma importância para evitar os danos oxidativos as células, incluindo células do músculo liso e endotélio vascular.

O papel antioxidante do estrógeno está associado na diminuição da atividade da NADPH oxidase, reduzindo a expressão das subunidades, e/ou no aumento da expressão/atividade das enzimas antioxidantes, contribuindo também dessa forma para controle do tônus vascular (Brosnihan et al.,1999; Fisher et al., 2002; Dantas et al., 2004; Xue et al., 2007; Yanes et al., 2010) e, assim, firmando cada vez mais a relação entre estrógeno e proteção cardiovascular.

\subsection{Terapia Hormonal - TH}

$\mathrm{O}$ uso de $\mathrm{TH}$ com conjugado estrogênio equino (CEE) para tratamento de sintomas da pós-menopausa vem sendo realizado desde 1942, época em que Food and Drug Administration (FDA) liberou a utilização do primeiro CEE (Premarin®), como TH, com o indicativo para a redução das ondas de calor (ou fogachos), umas das principais reclamações das mulheres no climatério e pós-menopausa (Fernandes et al., 2004). Essa nova terapia farmacológica foi bem aceita e de grande sucesso, pois as evidências eram claras de que amenizava os principais sintomas da pósmenopausa (Sprintzer, 1998). O Premarin® é um conjugado natural retirado da urina de éguas prenhes que contém pelo menos 10 estrógenos, sendo eles: estrona (48\%); equilin (24\%); 17ß-dihidroequilin (15\%); $\Delta 8$-estrona (4,3\%); 17a-estradiol (3,8\%); 17ß-dihidroequilin (1,8\%); equilenin (1,1\%); $17 \beta$-estradiol $(0,68 \%)$; $17 \alpha$ dihidroequilenin $(0,45 \%)$ e $17 \beta$-dihidroequilenin $(0,3 \%)$ (Bhavnano et al., 2003; Berrodin et al., 2009). Os componentes estrona, $\Delta 8$-estrona e equilin são metabolizados na circulação formando, respectivamente, $17 \beta$-estradiol, $\Delta 8-17 \beta$ estradiol e 17ß-dihidroequilenin (Bhavnano et al., 2003). Os componentes do CEE tem afinidade diferente pelos receptores de estrógeno, podendo desencadear diferentes respostas (Tabela 1).

Apesar de ser um dos medicamentos mais utilizados para TH na pósmenopausa e de ser incluído em protocolos de grandes estudos clínicos e 
multicentricos, as ações e os mecanismos do CEE (Premarin®) no sistema vascular ainda são um tanto controversas, mas a hipótese de que esta TH teria efeito benéfico ainda é considerada (Wingrove et al., 1999; Novensa et al., 2010).

Tabela 1 - Afinidade relativa de ligação (RAL) do CEE nos receptores de estrógeno $\alpha$ e $\beta$ (modificado de BHAVNANI, 2002)

\begin{tabular}{|c|c|c|c|}
\hline Estrógenos & $\begin{array}{c}\text { ERa } \\
\text { (RAL) }\end{array}$ & $\begin{array}{c}\text { ERß } \\
\text { (RAL) }\end{array}$ & Razão ER $\alpha /$ ER $\beta$ \\
\hline $17 \beta$-estradiol & 100 & 100 & 1.00 \\
\hline $17 \beta$-dihidroequilin & 113 & 108 & 1.05 \\
\hline $17 \beta$-dihidroequilenin & 68 & 90 & 0.75 \\
\hline$\Delta 8-17 \beta$-estradiol & 68 & 72 & 0.94 \\
\hline 17a-dihidroequilin & 42 & 32 & 1.30 \\
\hline Estrona & 26 & 52 & 0.50 \\
\hline 17a-dihidroequilenin & 20 & 49 & 0.40 \\
\hline$\Delta 8$-estrona & 19 & 32 & 0.60 \\
\hline $17 \alpha$-estradiol & 19 & 42 & 0.45 \\
\hline Equilenin & 15 & 29 & 0.50 \\
\hline Equilin & 13 & 49 & 0.26 \\
\hline
\end{tabular}

De fato, estudos epidemiológicos mostraram que a TH pode reduzir de 35$50 \%$ o risco de eventos cardiovasculares em mulheres na pós-menopausa (Limacher, 2002). Porém, é importante salientar que estudos clínicos randomizados multicêntricos, como o Heart and Estrogen/Progestin Replacement Study (HERS) e o Women's Health Initiative (WHI) levantaram dúvidas sobre os efeitos protetores do estrógeno na biologia cardiovascular. 
O estudo HERS foi um ensaio clínico randomizado e duplo-cego, iniciado na década de 1990, que testou a eficácia da terapia hormonal com CEE (Premarin® $0,625 \mathrm{mg})$ e acetato de medroxiprogesterona $(2,5 \mathrm{mg})$. Para participação neste ensaio clínico as mulheres deveriam estar na pós-menopausa, terem sido submetidas à histerectomia e apresentarem previamente doenças cardiovasculares (coronariopatia); sendo, portanto, um estudo de prevenção secundária. Neste estudo, um grupo de 2.763 mulheres, com idades entre 50 e 79 anos, foi acompanhado por um período de 4,1 anos. No primeiro ano de seguimento do estudo, as mulheres que utilizavam TH apresentaram aumento nos eventos coronarianos e tromboembólicos venosos quando comparadas a mulheres que não faziam uso de TH (Hulley et al., 1998). Entretanto, após o terceiro ano de estudo, os resultados mostraram que o risco cardiovascular poderia ser menor entre as usuárias de $\mathrm{TH}$ e, por isso, estendeu-se a pesquisa (Borrelli et al.,2005).

No segundo seguimento deste estudo (HERS II), não duplo-cego, um grupo de 2.321 foi acompanhado por mais 2,7 anos, completando 6,8 anos de ensaio clínico. Nesta fase, quando comparadas mulheres que faziam uso da TH com as que não faziam, nenhuma diferença foi encontrada em relação a ocorrência de infarto agudo do miocárdio, mortes por doença coronariana ou outros eventos cardiovasculares, exceto para arritmia ventricular que foi maior no grupo tratado (Grady et al., 2002).

Em 2002 foi realizado o WHI (Women's Health Initiative) estudo multicêntrico, randomizado e duplo-cego que avaliou, em 27.347 mulheres, o efeito da TH na prevenção primária da doença cardiovascular, diferentemente do HERS, que avaliou a prevenção secundária (Fernandes et al., 2004). Neste estudo houve a formação de dois grupos. O primeiro composto por mulheres na pós-menopausa natural e 0 segundo por mulheres na pós-menopausa induzida por histerectomia. O primeiro grupo recebeu o mesmo esquema de tratamento do HERS (associação de CEE com medroxiprogesterona) e o segundo somente o CEE (Grady et al., 2002; Borrelli et al., 2005). Foi observado nas pacientes do primeiro grupo um aumento de $29 \%$ no índice de eventos cardiovasculares, o que levou ao interrompimento do ensaio clínico. No segundo grupo, o estudo estendeu-se até 2004, resultando a análise denominada 
"braço terapêutico do WHI". Os resultados deste "braço terapêutico do WHI" mostraram que o uso isolado de CEE nessas mulheres, embora não estatisticamente significante, promoveu redução de quatro eventos por ano para cada dez mil mulheres, quando comparadas com o grupo placebo, demonstrando que a $\mathrm{TH}$ em mulheres com baixo risco de eventos cardiovasculares pode causar proteção neste sistema (Grady et al., 2002; Fernandes et al., 2004).

É importante destacar que os estudos realizados são considerados de excelente qualidade, no entanto, são alvos de diversas críticas, uma vez que a seleção de pacientes incluiu mulheres com idade uma década superior àquela em que normalmente a TH é recomendada (média do grupo 63,2 anos). Além disso, no HERS I as mulheres apresentavam risco prévio para as complicações cardiovasculares (Windler et al., 2007) e no WHI não foi investigado se as mulheres selecionadas apresentavam alguma predisposição para eventos cardiovasculares; foram considerados apenas sintomas clínicos (Fernandes et al., 2004).

Os dados negativos quanto à proteção cardiovascular promovida pela $\mathrm{TH}$ contrariaram os dados obtidos tanto em estudos observacionais, quanto àqueles desenvolvidos em animais de experimentação, uma vez que estes apontavam o efeito protetor do estrógeno no sistema cardiovascular (Fernandes et al., 2004). O que pode se destacar é que há evidências de estudos em primatas (Clarkson, 2005) coelho (Hanke et al., 1999) e camundongos (Rosenfeld et al., 2002) de que os efeitos benéficos da $\mathrm{TH}$, na prevenção da aterosclerose, ocorrem somente se for iniciada antes do seu desenvolvimento (Maas et al., 2009), o que colabora, talvez, para a dificuldade de interpretação dos estudos multicêntricos.

Recentemente, com os novos seguimentos dos estudos multicêntricos e com a reconsideração dos resultados obtidos no primeiro seguimento, vem sendo sugerido que a TH quando iniciada no climatério e não na pós-menopausa, ou seja, em mulheres mais jovens, poderia promover algum tipo de proteção cardiovascular (Brezezinski, Danenberg, 2005). De fato, se considerado que, a partir dos 50 anos, as mulheres podem apresentar níveis pressóricos mais elevados e que as complicações cardiovasculares geralmente ocorrem por volta dos 65 anos de idade (Dubey et al., 2005) e que os estudos em sua maioria alocaram pacientes com mais 
de 60 anos, é aceitável considerar que durante o período inicial da pós-menopausa exista uma "janela de oportunidade", quando o tratamento hormonal pode conferir cardioproteção (Brezezinski, Danenberg, 2005) e isso deve ser considerado e avaliado em todos os estudos realizados .

\subsection{Menopausa, distúrbio da atividade sexual e terapia hormonal com testosterona}

Apesar de serem controversos os efeitos da TH com estrógenos sobre 0 sistema cardiovascular, sua ação benéfica sobre alterações psicológicas, somáticas, vasomotora, urogenital e osteoporose está bem evidenciada (Greene et al., 1998). Porém, além dos sintomas descritos, a pós-menopausa (fisiológica ou cirúrgica) também pode promover importantes alterações no comportamento sexual, como a perda da libido, sendo que a TH com estrógeno (CEE ou 17ß-estradiol) não leva a melhora neste quadro (Schimdt et al., 1994).

$\mathrm{O}$ atual tratamento para as alterações da libido envolve o TH com estrogênios associados à testosterona. Esse tratamento tem se mostrado altamente eficiente na pós-menopausa e em mulheres histerectomizadas, uma vez que, essas apresentaram aumento na frequência e na satisfação sexual com o uso de testosterona (Basson et al., 2009; Buster et al. 2005; Simon et al. 2005; Shifren et al., 2002). Entretanto, são escassos os estudos que avaliam as ações androgênicas no sistema cardiovascular em mulheres na pós-menopausa.

A testosterona é o principal andrógeno natural produzido nos homens e nas mulheres, sendo responsável pelas características sexuais (sexo masculino), libido, aumento da massa óssea e muscular. Nos homens, é produzida nas células de Leydig do testículo, nas adrenais (em pequena proporção), ou por conversão periférica a partir de outros andrógenos como a desidroepiandrosterona e a androstenodiona (Winters, 1999). Nas mulheres é produzida no folículo ovariano, no córtex adrenal, pelo fígado e pele (El-Alfy et al. 1999). No organismo feminino, a testosterona encontra-se, em sua maior parte, ligada a proteína transportadora de hormônios sexuais (do inglês $S H B G$ ) e albumina, tornando esse hormônio pouco disponível para ação tecidual na mulher (Burger et al., 2002), diferentemente do 
observado no gênero masculino. No climatério e nos primeiros anos da pósmenopausa a testosterona também sofre redução na produção e nos níveis plasmáticos e, por volta dos 70 anos de idade, restauram-se a níveis prémenopausa, por produção exclusiva do ovário (Judd et al., 1974).

A testosterona exerce suas ações pela interação com dois tipos de receptores, um denominado receptor citosólico, pertencente à família dos receptores nucleares para hormônios esteróides, e outro localizado na membrana plasmática, desencadeando efeitos genômicos e não-genômicos. É importante destacar que os receptores nucleares são mais abundantes no gênero masculino do que no feminino, contribuindo ainda mais para que esse hormônio tenha maior efeito nos homens (Lin et al., 1990).

Para ativação dos receptores citosólicos a testosterona atravessa a membrana plasmática, liga-se ao receptor, formando o complexo testosteronareceptor que migra para o núcleo e modifica a transcrição gênica, promovendo os efeitos genômicos (Jones et al., 2004). A testosterona desencadeia também efeitos não-genômicos pela ligação aos receptores de membrana, levando a ativação de segundos mensageiros, como a PKC, PKA e MAPKs, ocasionando efeitos de acordo com a necessidade/efeito do tecido-alvo (Heinlein, Chang, 2002). Os dois tipos de receptores de testosterona já foram descritos em diversos tecidos, incluindo células endoteliais e do músculo liso vascular de humanos e modelos animais (LittletonKearney et al., 2004; Sinha-Hikim et al., 2004).

Os efeitos vasculares da testosterona são controversos, complexos e, em geral, dependem da dose utilizada, do tempo de exposição, de prévia doença vascular e do gênero. Exemplificando, a testosterona pode exercer efeito vasodilatador (Adams et al.,1995) ou vasoconstritor (Teoh et al., 2000; LittletonKearney et al., 2004) em diferentes leitos vasculares. Em homens, a administração intracoronariana de testosterona causa relaxamento e aumento no fluxo sanguíneo em pacientes com doença coronariana estabelecida (Webb et al., 1999) e em ratos e coelhos também causam relaxamento de artérias coronárias por antagonizar canais de cálcio (Yue et al., 1995; Honda et al., 1999). 
Em cultura de células do músculo liso vascular da microcirculação mesentérica de ratos espontaneamente hipertensos (SHR), a testosterona induz a geração de EROs e a migração dessas células, sugerindo que este hormônio possa induzir lesão vascular (Chinaglia, 2009). Além disso, a testosterona vem sendo apontada como um importante fator para o desenvolvimento e manutenção da hipertensão em SHR machos (Reckelhoff et al.; 1998). Em machos, a remoção cirúrgica dos testículos e a consequente queda da produção de testosterona reduzem a PA que é restabelecida com a reposição de testosterona (Reckelhoff et al.; 1998).

Poucos estudos descrevem as ações dos andrógenos no sistema cardiovascular de fêmeas. Foi observado por Reckelhoff et al. (1998) e por TatchumTalom et al. (2002) que a administração de testosterona em ratas SHR ovariectomizadas, apesar de aumentar a resposta vasodilatadora à ACh pelo aumento na produção de $\mathrm{NO}$ e prostaglandinas vasodilatadoras, causa aumento da PA. Dois importantes mecanismos foram descritos para explicar o aumento da PA em fêmeas SHR. O primeiro, por ação renal devido ao aumento na reabsorção de sódio pelo túbulo proximal do néfron (Ramon et al.,2002) e, segundo, pela produção do 20-HETE (20-hydroxyeicosatetraenoic ácid) um metabólito do ácido araquidônico com ação vasoconstritora (Croft et al., 2000; Yanes et al., 2005). O ácido araquidônico é metabolizado pelo citocromo P-450 (CYP) formando diversos produtos (metabólitos), dentro eles o 20-HETE (20-hydroxyeicosatetraenoic ácid), um potente vasoconstritor. Sua produção pode ser estimulada pela ANG II, vasopressina, endotelina em tecido renal e vascular (McGiff et al., 1999) e por hormônios sexuais, como a testosterona (Yanes et al., 2005).

Frente ao exposto, e considerando que a testosterona vem sendo empregada para o tratamento de distúrbio da hipoatividade sexual relacionada a pósmenopausa, estudos que avaliem os efeitos cardiovasculares dos andrógenos em mulheres tornam-se de grande importância. 


\subsection{Objetivo}

Avaliar em ratas SHR-OVX os efeitos do tratamento com CEE associado à testosterona na pressão arterial e na reatividade de anéis de aorta a agentes vasodilatadores e vasoconstritores. Paralelamente, foram estudados os mecanismos envolvidos nas ações vasculares da associação CEE e testosterona, considerando o papel da geração de EROs e da ANG II. 


\section{MATERIAL E MÉTODOS}

\subsection{Animais}

Foram utilizadas para os experimentos ratas espontaneamente hipertensas (SHR), provenientes do Biotério Central do Instituto de Ciências Biomédicas (ICBUSP), recebidas com 10 semanas de idade e peso entre 150-160 gramas. Os animais foram alojados no Biotério do Departamento de Farmacologia (ICB-USP) e mantidos em caixa de polipropileno ( 5 animais por caixa) em ambiente com temperatura controlada $\left(22{ }^{\circ} \mathrm{C}\right)$, ciclos claro e escuro (12h/12h), $60 \%$ de umidade e acesso livre a alimentação e água.

Os procedimentos experimentais realizados estão de acordo com os Princípios Éticos de Experimentação Animal adotados pela Sociedade Brasileira de Ciência em Animal de Laboratório (SBCAL) e aprovado pela Comissão Experimental no Uso de Animais (CEUA), do Instituto de Ciências Biomédicas (ICB-USP), na data 06 de dezembro de 2010 sob o número 145, folha 95, livro 2.

\subsection{Procedimento cirúrgico de ovariectomia}

Com doze semanas de idade, as ratas foram anestesiadas com Xilasina $(7,4$ $\mathrm{mg} / \mathrm{Kg}$ de peso, ip) e Cetamina (113 mg/Kg de peso, ip). Após anestesia, os pelos da região abdominal foram removidos e uma incisão de aproximadamente dois centímetros foi realizada no local. A partir desta incisão, o útero foi exposto e os ovários removidos. Após este procedimento, a incisão foi suturada e higienizada com álcool iodado $3 \%$. Os animais controle foram submetidos aos mesmos procedimentos cirúrgicos, porém não tiveram os ovários removidos.

Trinta dias após a ovariectomia, quando os níveis hormonais encontravam-se abaixo dos observados em ratas em estro-fisiológico (Wayntorth et al, 1980; Dantas et al., 1999), os tratamentos hormonais foram iniciados. Ao final dos tratamentos as ratas apresentavam dezoito semanas de idade. 


\subsection{Determinação do Estro Fisiológico}

Foi realizada coleta de material vaginal utilizando uma haste de algodão embebida em solução salina $0,9 \%$. Após a coleta, um esfregaço em lâmina de vidro foi feito para observação a fresco em microscópio óptico. $O$ exame celular desta secreção permite diferenciar as fases do ciclo-estral das ratas. As ratas do grupo controle foram utilizadas em estro-fisiológico (Marcondes et al., 2002).

\subsection{Tratamento com Conjugado Estrogênio Equino (CEE)}

Após trinta dias de ovariectomia, as ratas receberam uma dose diária do CEE $(9,6 \mu \mathrm{g} / \mathrm{Kg} /$ dia - Premarin $\AA)$ por gavagem durante duas semanas. Este regime de tratamento foi escolhido tendo como base à dose administrada para reposição hormonal em mulheres na menopausa (WHI, 2002).

\subsection{Tratamento com CEE associado à Testosterona}

Após trinta dias de ovariectomia, os animais receberam a dose diária de CEE $(9,6 \mathrm{\mu g} / \mathrm{Kg} / \mathrm{dia})$, por gavagem, durante duas semanas, e cipionato de testosterona ( $2,85 \mathrm{mg} / \mathrm{Kg} / \mathrm{semana}$ - Deposteron $\AA)$. O cipionato de testosterona foi aplicado uma vez por semana, por injeção intramuscular, durante duas semanas. As injeções intramusculares foram aplicadas na pata traseira direita (músculo gastrocnêmio), utilizando óleo de amendoim como veículo, conforme instruções do fabricante (EMS S/A, Brasil). A dose da testosterona foi escolhida baseada na dose utilizada para tratamento hormonal em mulheres na pós-menopausa (Krapf et al., 2009) e em estudo realizado em animais de experimentação (Ramos et al., 2007).

\subsubsection{Grupo controle e ovariectomizado}

Durante o período de tratamento hormonal os grupos controle e ovariectomizadas sem tratamento (OVX) foram submetidos a procedimentos similares aos utilizados nos tratamentos. Dessa forma, as ratas OVX e controle receberam, por gavagem, volume de água equivalente ao volume de CEE e também injeções intramusculares semanais de óleo de amendoim. 


\subsection{Grupos experimentais}

Para os experimentos as ratas SHR foram divididas em 4 grupos experimentais:

C - fêmeas SHR controle em estro-fisiológico;

OVX - fêmeas SHR ovariectomizadas;

CEE - fêmeas SHR ovariectomizadas, tratadas com CEE;

CEE+T - fêmeas SHR ovariectomizadas tratadas com o CEE associado à Cipionato de Testosterona;

\subsection{Evolução ponderal}

Para o estudo da evolução ponderal, as ratas foram pesadas na décima segunda, décima sexta e décima oitava semanas de idade. $O$ delta de peso $(\Delta)$ foi calculado subtraindo o peso final do peso inicial.

\subsection{Determinação da eficácia da ovariectomia e dos tratamentos hormonais}

\subsubsection{Peso do útero}

Os animais foram anestesiados com tiopental sódico (50 mg/Kg/intraperitonial) e, após anestesia, as ratas foram submetidas à laparotomia e o útero foi removido, pesado (peso úmido) e colocado por 24 horas em estufa à $\quad 37 \stackrel{\circ}{\circ} \mathrm{C}$ para secagem (peso seco). Os resultados foram expressos em miligramas de útero por centímetro de tíbia $(\mathrm{mg} / \mathrm{cm})$.

\subsubsection{Dosagem hormonal}

A concentração dos hormônios 17ß-estradiol, progesterona, estrona e testosterona foi determinado no soro das ratas dos diferentes grupos experimentais, utilizando o método de radioimunoensaio (RIA-Kit Siemens Healthcare Diagnostics, $E \cup A$ ). Para isso, os animais foram anestesiados com tiopental sódico (50 $\mathrm{mg} / \mathrm{Kg} /$ intraperitonial), o sangue foi coletado pela aorta abdominal e colocado em 
tubo de vidro para centrifugação à $3000 \mathrm{~g}, 15^{\circ} \mathrm{C}$, durante 15 minutos. $\mathrm{O}$ soro foi separado e armazenado em freezer $-80 \stackrel{\circ}{\circ}$.

O método de radioimunoensaio é baseado na competição entre um antígeno radioativo (hormônio marcado $\mathrm{I}^{125}$ ) e outro não radioativo, por uma quantidade limitada de anticorpo policlonal específico obtido de coelho. Após a incubação, a separação entre anticorpos ligados e livres é obtida por decantação e o tubo com a amostra é colocado em um contador gama. A quantidade de hormônio marcado é inversamente proporcional à quantidade de hormônio da amostra.

\subsection{Medida de pressão arterial direta}

Para a medida da pressão arterial (PA) foi utilizado o método direto (invasivo). Os animais foram anestesiados com Xilasina $(7,4 \mathrm{mg} / \mathrm{Kg}$ de peso, ip) e Cetamina (113 mg/Kg de peso, ip). Após anestesia, uma incisão na região centro-escapular foi realizada, expondo a artéria carótida. Nessa artéria, foi inserido um cateter de polietileno heparinizado e a região foi suturada e higienizada com álcool iodado $3 \%$. Após 24 horas, o catéter inserido na carótida foi conectado a um transdutor de pressão elétrico (PE-399) que, por sua vez, estava conectado a um sistema de transdução (PowerLab, AD Instruments, Melboume, Austrália). Depois de 20 minutos de estabilização três áreas foram selecionadas em intervalos de cinco minutos e neste foram registrados a pressão sistólica (PS), diastólica (PD) e a pressão arterial média (PAM). A pressão arterial média foi obtida a partir do cálculo: PAM: PAD $+(\triangle P \times 40 \%)$.

\subsection{Reatividade vascular}

Para os estudos de reatividade vascular foi utilizada a aorta torácica isolada, conforme técnica inicialmente descrita por Carvalho et al. (1987). Para isso, os animais foram anestesiados com tiopental sódico (50 mg/Kg/intraperitoneal) e após toracotomia a aorta torácica foi removida, dissecada e imersa em solução nutriente de Krebs Henseleit modificado (mmol/L: $\mathrm{NaCl} 113 ; \mathrm{KCl} 4,7 ; \mathrm{CaCl} 2$ 2,5; $\mathrm{NaHCO} 325$; MgSO4 1,1; KH2PO4 1,1; EDTA 0,03; glicose 5,5, pH 7.4), saturada com 95\% de $\mathrm{O}_{2}$, 
$5 \%$ de $\mathrm{CO}_{2}$ e mantida a $37^{\circ} \mathrm{C}$. A aorta torácica foi cortada em anéis de $4 \mathrm{~mm}$ sendo que em alguns anéis o endotélio foi mantido intacto e em outros a camada endotelial foi removida por fricção, utilizando uma haste fina envolta com algodão embebido em Krebs Henseleit.

Em seguida, um par de ganchos de aço inoxidável, em forma de "L", foi introduzido no lúmem dos anéis de aorta. Os anéis de aorta foram suspensos pelos ganchos e colocados em uma cuba de vidro para estudo de órgãos isolados, contendo $10 \mathrm{ml}$ de solução de Krebs Henseleit modificado saturado com $95 \%$ de $\mathrm{O}_{2}$, $5 \%$ de $\mathrm{CO}_{2}$ e mantido a $37{ }^{\circ} \mathrm{C}$ durante todo o protocolo experimental. Nessa condição, um dos ganchos foi fixado na base da cuba de vidro e o outro gancho conectado a um transdutor isométrico de tensão (ML T001, PowerLab/8S, ADInstruments, Ltda) que, por sua vez, estava acoplado a um computador. Essas preparações foram mantidas por 60 minutos, sob tensão inicial de 1,5 gramas. Durante o período de estabilização a solução nutriente foi trocada três vezes em intervalos de 20 minutos e a tensão ajustada quando necessário. Após este procedimento, foram realizadas curvas concentração-efeito cumulativas para 0 agente vasoconstritor ANG \| $(0,01 \mathrm{nM}-10 \mu \mathrm{M})$, cuja as concentrações foram aplicadas de maneira crescente em intervalos de aproximadamente 1 minuto. Os resultados para as curvas concentração-efeito cumulativa para ANG II foram expressos em delta de tensão $(\mathrm{g})$, obtidos pela subtração do valor de tensão basal (inicial) dos valores de tensão obtidos com as diferentes concentrações de ANG II.

Em outra série de experimentos, foram construídas curvas concentraçãoefeito cumulativas para $\mathrm{ACh}(0,01 \mathrm{nM}-10 \mu \mathrm{M})$, agente vasodilatador dependente do

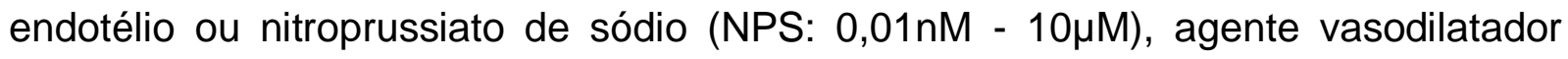
independente do endotélio em anéis de aorta pré-contraídos com noradrenalina (NOR: $0,1 \mu \mathrm{M}$ ), concentração essa capaz de causar de $60-80 \%$ da contração máxima. Os resultados para os agentes vasodilatadores foram expressos em porcentagem da contração obtida com a NOR.

Os experimentos acima descritos foram realizados em anéis de aorta com e sem endotélio. Para confirmar a eficácia da remoção do endotélio os anéis de aorta foram pré-contraídos com NOR $(0,1 \mu \mathrm{M})$ e então o agente vasodilatador dependente 
do endotélio $A C h(0,1 \mu \mathrm{M})$ foi adicionado. $O$ endotélio foi considerado removido quando a ACh não promoveu relaxamento ou este foi inferior a $5 \%$.

Em outra série de experimentos as curvas concentração-efeito para ACh foram realizadas após a incubação dos anéis de aorta com endotélio com o inibidor da NOS (L-NAME - 10 $\mathrm{MM}$ ), ou antagonista de receptor AT1 de ANG II (losartan $1 \mu \mathrm{M}$ ), ou inibidor da NADPH oxidase (apocinina - $1 \mu \mathrm{M}$ ), por $30 \mathrm{~min}$.

Para comparação entre os grupos foram utilizadas: 1) a diferença na contração ou relaxamento a cada ponto da curva concentração efeito 2) e as respostas máximas (Rmax) produzidas pelos diferentes agonistas. A avaliação da sensibilidade das preparações aos agonistas foi realizada pelo pD2 (logarítimo da concentração molar que produz $50 \%$ da Rmax) somente quando não havia diferença entre as Rmax.

\subsection{Expressão do RNAm por Reação em Cadeia da Polimerase (RT-PCR) em tempo real}

A expressão do RNAm dos receptores de estrógeno (ERa eER $\beta$ ), do receptor de andrógeno, dos receptores de ANG II (AT1 e AT2) e das subunidades da NADPH oxidase gp91 ${ }^{\text {phox }}$, p4 $7^{\text {phox }}$ e p22 ${ }^{\text {phox }}$ foi avaliada por RT-PCR em tempo real. As amostras de aorta foram removidas e congeladas em nitrogênio líquido e pulverizadas num almofariz de porcelana com o auxílio de um pistilo.

O RNA total foi obtido utilizando o método de Trizol (Invitrogen, CO.,EUA), seguindo as orientações do fabricante. Com a obtenção do RNA total, a integridade das amostras foi avaliada pela presença das bandas $18 \mathrm{~s}$ e $28 \mathrm{~s}$ íntegras. As amostras, então, foram submetidas à digestão do DNA remanescente. A síntese da fita simples de DNA complementar (cDNA) (reação de transcrição reversa - RT) foi realizada utilizando-se a enzima MMLV a partir de $2 \mu \mathrm{g}$ de RNA total. Adicionou-se inibidores de RNAse para proteger o RNA durante esse processo. A reação de PCR em tempo real foi realizada com volume final de $12,5 \mu \mathrm{L}$, contendo os oligonucleotídeos específicos para os receptores de estrógeno (ERa e ERß), andrógeno, AT1R e AT2R de ANGll e das subunidades da NADPH oxidase (gp91phox, p47phox e p22phox) (Tabela 2). A quantidade de cDNA foi avaliada 
utilizando o reagente Platinum ${ }^{\circledR}$ SYBR $^{\circledR}$ green qPCR SuperMix UDG (Invitrogen) e o sistema Corbett Research (Corbett Life Sciences, Australia).

Para amplificação do RNAm as amostras foram mantidas 2 minutos a $95^{\circ} \mathrm{C}$, seguido por 40 ciclos na seguinte condição: $95{ }^{\circ} \mathrm{C}$ por 15 segundos, $60{ }^{\circ} \mathrm{C}$ por 1 minuto e $72{ }^{\circ} \mathrm{C}$ por 20 segundos. A especificidade da reação com SYBR ${ }^{\circledR}$ green foi confirmada pela análise da curva de dissociação utilizando como base a temperatura de dissociação - melting point. A expressão do RNAm foi quantificada utilizando o cálculo do $2^{\Delta \mathrm{Ct}}$ (cycle threshold), como descrito por Pfaffl et al. (2001). O resultado foi expresso em unidades arbitrárias após normalização pela expressão de RNAm de $\beta$ actina.

Tabela 2 - Oligonucleotídeos para receptores de AT1 e AT2 (de ANGII), a e $\beta$ (de estrógeno), de andrógeno e das subunidades da $\mathrm{NAD}(\mathrm{P}) \mathrm{H}$ oxidase $\left(\right.$ gp91 ${ }^{\text {phox }}$, p4 $7^{\text {phox }}$ p22 $\left.{ }^{\text {phox }}\right)$

\begin{tabular}{ccc}
\hline \hline & Sense & Anti-sense \\
\hline Receptor AT1 & CACTTTCCTGGATGTGCTGA & CCCAGAAAGCCGTAGAACAG \\
Receptor de estrógeno $\alpha$ & GAACGAGCCCAGCGCCTACG & TCTCGGCCATTCTGGCGTCG \\
Receptor de estrógeno $\beta$ & TATCTCCTCCCAGCAGCAGT & TCATGCTGAGCAGATGTTCC \\
Receptor de andrógeno & CCGGACCTTATGGGGACATGCG & GGCAGGTCTTCTGGGGTGGGA \\
gp91phox & TTCCCTGGAACAAGAGATGG & GACGTCAGTGGCTCTGTCAA \\
p47phox & GGCCAAAGATGGCAAGAATA & TGTCAAGGGGCTCCAAATAG \\
p22phox & GGGGTCTCCTCCACTTACTG & TAGGCTCAATGGGACTCCAC \\
\hline \hline
\end{tabular}

\subsection{Geração de Espécies Reativas de Oxigênio (EROs)}

A geração de EROs foi determinada pelo método da DHE (dihidroetidina). Este método tem como base a oxidação da DHE, que na presença de ânion superóxido é oxidada formando o composto 2-hidroxietídio e na presença de outras 
espécies reativas de oxigênio, como o peróxido de hidrogênio é oxidada formando o etídeo. Estes dois produtos da oxidação da DHE têm afinidade pelo DNA nuclear, intercalando-se a ele e emitindo fluorescência vermelha a partir do núcleo que pode ser detectada no comprimento de onda da rodamina (Fernandes et al., 2007). Seguindo o protocolo já descrito no item 2.10, a aorta foi removida do animal, dissecada e cortada em anéis. Em seguida esses anéis foram imersos em meio de congelamento, congelados e cortados na posição transversal $(8 \mu \mathrm{m})$ em criostato a $25 \stackrel{\circ}{\circ}$. Em alguns anéis de aorta foi aplicado por 30 minutos o antagonistade AT1R (losartan $10^{-6} \mathrm{M}$ ), o inibidor da NADPH oxidase (apocinina $10^{-5} \mathrm{M}$ ) e o inibidor do 20 HETE $\left(0016 \mathrm{HET} 10^{-5} \mathrm{M}\right)$. Os cortes de aorta foram colocados em lâminas de vidro tratadas com o adesivo poli-lisina e mantidos em placa quente $\left(37^{\circ} \mathrm{C}\right)$ por 20 minutos para descongelamento. Os cortes foram circundados com caneta hidrofóbica e incubados com tampão fosfato $(\mathrm{PB}) \quad 0,1 \mathrm{M}$, a $37^{\circ} \mathrm{C}$, em câmara úmida por dez minutos para hidratação. O PB foi removido e os cortes incubados com $100 \mu \mathrm{L}$ de DHE $5 \mu \mathrm{M}$, por 60 minutos, a $37^{\circ} \mathrm{C}$ em estufa protegida da luz. As lâminas foram observadas em microscópio óptico (ZEISS), equipado com filtro para rodamina e câmara fotográfica, utilizando uma objetiva para fluorescência com aumento de 20x.

Foram analisados dois cortes de cada aorta e em cada corte cinco diferentes áreas foram selecionadas observando a integridade das camadas de músculo liso vascular e marcação dos núcleos célulares, utilizando esses parâmetros para captação da imagem. A densidade óptica em cada área foi determinada utilizando o programa ImageJ (Wayne Rasband, National Institutes of Health, USA, Java 1.6.0, 32 bit) e normalizada pelo tamanho da área analisada. Os resultados obtidos forma expressos como porcentagem da média do grupo controle.

\subsection{Expressão protéica por Western Blotting}

A aorta torácica foi isolada dos animais dos diferentes grupos experimentais, dissecada, congelada em nitrogênio líquido e armazenada em freezer $-80 \stackrel{\circ}{\circ}$. As amostras de aorta congeladas foram pulverizadas num almofariz de porcelana com auxílio de um pistilo. Após este procedimento foram incubadas, por 10 minutos, em tampão de lise gelado contendo inibidores de proteases: 4-\{2-aminoetil\} fluoreto de 
benzenosulfonil; pepstatina A; E-64; bestatina; leupeptina; aprotinina; ortovanadato de sódio (10mM); PMSF (fluoreto de fenilmetil-sulfonil, $10 \mathrm{mM}$ ). As amostras foram centrifugadas à $10000 \mathrm{rpm}, 4 \stackrel{\circ}{\mathrm{C}}$ por 50 minutos para a remoção do material insolúvel. Após a centrifugação, o conteúdo protéico total foi quantificado utilizando o método de BCA (ácido bicincônínico, Thermo Scientific). As amostras dos diferentes grupos foram então tratadas com tampão de Laemmli contendo DTT (ditiotreitol, $200 \mathrm{mM}$ ) e $70 \mu \mathrm{g}$ de proteína total foi submetida à eletroforese em gel de poliacrilamida (SDS PAGE 10\%) em aparelho para mini gel (BioRAD, Hercules, USA). Em cada gel foi aplicado um marcador de peso molecular com valores estabelecidos. A transferência das proteínas do gel para a membrana de nitrocelulose foi realizada eletricamente, por meio de aparelho da BioRad pelo período de 2 horas a 100V em tampão de transferência contendo SDS $(0,1 \%)$.

\subsubsection{Immunoblotting}

As membranas foram incubadas com solução bloqueadora (leite desnatado $5 \%$ ) a temperatura ambiente por 2 horas para reduzir a ligação inespecífica dos anticorpos à membrana. Logo após, essas membranas foram incubadas individualmente com diferentes anticorpos: anti-Cu/Zn SOD (1:1000 Sigma) ou anticatalase (1:1000, Sigma) ou anti-eNOS total (1:2000, Sigma) e para controle interno anti- $\beta$-actina (1:20000, Sigma) ou anti- $\alpha$-actina (1:20000, Sigma). Essas incubações foram realizadas na presença de solução bloqueadora (albumina bovina 3\%) por dezoito horas a $4 \stackrel{\circ}{\circ}$. Em seguida as membranas foram lavadas com solução tampão contendo $0,1 \%$ de Tween 20 (TTBS) por 30 minutos e incubadas com o anticorpo secundário conjugado com peroxidase, por 1 hora em temperatura ambiente. Após este procedimento as membranas foram lavadas e incubadas com solução quimioluminescênte, como descrito no protocolo do fabricante (Super Signa West Pico Chemiluminescent, Thermo Scientific). A quimioluminescência foi detectada e visualizada utilizando filmes fotográficos. A intensidade das bandas foi quantificada por densitometria óptica utilizando o programa ImageJ (Wayne Rasband, National Institutes of Health, USA, Java 1.6.0, 32 bit). Os valores foram expressos como porcentagem da expressão do controle interno. 


\subsection{Análise estatística}

Os resultados foram expressos como média \pm erro padrão da média (epm). A análise estatística foi realizada no programa Prisma versão 7, utilizando a análise de variância de uma via (ANOVA-one way) seguido do teste de múltiplas comparações, Tukey, análise de variância de duas vias (ANOVA-two way) ou teste $t$ quando pertinente. Foi adotado o nível de significância $p<0,05$. 


\section{Resultados}

\subsection{Caracterização do modelo de ovariectomia}

\subsubsection{Peso uterino e concentração sérica de 17ß-estradiol, progesterona, testosterona e estrona}

A eficácia da ovariectomia, bem como dos tratamentos hormonais foi analisada por meio do peso uterino e das concentrações séricas de estrógeno,estrona, progesterona e testosterona nos diferentes grupos experimentais, conforme indicado na Tabela 3.

Nas ratas OVX foi observado: redução do peso uterino (seco e úmido) e dos níveis séricos de estrógeno, progesterona, testosterona e estrona em relação aos demais grupos, confirmando a eficácia da remoção dos ovários.

No tratamento das ratas OVX com CEE foi observado: restauração do peso uterino seco e úmido e da concentração sérica de estrona para níveis semelhantes ao do grupo C. A concentração sérica de $17 \beta$-estradiol aumentou em comparação com a do grupo C e OVX, atingindo valores suprafisiológicos. Os níveis de progesterona e testosterona permaneceram similares aos do grupo OVX.

Por sua vez, no tratamento com $\mathrm{CEE}+\mathrm{T}$ foi observado: aumento do peso uterino úmido e seco, quando comparado com o do grupo OVX, porém, o peso úmido ainda foi inferior aos encontrados nos grupos $C$ e CEE. O nível sérico de estrona foi restaurado para valor similar ao do grupo $C$. Os valores séricos de $17 \beta-$ estradiol foram maiores do que os observados nos grupos $\mathrm{C}$ e OVX e similares aos do grupo CEE. A concentração sérica de testosterona foi maior no grupo $C E E+T$ quando comparada com os demais grupos experimentais, confirmando a eficácia do tratamento com este hormônio. 
Tabela 3 - Efeito da ovariectomia e dos tratamentos hormonais (CEE e CEE+T) no peso seco e úmido do útero e nos níveis séricos de 17ß-estradiol, estrona, progesterona e testosterona de fêmeas SHR.

\begin{tabular}{ccccccc}
\hline \hline Grupos & $\begin{array}{c}\text { Peso } \\
\text { útero } \\
\text { úmido } \\
(\mathbf{m g} / \mathbf{c m} \\
\text { tíbia) }\end{array}$ & $\begin{array}{c}\text { Peso } \\
\text { útero } \\
\mathbf{s e c 0} \\
(\mathbf{m g} / \mathbf{c m} \\
\text { tíbia) }\end{array}$ & $\begin{array}{c}\mathbf{1 7 \beta} \\
\text { Estradiol } \\
(\mathbf{p g} / \mathbf{m l})\end{array}$ & $\begin{array}{c}\text { Estrona } \\
(\mathbf{n g} / \mathbf{m l})\end{array}$ & $\begin{array}{c}\text { Progesterona } \\
(\mathbf{n g} / \mathbf{m l})\end{array}$ & $\begin{array}{c}\text { Testoster } \\
\text { ona } \\
(\mathbf{n g} / \mathbf{m l})\end{array}$ \\
\hline C & $\begin{array}{c}9,1 \pm 0,1 \\
(\mathrm{n}=7)\end{array}$ & $\begin{array}{c}2,6 \pm 0,1 \\
(\mathrm{n}=7)\end{array}$ & $\begin{array}{c}31,9 \pm 1,2 \\
(\mathrm{n}=7)\end{array}$ & $\begin{array}{c}42,4 \pm 1,6 \\
(\mathrm{n}=7)\end{array}$ & $\begin{array}{c}23,3 \pm 1,4 \\
(\mathrm{n}=6)\end{array}$ & $\begin{array}{c}4,8 \pm 0,6 \\
(\mathrm{n}=7)\end{array}$ \\
OVX & $\begin{array}{c}1,5 \pm 0,1^{*} \\
(\mathrm{n}=6)\end{array}$ & $\begin{array}{c}0,7 \pm 0,1^{*} \\
(\mathrm{n}=6)\end{array}$ & $\begin{array}{c}17,9 \pm 0,3^{*} \\
(\mathrm{n}=6)\end{array}$ & $\begin{array}{c}29,8 \pm 0,9^{*} \\
(\mathrm{n}=8)\end{array}$ & $\begin{array}{c}3,2 \pm 0,7^{*} \\
(\mathrm{n}=5)\end{array}$ & $\begin{array}{c}1,4 \pm 0,1 \\
(\mathrm{n}=7)\end{array}$ \\
CEE & $\begin{array}{c}8,2 \pm 0,2^{\#} \\
(\mathrm{n}=8)\end{array}$ & $\begin{array}{c}2,3 \pm 0,1^{\#} \\
(\mathrm{n}=8)\end{array}$ & $\begin{array}{c}114,4 \pm 13,7^{*} \# \\
(\mathrm{n}=6)\end{array}$ & $\begin{array}{c}38,9 \pm 1,3 \# \\
(\mathrm{n}=7)\end{array}$ & $\begin{array}{c}7,2 \pm 1,5^{*} \\
(\mathrm{n}=6)\end{array}$ & $\begin{array}{c}1,8 \pm 0,1 \\
(\mathrm{n}=7)\end{array}$ \\
CEE+T & $\begin{array}{c}6,5 \pm 0,3^{* \#+} \\
(\mathrm{n}=7)\end{array}$ & $\begin{array}{c}2,2 \pm 0,1^{\#} \\
(\mathrm{n}=7)\end{array}$ & $\begin{array}{c}80,7 \pm 4,1^{* \#} \\
(\mathrm{n}=7)\end{array}$ & $\begin{array}{c}36,4 \pm 1,4^{\#} \\
(\mathrm{n}=7)\end{array}$ & $\begin{array}{c}9,2 \pm 1,9^{*} \\
(\mathrm{n}=6)\end{array}$ & $\begin{array}{c}29,4 \pm 3,8^{* *+} \\
(\mathrm{n}=7)\end{array}$ \\
\hline \hline
\end{tabular}

Resultados expressos como média \pm epm. $O$ número de animais/grupo está indicado entre parênteses. Foi utilizado o teste ANOVA de uma via para análise. ${ }^{*} p<0,05$ vs controle; ${ }^{\#} p<0,05$ vs OVX; ${ }^{+} p<0,05$ vs CEE. 


\subsubsection{Peso corpóreo (g)}

$\mathrm{Na}$ décima segunda semana de idade as fêmeas SHR dos diferentes grupos experimentais apresentaram peso corpóreo semelhante, como demonstrado na tabela 4. Os animais que passaram pelo procedimento cirúrgico de remoção dos

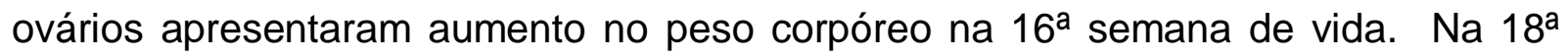
semana as OVX apresentaram aumento do peso corpóreo em relação ao peso das do grupo C. O tratamento hormonal com CEE não alterou o peso corpóreo em comparação com o grupo OVX. O tratamento com CEE+T promoveu aumento de peso corpóreo quando comparado com o peso do grupo $\mathrm{C}$, porém permaneceu semelhante aos observados no grupo OVX e CEE (Tabela 4).

Analisando o ganho de peso ao longo do tratamento $(\Delta)$ foi observado que no grupo OVX há o aumento do delta de peso em comparação com o grupo $\mathrm{C}$. $\mathrm{O}$ tratamento com o CEE reduz o delta de peso em comparação com o grupo OVX, porém permanece ainda diferença do grupo $\mathrm{C}$. No tratamento com $\mathrm{CEE}+\mathrm{T}$ houve aumento de delta de peso em comparação com o grupo $\mathrm{C}$, porém este ainda permaneceu semelhante aos grupos OVX e CEE.

Tabela 4- Efeito da ovariectomia e dos tratamentos hormonais (CEE e CEE+T) no peso corpóreo (g) de fêmeas SHR

\begin{tabular}{|c|c|c|c|c|}
\hline Grupo & $\begin{array}{c}\text { Peso corpóreo } \\
12^{\mathrm{a}} \text { Semana } \\
\text { (antes da OVX) }\end{array}$ & $\begin{array}{c}\text { Peso corpóreo } \\
16^{\mathrm{a}} \text { semana }\end{array}$ & $\begin{array}{c}\text { Peso corpóreo } \\
\text { 18a semana }\end{array}$ & $\begin{array}{c}\Delta \\
\text { de peso }\end{array}$ \\
\hline C & $\begin{array}{c}171,7 \pm 4,8 \\
(\mathrm{n}=20)\end{array}$ & $\begin{array}{c}184,5 \pm 3,4 \\
(n=20)\end{array}$ & $\begin{array}{c}191,8 \pm 3,9 \\
(n=20)\end{array}$ & $\begin{array}{c}20,8 \pm 2,0 \\
(n=20)\end{array}$ \\
\hline OVX & $\begin{array}{c}170,4 \pm 4,8 \\
(n=20)\end{array}$ & $\begin{array}{c}219,0 \pm 5,2^{*} \\
(n=20)\end{array}$ & $\begin{array}{c}226,8 \pm 5,7^{*} \\
(n=20)\end{array}$ & $\begin{array}{c}56,4 \pm 3,0^{*} \\
(n=20)\end{array}$ \\
\hline CEE & $\begin{array}{c}173,4 \pm 3,8 \\
(n=20)\end{array}$ & $\begin{array}{c}223,7 \pm 1,7^{*} \\
(n=20)\end{array}$ & $\begin{array}{c}213,4 \pm 2,7^{*} \\
(n=20)\end{array}$ & $\begin{array}{c}40,4 \pm 2,8^{*} \# \\
(n=20)\end{array}$ \\
\hline CEE+T & $\begin{array}{c}176,5 \pm 5,2 \\
(n=20)\end{array}$ & $\begin{array}{c}220,7 \pm 3,7^{*} \\
(n=20)\end{array}$ & $\begin{array}{c}227,4 \pm 3,0^{*} \\
(\mathrm{n}=20)\end{array}$ & $\begin{array}{c}50,9 \pm 2,6^{*} \\
(\mathrm{n}=20)\end{array}$ \\
\hline
\end{tabular}

Resultados expressos como média \pm epm. $\Delta$ : diferença entre o peso corpóreo inicial $\left(12^{\text {a }}\right.$ semana) e final (18 $8^{\mathrm{a}}$ semana). O número de animais/grupo está indicado entre parênteses. Foi utilizado o teste ANOVA de uma via para análise. ${ }^{*} p<0,05$ vs controle. \# $p<0,05$ vs OVX. 


\subsubsection{Peso muscular e de gordura retroperitonial}

Como demonstrado na Tabela 5, não houve diferença no peso seco dos músculos EDL (do inglês Extensor Digitorum Longus) e sólis quando comparados os quatro grupos experimentais. Por outro lado, houve aumento no peso do músculo gastrocnêmio no grupo OVX quando comparado com os do grupo $\mathrm{C}$. $\mathrm{O}$ tratamento hormonal com CEE corrigiu esse aumento da massa muscular, porém essa diferença foi abolida quando o CEE foi associado à testosterona (grupo CEE+T). A ovariectomia aumentou o depósito de gordura retroperitonial nas fêmeas SHR quando comparado com o grupo $\mathrm{C}$, o tratamento com CEE não teve efeito sobre este parâmetro aumentado. $\mathrm{O}$ tratamento com $\mathrm{CEE}+\mathrm{T}$ intensificou o depósito de gordura retroperitonial nas ratas OVX.

Tabela 5 - Efeito da ovariectomia e dos tratamentos hormonais (CEE e CEE+T) sobre o peso dos músculos e de gordura retroperitonial de fêmeas SHR.

\begin{tabular}{|c|c|c|c|c|}
\hline Grupo & $\begin{array}{c}\text { Peso do } \\
\text { EDL } \\
\text { (seco) } \\
\text { (mg/cm } \\
\text { tíbiax100) }\end{array}$ & $\begin{array}{c}\text { Peso do } \\
\text { Sóleo } \\
\text { (seco) } \\
\text { (mg/cm } \\
\text { tíbiax100) }\end{array}$ & $\begin{array}{c}\text { Peso do } \\
\text { Gastrocnêmio } \\
\text { (seco) } \\
\text { (mg/cm } \\
\text { tíbiax100) } \\
\end{array}$ & $\begin{array}{c}\text { Gordura } \\
\text { retroperitonial } \\
\text { (mg/g peso) }\end{array}$ \\
\hline C & $\begin{array}{c}0,71 \pm 0,09 \\
(n=7)\end{array}$ & $\begin{array}{c}0,81 \pm 0,08 \\
(n=5)\end{array}$ & $\begin{array}{c}8,2 \pm 0,08 \\
(n=5)\end{array}$ & $\begin{array}{c}4,41 \pm 0,36 \\
(n=12)\end{array}$ \\
\hline OVX & $\begin{array}{c}0,78 \pm 0,06 \\
(n=6)\end{array}$ & $\begin{array}{c}0,87 \pm 0,02 \\
(n=6)\end{array}$ & $\begin{array}{c}9,8 \pm 0,40 * \\
(n=6)\end{array}$ & $\begin{array}{c}5,59 \pm 0,10^{*} \\
(n=8)\end{array}$ \\
\hline CEE & $\begin{array}{c}0,73 \pm 0,03 \\
(n=5)\end{array}$ & $\begin{array}{c}0,83 \pm 0,01 \\
(n=5)\end{array}$ & $\begin{array}{c}8,55 \pm 0,14 \# \\
(n=7)\end{array}$ & $\begin{array}{c}5,69 \pm 0,20^{*} \\
(n=8)\end{array}$ \\
\hline $\mathrm{CEE}+\mathrm{T}$ & $\begin{array}{c}0,84 \pm 0,01 \\
(n=8)\end{array}$ & $\begin{array}{c}0,85 \pm 0,03 \\
(n=5)\end{array}$ & $\begin{array}{c}10,3 \pm 0,24^{*}+ \\
(n=6)\end{array}$ & $\begin{array}{c}7,49 \pm 0,20 * \# \\
(n=8)\end{array}$ \\
\hline
\end{tabular}

Resultados expressos como média \pm epm. $O$ número de animais/grupo está indicado entre parênteses. Foi utilizado o teste ANOVA de uma via para análise. ${ }^{*} p<0,05$ vs $C$. $\# p<0,05$ vs OVX. $+p<0,05$ vs CEE. 


\subsubsection{Avaliação da pressão arterial direta}

As ratas dos quatro grupos experimentais apresentaram na décima oitava semana de vida níveis de pressão sistólica, diastólica e de pressão arterial média acima do que normalmente se observa em animais normotensos (Reckelhoff et al.; 1998; Perez-Torres et al., 2008), confirmando assim a hipertensão arterial. A ovariectomia (grupo OVX) e o tratamento hormonal com CEE (grupo CEE) não alteraram os valores de pressão arterial quando comparados com grupo C. Porém, no grupo CEE+T os níveis pressóricos sistólicos e diastólicos e a pressão arterial média apresentaram-se aumentados em comparação com os grupos C, OVX e CEE+T (Tabela 6).

Tabela 6 - Efeito da ovariectomia e dos tratamentos hormonais (CEE e CEE+T) sobre a pressão arterial direta das fêmeas SHR.

\begin{tabular}{cccc}
\hline \hline Grupo & $\begin{array}{c}\text { Pressão arterial } \\
\text { média }(\mathbf{m m H g})\end{array}$ & $\begin{array}{c}\text { Pressão arterial } \\
\text { sistólica }(\mathbf{m m H g})\end{array}$ & $\begin{array}{c}\text { Pressão arterial } \\
\text { diastólica }(\mathbf{m m H g})\end{array}$ \\
\hline C & $145,7 \pm 1,17$ & $173,8 \pm 1,64$ & $127,7 \pm 0,61$ \\
& $(\mathrm{n}=10)$ & $(\mathrm{n}=10)$ & $(\mathrm{n}=10)$ \\
OVX & $145,6 \pm 2,60$ & $170,5 \pm 3,23$ & $125,1 \pm 2,96$ \\
& $(\mathrm{n}=8)$ & $(\mathrm{n}=8)$ & $(\mathrm{n}=8)$ \\
CEE & $147,0 \pm 1,74$ & $174,0 \pm 2,03$ & $128,4 \pm 2,48$ \\
& $(\mathrm{n}=7)$ & $(\mathrm{n}=7)$ & $(\mathrm{n}=7)$ \\
CEE+T & $158,5 \pm 2,57^{*} \#+$ & $187,4 \pm 2,33^{*} \#+$ & $139,2 \pm 2,83^{*} \#+$ \\
& $(\mathrm{n}=5)$ & $(\mathrm{n}=5)$ & $(\mathrm{n}=5)$ \\
\hline \hline
\end{tabular}

Resultados expressos como média \pm epm. O número de animais/grupo está indicado entre parênteses. Foi utilizado o teste ANOVA de uma via para análise * $p<0,05$ vs $C$. \# $p<0,05$ vs $O V X .+p<0,05$ vs CEE. 


\section{REATIVIDADE VASCULAR}

\subsection{Avaliação da resposta vasoconstritora a ANG II em anéis de aorta com e sem endotélio isolados de fêmeas SHR}

A ANGII promoveu vasoconstrição dependente de concentração nos anéis de aorta com e sem endotélio dos quatro grupos experimentais estudados (Figuras $2 \mathrm{~A}$ e 3A). Os anéis de aortas com endotélio das OVX apresentaram aumento na Rmax para ANG II em comparação com aquela do grupo C (Figura 2B). O tratamento com CEE corrigiu a Rmax encontrada nas OVX para níveis semelhantes ao do grupo $\mathrm{C}$, porém este efeito foi abolido no grupo $\mathrm{CEE}+\mathrm{T}$ (Figura 2B).

A remoção do endotélio aumentou a Rmax para ANG II em todos os grupos experimentais, quando os valores foram comparados com os dos anéis de aorta com endotélio. A Rmax para ANG II nos anéis de aorta sem endotélio foi similar entre os grupos C, OVX, CEE e CEE+T (Figuras 3A e 3B). 
Figura 2 - Efeito da ovariectomia e dos tratamentos hormonais (CEE e CEE+T) sobre a resposta vasoconstritora a angiotensina II em anéis de aorta com endotélio

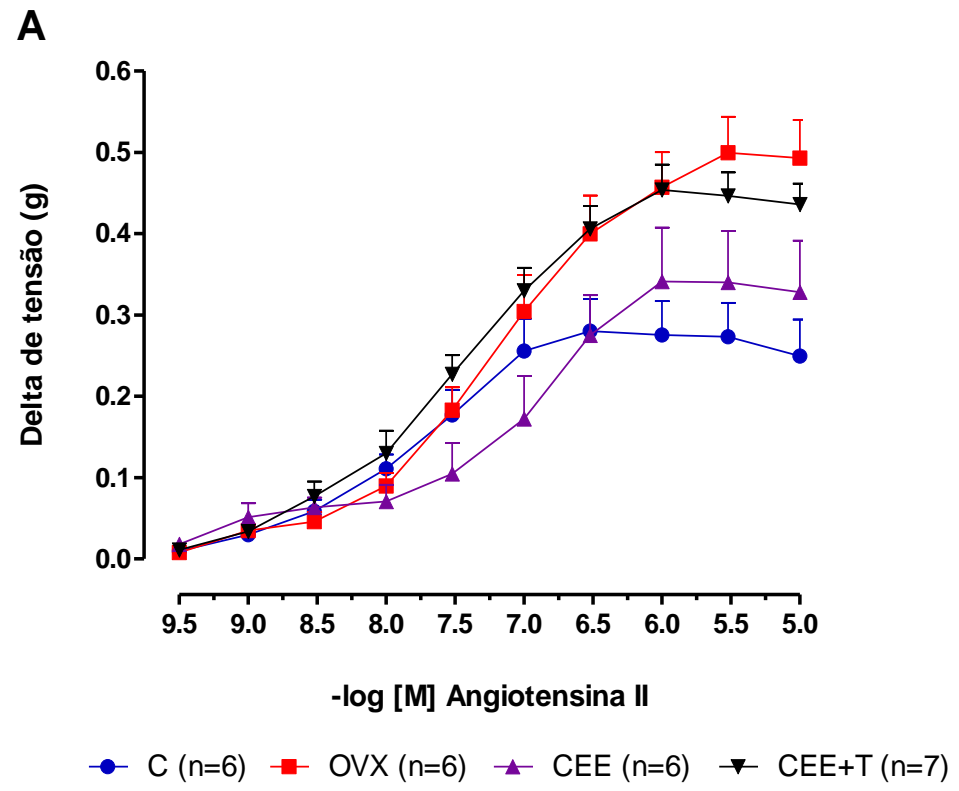

B

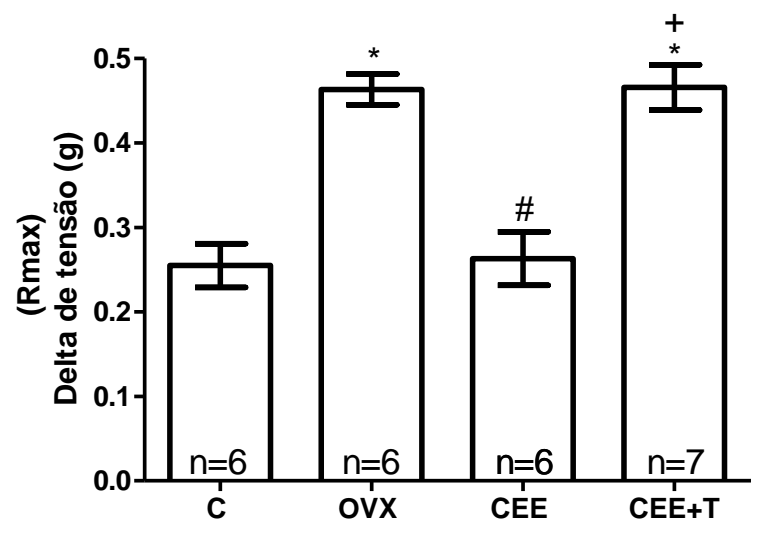

Curvas concentração-efeito cumulativas $(A)$ e resposta máxima $(B)$ à angiotensina II obtidas em anéis de aorta, com endotélio, isolados de fêmeas SHR. C - representa o grupo controle; OVX - ovariectomizadas; CEE - tratadas com Conjugado Estrogênio Equino; $\mathrm{CEE}+\mathrm{T}$ - tratadas com Conjugado Estrogênio Equino associado à testosterona. $O$ número de animais utilizados encontra-se entre parênteses $(A)$ e dentro das barras (B). Os valores foram expressos como média \pm EPM. Foi utilizado 0 teste ANOVA de uma via para análise. ${ }^{*} p<0,05$ vs $C ; \# p<0,05$ vs $O V X ;+p<0,05$ vs CEE.

Fonte: Costa, 2012. 
Figura 3 - Efeito da ovariectomia e dos tratamentos hormonais (CEE e CEE+T) sobre a resposta vasoconstritora a angiotensina II em anéis de aorta sem endotélio.

A

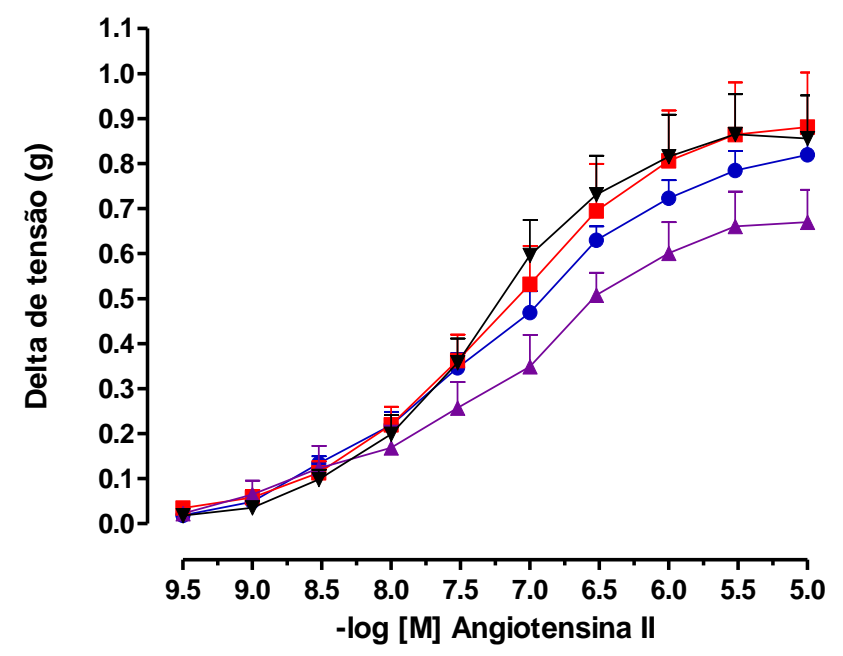

$\bullet C(n=7)-\operatorname{OVX}(n=7) \rightarrow \operatorname{CEE}(n=5) \rightarrow \operatorname{CEE}+T(n=7)$

B

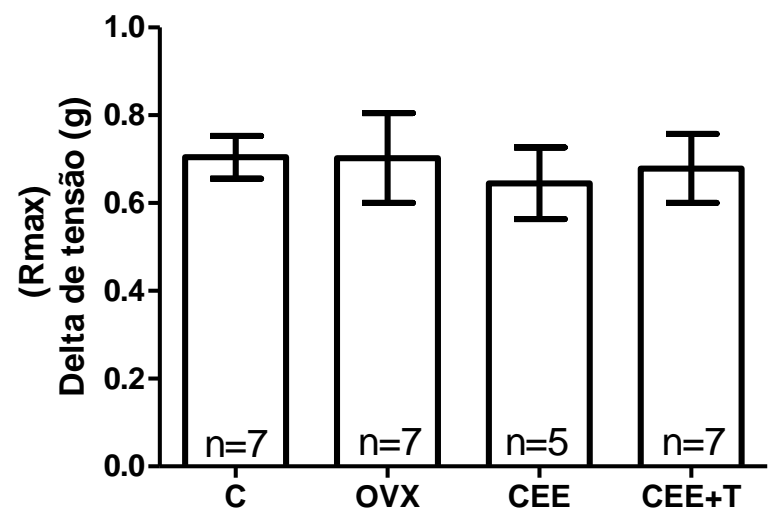

Curvas concentração-efeito cumulativas $(A)$ e resposta máxima $(B)$ à angiotensina II obtidas em anéis, sem endotélio, isolados de fêmeas SHR. C - representa o grupo controle; OVX - ovariectomizadas; CEE - tratadas com Conjugado Estrogênio Equino; $\mathrm{CEE}+\mathrm{T}$ - tratadas com Conjugado Estrogênio Equino associado à testosterona. $O$ número de animais utilizados encontra-se entre parênteses $(A)$ e dentro das barras (B). Os valores foram expressos como média \pm EPM. Foi utilizado o teste ANOVA de uma via para análise.

Fonte: Costa, 2012 


\subsection{Avaliação da resposta vasodilatadora à ACh em anéis de aorta com e sem endotélio isolados de fêmeas SHR}

A ACh, agonista muscarínico, promoveu resposta bifásica, isto é, vasodilatação (primeira fase) seguida de vasoconstrição (segunda fase) nos anéis de aorta com endotélio das fêmeas do grupo C, OVX, CEE e CEE+T (Figura 4). A remoção do endotélio aboliu a resposta induzida pela ACh (dados não mostrados).

A Rmax vasodilatadora à ACh foi reduzida no grupo OVX quando comparado com aquela do grupo $\mathrm{C}$ e o tratamento com CEE corrigiu este parâmetro. $O$ tratamento com $\mathrm{CEE}+\mathrm{T}$ reduziu a Rmax vasodilatadora quando comparada com os grupos $\mathrm{C}$ e CEE, igualando-se ao grupo OVX (Figura 5).

$\mathrm{Na}$ fase de vasoconstrição foi observado que o grupo OVX apresentou aumento na resposta contrátil quando comparado com os demais grupos $\mathrm{C}$, CEE e $C E E+T$, os quais não apresentaram diferença entre si (Figura 4). 
Figura 4 - Efeito da ovariectomia e dos tratamentos hormonais (CEE e CEE+T) sobre a resposta vasodilatadora a ACh em anéis de aorta com endotélio.

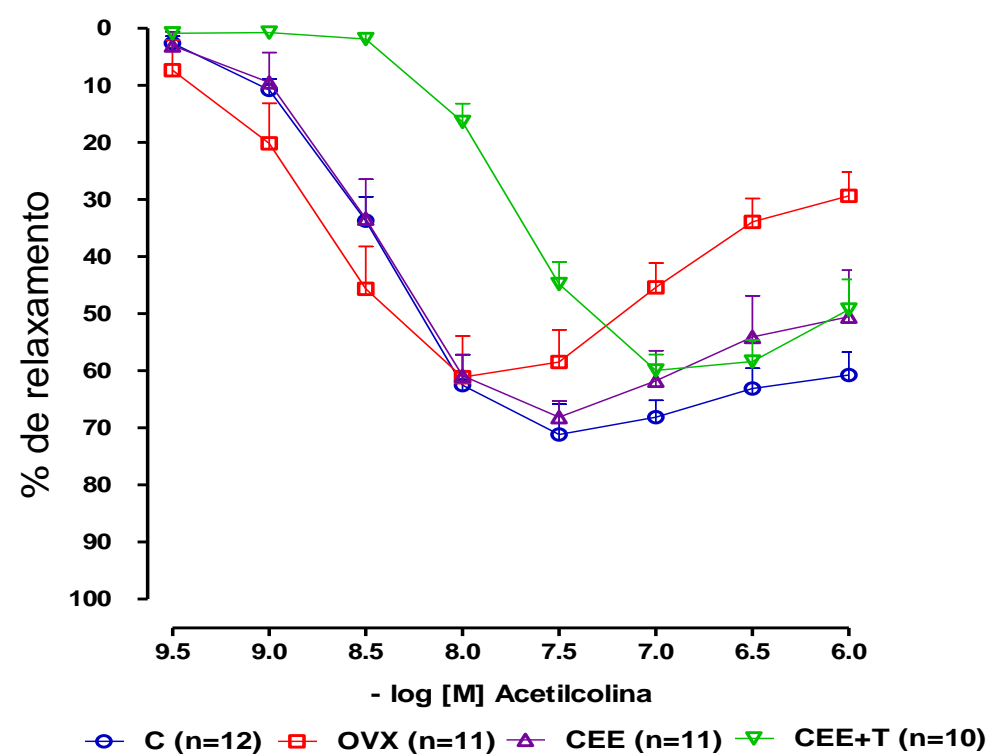

Curvas concentração-efeito cumulativas à acetilcolina obtidas em anéis, com endotélio, isolados de fêmeas SHR. C - representa o grupo SHR controle; OVX ovariectomizadas; CEE - tratadas com Conjugado Estrogênio Equino; CEE+T tratadas com Conjugado Estrogênio Equino associado à testosterona. $\mathrm{O}$ número de animais utilizados por grupo encontra-se entre parênteses. Os valores foram expressos como média $\pm E P M . ~{ }^{*} p<0,05$ vs $C ; \# p<0,05$ vs OVX; $+p<0,05$ vs CEE.

Fonte: Costa, 2012 
Figura 5 - Efeito da ovariectomia e dos tratamentos hormonais (CEE e CEE+T) sobre a resposta máxima vasodilatadora a ACh em anéis de aorta com endotélio.

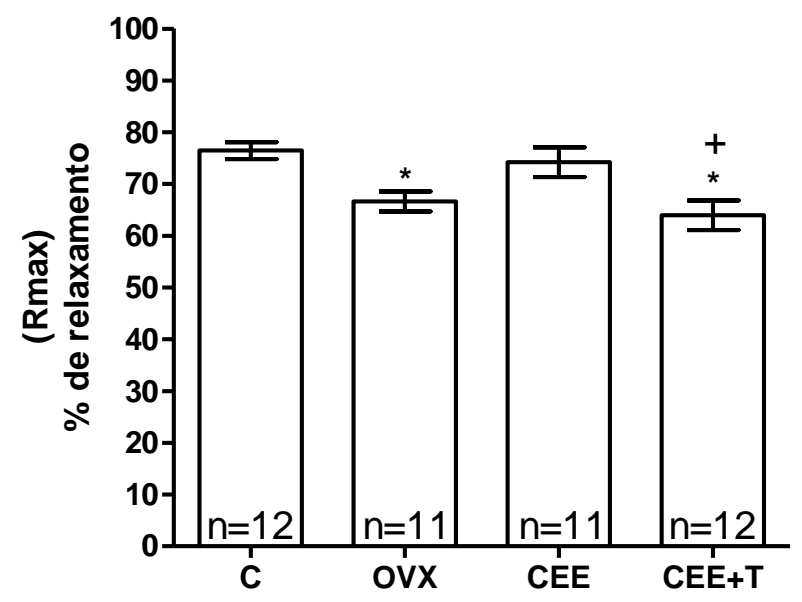

Resposta máxima à acetilcolina obtida em anéis de aorta, com endotélio, isolados de fêmeas SHR. C - representa o grupo SHR controle; OVX - ovariectomizadas; CEE tratadas com Conjugado Estrogênio Equino; $\mathrm{CEE}+\mathrm{T}$ - tratadas com Conjugado Estrogênio Equino associado à testosterona. Os valores foram expressos como média \pm EPM. Foi utilizado o teste ANOVA de uma via para análise. ${ }^{*} \mathrm{p}<0,05$ vs $\mathrm{C}$; \# $p<0,05$ vs OVX; $+p<0,05$ vs CEE.

Fonte: Costa, 2012 


\subsection{Avaliação da resposta vasodilatadora ao NPS em anéis de aorta com endotélio isolados de fêmeas SHR}

O NPS promoveu vasodilatação, independente do endotélio, nos quatro grupos experimentais (Figura 6). A Rmax vasodilatadora para o NPS foi semelhante entre os grupos estudados (Figura 7).

Figura 6 - Efeito da ovariectomia e dos tratamentos hormonais (CEE e CEE+T) sobre a resposta vasodilatadora ao nitroprussiato de sódio em anéis de aorta com endotélio.

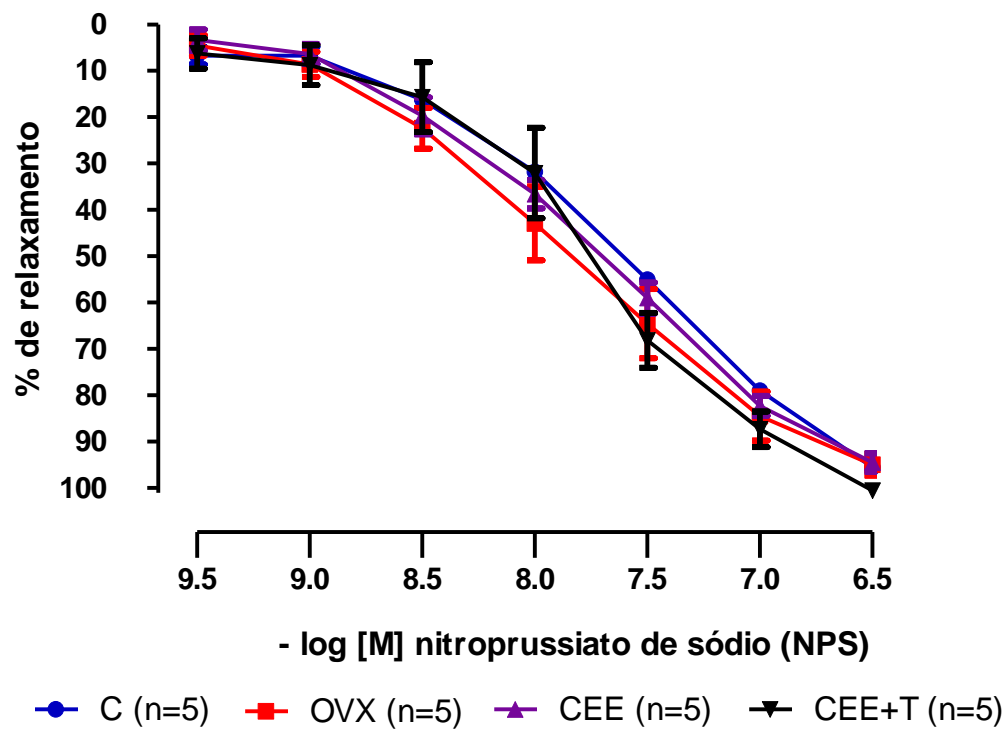

Curvas concentração-efeito cumulativas ao nitroprussiato de sódio (NPS) obtidas em anéis de aorta, com endotélio, isolados de fêmeas SHR. C - representa o grupo SHR controle; OVX - ovariectomizadas; CEE - tratadas com Conjugado Estrogênio Equino; $\mathrm{CEE}+\mathrm{T}$ - tratadas com Conjugado Estrogênio Equino associado à testosterona. $O$ número de animais utilizados por grupo encontra-se entre parênteses. Os valores foram expressos como média \pm EPM. Foi utilizado o teste ANOVA de uma via para análise.

Fonte: Costa, 2012. 
Figura 7 - Efeito da ovariectomia e dos tratamentos hormonais (CEE e CEE+T) sobre a resposta máxima vasodilatadora ao nitroprussiato de sódio em anéis de aorta com endotélio.

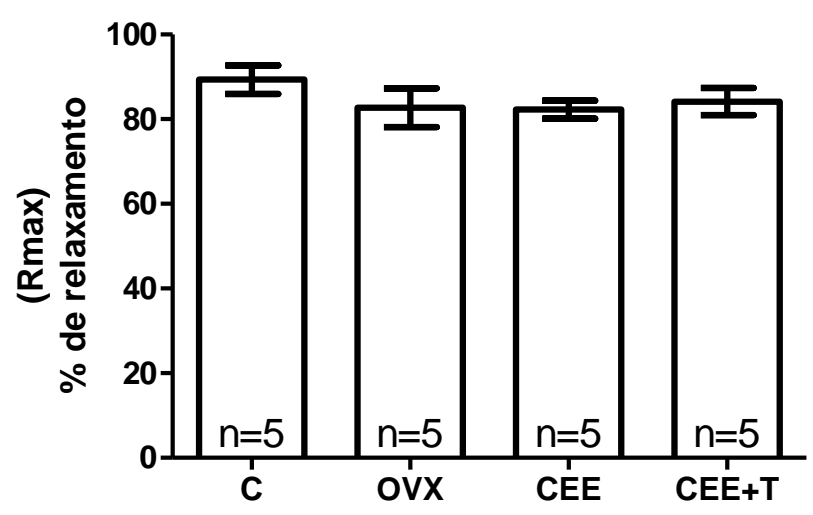

Resposta máxima ao nitroprussiato de sódio (NPS) em anéis de aorta, com endotélio, isolados de fêmeas SHR. C - representa o grupo SHR controle; OVX ovariectomizadas; CEE - tratadas com Conjugado Estrogênio Equino; CEE+T tratadas com Conjugado Estrogênio Equino associado à testosterona. Os valores foram expressos como média \pm EPM.

Fonte: Costa, 2012. 


\subsection{Avaliação da resposta vasoconstritora à fenilefrina em anéis de aorta com endotélio isolados de fêmeas SHR}

A fenilefrina (FE) promoveu vasoconstrição dependente de concentração nos anéis de aorta com endotélio dos quatro grupos experimentais estudados (Figura $8 \mathrm{~A})$. As respostas vasoconstritoras nas concentrações de $10^{-8}$ a $10^{-5} \mathrm{M}$ foram maiores nas aortas do grupo OVX quando comparado com o grupo C. O tratamento com CEE corrigiu essas respostas em todas as concentrações, porém no grupo $C E E+T$ o efeito do CEE foi abolido.

Os anéis de aortas com endotélio do grupo OVX apresentaram aumento na Rmax para FE em comparação com aquela do grupo C (Figura 8B). O tratamento com CEE corrigiu a Rmax encontrada nas OVX para níveis semelhantes ao do grupo $\mathrm{C}$, porém este efeito foi abolido no grupo $\mathrm{CEE}+\mathrm{T}$ (Figura 8B). 
Figura 8 - Efeito da ovariectomia e dos tratamentos hormonais (CEE e CEE+T) sobre a resposta vasoconstritora a fenilefrina em anéis de aorta com endotélio.

\section{A}

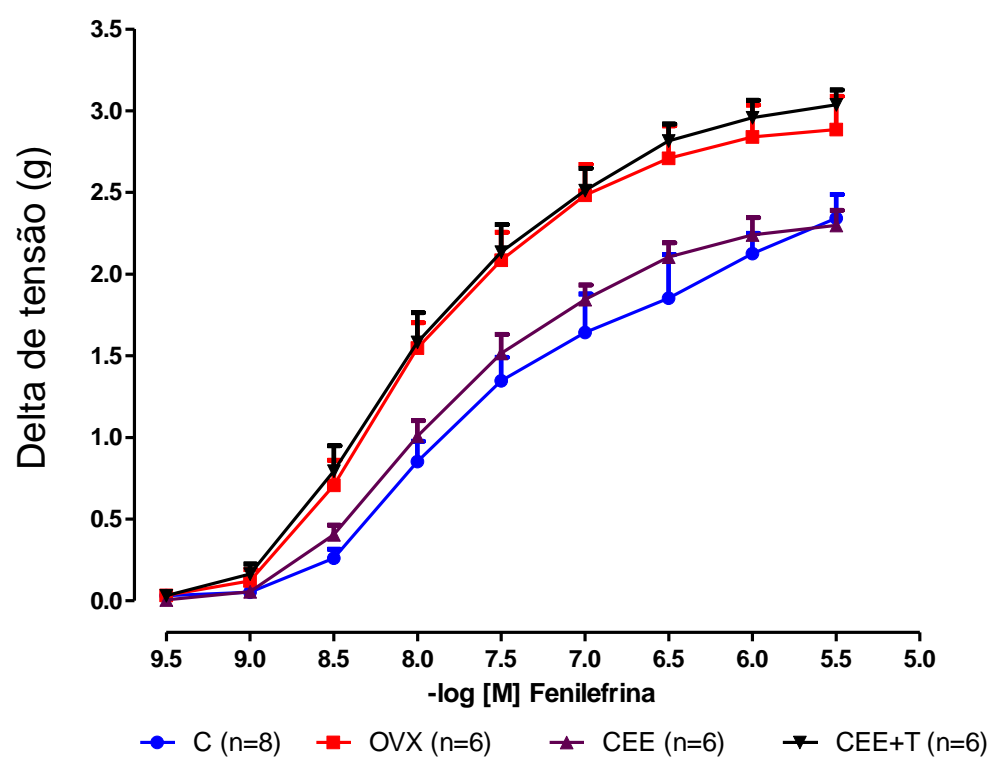

B

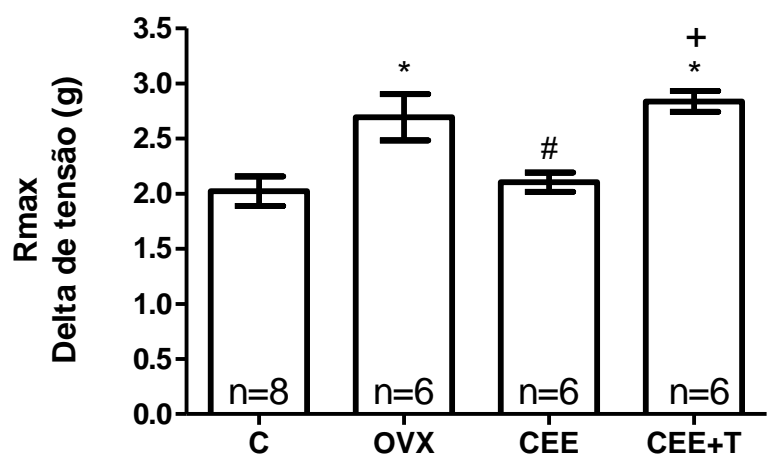

Curvas concentração-efeito cumulativas $(A)$ e resposta máxima $(B)$ à fenilefrina $(F E)$ obtidas em anéis, com endotélio, isolados de fêmeas SHR. C - representa o grupo SHR controle; OVX - ovariectomizadas; CEE - tratadas com Conjugado Estrogênio Equino; $\mathrm{CEE}+\mathrm{T}$ - tratadas com Conjugado Estrogênio Equino associado à testosterona. O número de animais utilizados por grupo encontra-se entre parênteses (A) e dentro das barras (B). Os valores foram expressos como média $\pm E P M$. Foi utilizado o teste ANOVA DE uma via para análise. ${ }^{*} p<0,05$ vs $C$; $\# p<0,05$ vs $O V X$; $+p<0,05$ vs CEE.

Fonte: Costa, 2012 
4.5 Avaliação da resposta vasodilatadora à $\mathrm{ACh}$ na presença do antagonista do AT1R de ANG II (losartan) em anéis de aorta isolados de fêmeas SHR

$\mathrm{O}$ antagonismo do $\mathrm{AT1R}$, com losartan, não interferiu no comportamento bifásico da curva concentração-efeito cumulativa e na Rmax vasodilatadora para ACh nas aortas dos grupos C (Figuras 9A e 10A) e CEE (Figuras 9C e 10C) quando comparados com seus respectivos controles sem losartan. No grupo OVX, O antagonismo do AT1R não alterou o comportamento da fase relaxante, mas aumentou a Rmax vasodilatadora e aboliu a resposta contrátil induzida pela ACh em comparação com seu respectivo controle; OVX sem losartan (Figuras 9B e 10B). No grupo $C E E+T$ o antagonismo do AT1R aumentou o relaxamento e inibiu a fase contrátil, em comparação com o seu respectivo controle; $C E E+T$ sem losartan (Figuras 9D e 10D).

A Rmax vasodilatadora para ACh na presença do antagonista do AT1R foi semelhante entre os grupos C, OVX, CEE e CEE+T (Figura 11). 
Figura 9 - Efeito da ovariectomia e dos tratamentos hormonais (CEE e CEE+T) sobre a resposta vasodilatadora a ACh em anéis de aorta, com endotélio, na presença do losartan, antagonista do AT1R.

A

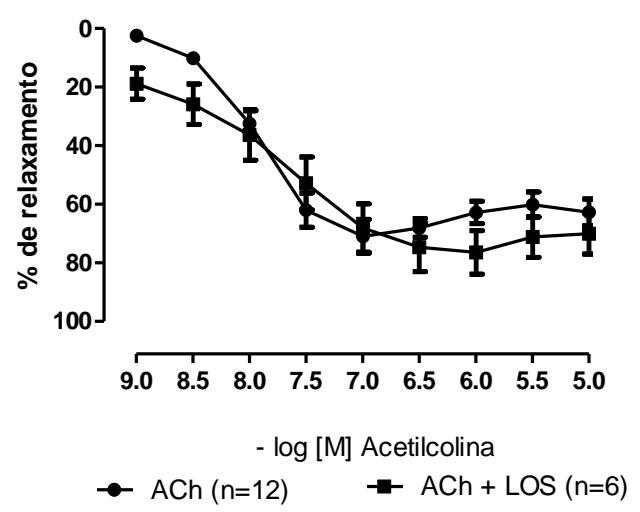

C

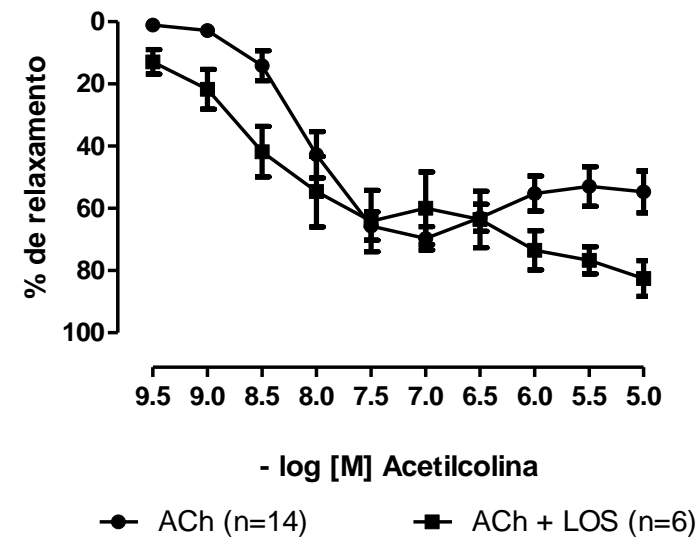

B

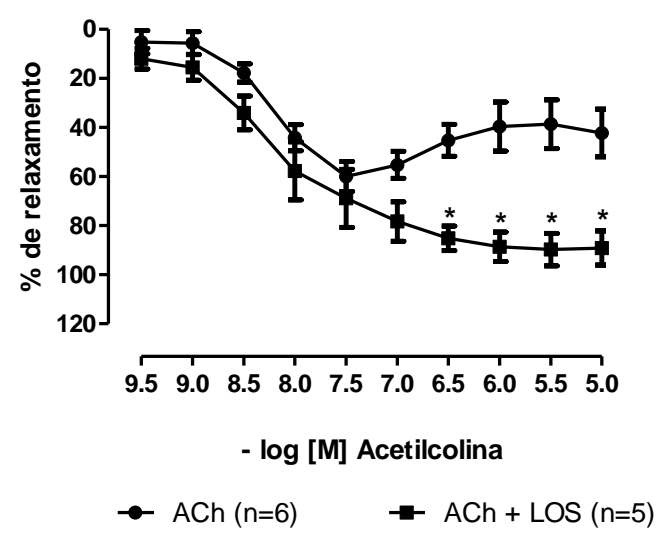

D

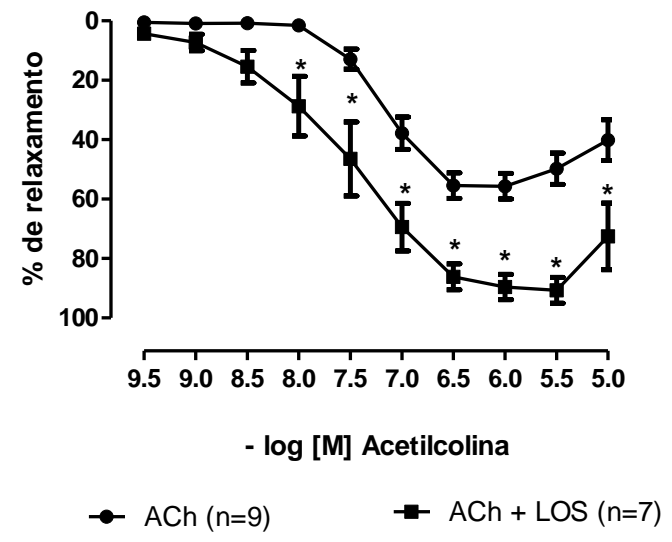

Curva concentração-efeito cumulativa à acetilcolina na presença de losartan, antagonista do receptor AT1 de angiotensina II (ACh+LOS) em anéis de aorta com endotélio isolados de ratas. (A) grupo SHR controle; (B) OVX - ovariectomizadas; (C) CEE - tratadas com Conjugado Estrogênio Equino; (D) $C E E+T$ - tratadas com Conjugado Estrogênio Equino associado à testosterona. $O$ número de animais utilizados por grupo encontra-se entre parênteses. Os valores foram expressos como média \pm EPM. Foi utilizado $o$ teste ANOVA de duas vias para análise. ${ }^{*} p<0,05$ vs ACh

Fonte: Costa, 2012 
Figura 10 - Efeito da ovariectomia e dos tratamentos hormonais (CEE e CEE+T) sobre a resposta máxima vasodilatadora a ACh em anéis de aorta, com

A endotélio, na presença ou não do losartan, antagonista do AT1R.

B
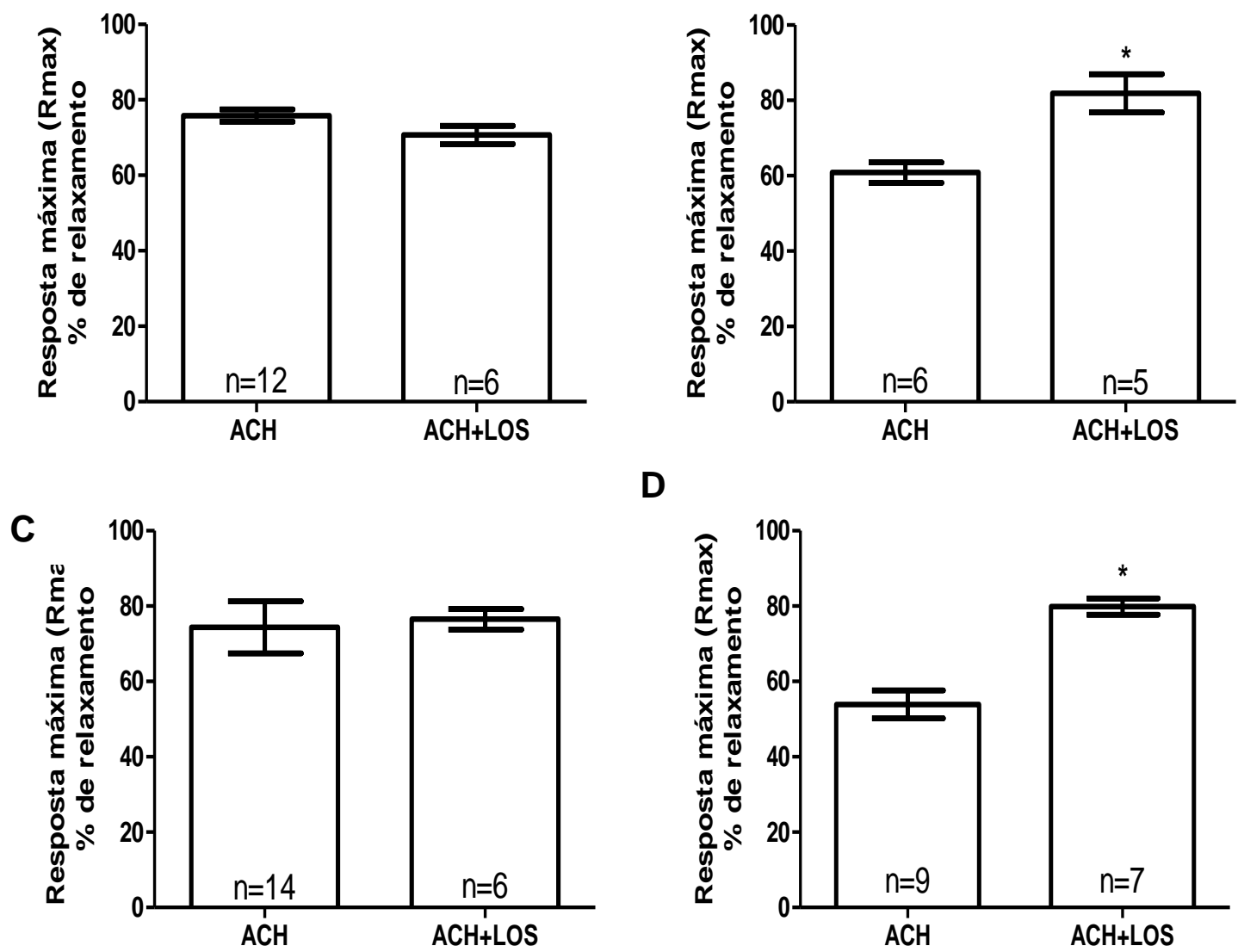

D

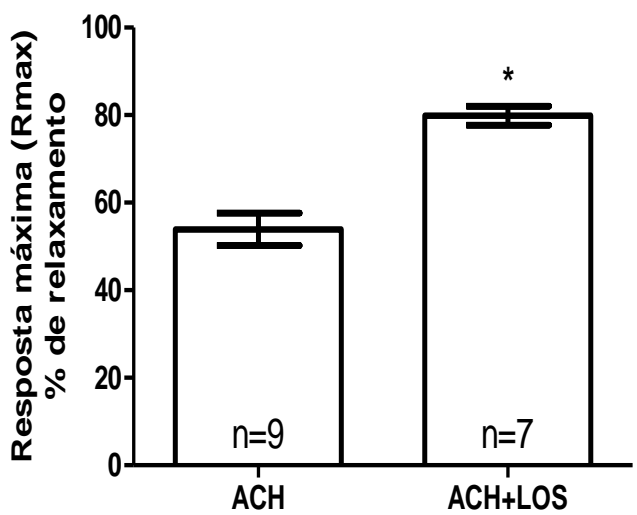

Respota máxima (Rmax) vasodilatadora à acetilcolina na presença $(A C h+L O S)$ e na ausência (ACh) de losartan, antagonista do receptor AT1 de angiotensina II em anéis de aorta com endotélio isolados de fêmeas SHR. (A) grupo SHR controle; (B) OVX ovariectomizadas; (C) CEE - tratadas com Conjugado Estrogênio Equino; (D) CEE+T - tratadas com Conjugado Estrogênio Equino associado à testosterona. O número de animais utilizados por grupo encontra-se dentro das barras. Os valores foram expressos como média \pm EPM. Foi utilizado o teste t para comparação entre as Rmax. ${ }^{*} \mathrm{p}<0,05$ vs $\mathrm{ACh}$.

Fonte: Costa, 2012 
Figura 11 - Efeito da ovariectomia e dos tratamentos hormonais (CEE e CEE+T) sobre a resposta máxima vasodilatadora a ACh em anéis de aorta, com endotélio, na presença do losartan, antagonista do AT1R.

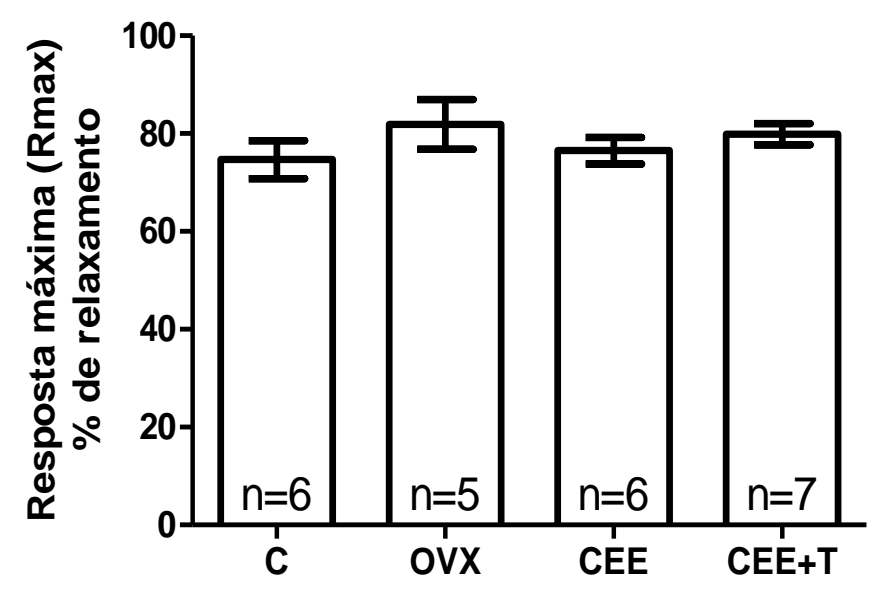

Resposta máxima (Rmax) vasodilatadora à acetilcolina na presença de losartan, antagonista do receptor AT1 de angiotensina II em anéis de aorta, com endotélio, isolados de fêmeas SHR. C - representa o grupo SHR controle; OVX ovariectomizadas; CEE -tratadas com Conjugado Estrogênio Equino; $C E E+T$ tratadas com Conjugado Estrogênio Equino associado à testosterona. $\mathrm{O}$ número de animais utilizados por grupo encontra-se dentro das barras. Os valores foram expressos como média tepm. Foi utilizado o teste ANOVA de uma via para análise.

Fonte: Costa, 2012 


\subsection{Avaliação da resposta vasodilatadora à $\mathrm{ACh}$ na presença da apocinina, inibidor da NADPH oxidase em anéis de aorta isolados de fêmeas SHR}

O inibidor inespecífico da NADPH oxidase, apocinina, não exerceu efeito na curva concentração-efeito cumulativa bifásica e na Rmax vasodilatadora à $A C h$ nos anéis de aorta com endotélio dos grupos C (Figura 12A e 13A) e CEE (Figura 12C e 13C). Nos grupos OVX e CEE+T o bloqueio da NADPH oxidase aboliu a fase contrátil (Figura 12B e 12D) e aumentou a Rmax vasodilatadora (Figura 13B e 13 D) induzida pela ACh, em comparação com seus controles sem apocinina.

Após inibição da NADPH oxidase, a Rmax vasodilatadora para ACh foi semelhante entre os grupos C, OVX, CEE e CEE+T (Figura14). 
Figura 12 - Efeito da ovariectomia e dos tratamentos hormonais (CEE e CEE+T) sobre a resposta vasodilatadora a ACh em anéis de aorta, com endotélio, na presença de apocinina, inibidor da NADPH oxidase.

A

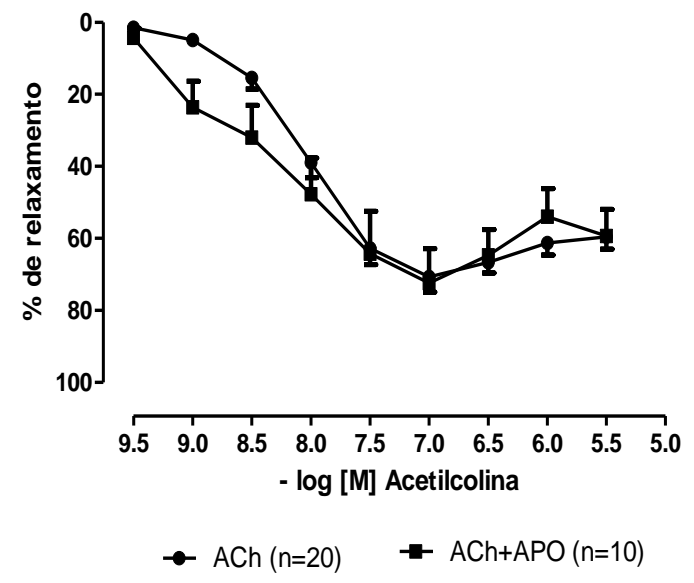

C

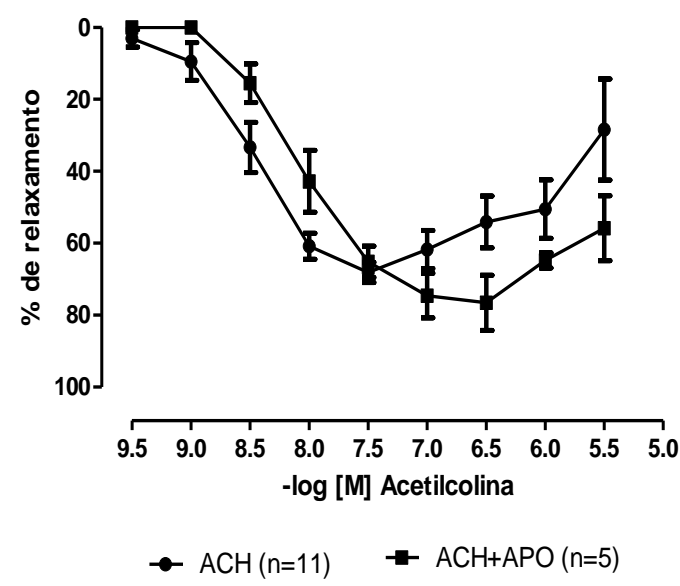

B

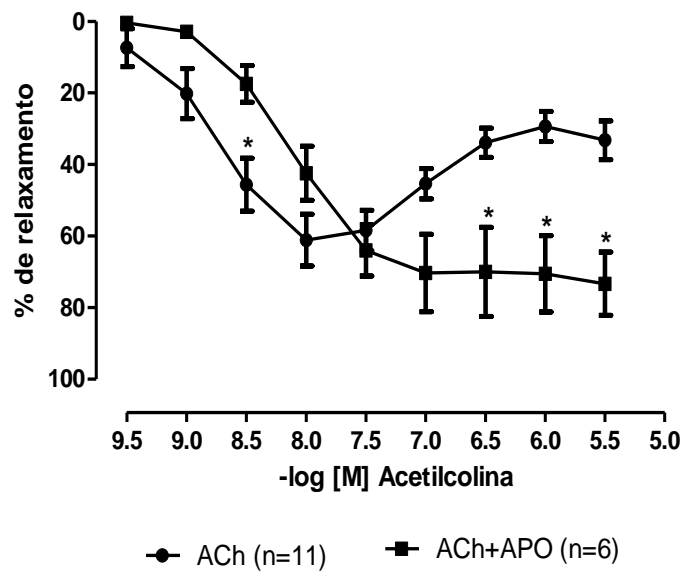

D

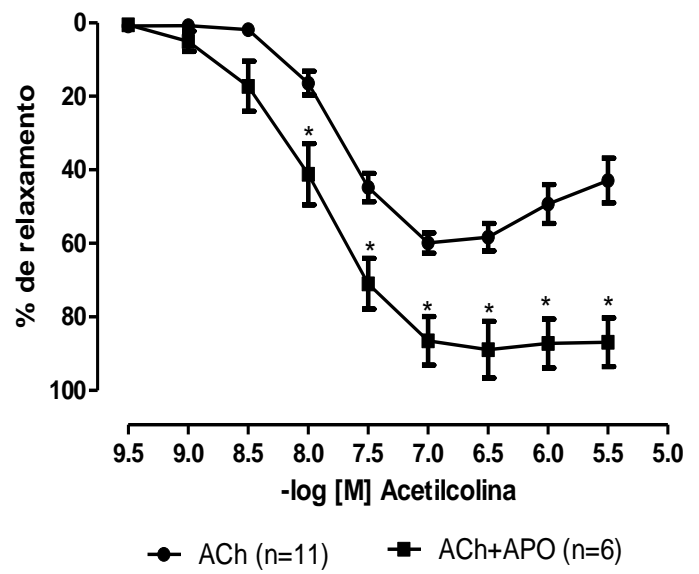

Curvas concentração-efeito cumulativas à acetilcolina na presença de apocinina, inibidor da $\mathrm{NAD}(\mathrm{P}) \mathrm{H}$ oxidase (ACh+APO) em anéis de aorta com endotélio isolados de fêmeas SHR. (A) grupo SHR controle; (B) OVX - ovariectomizadas; (C) CEE tratadas com Conjugado Estrogênio Equino; (D) $C E E+T$ - tratadas com Conjugado Estrogênio Equino associado à testosterona. $O$ número de animais utilizados por grupo encontra-se entre parênteses. Os valores foram expressos como média $\pm E P M$. Foi utilizado ANOVA de duas vias para análise. ${ }^{*} p<0,05$ vs $A C h$. Fonte: Costa, 2012. 
Figura 13 - Efeito da ovariectomia e dos tratamentos hormonais (CEE e CEE+T) sobre a resposta máxima vasodilatadora a ACh em anéis de aorta, com endotélio, na presença ou não de apocinina, inibidor da NADHP oxidase.

A
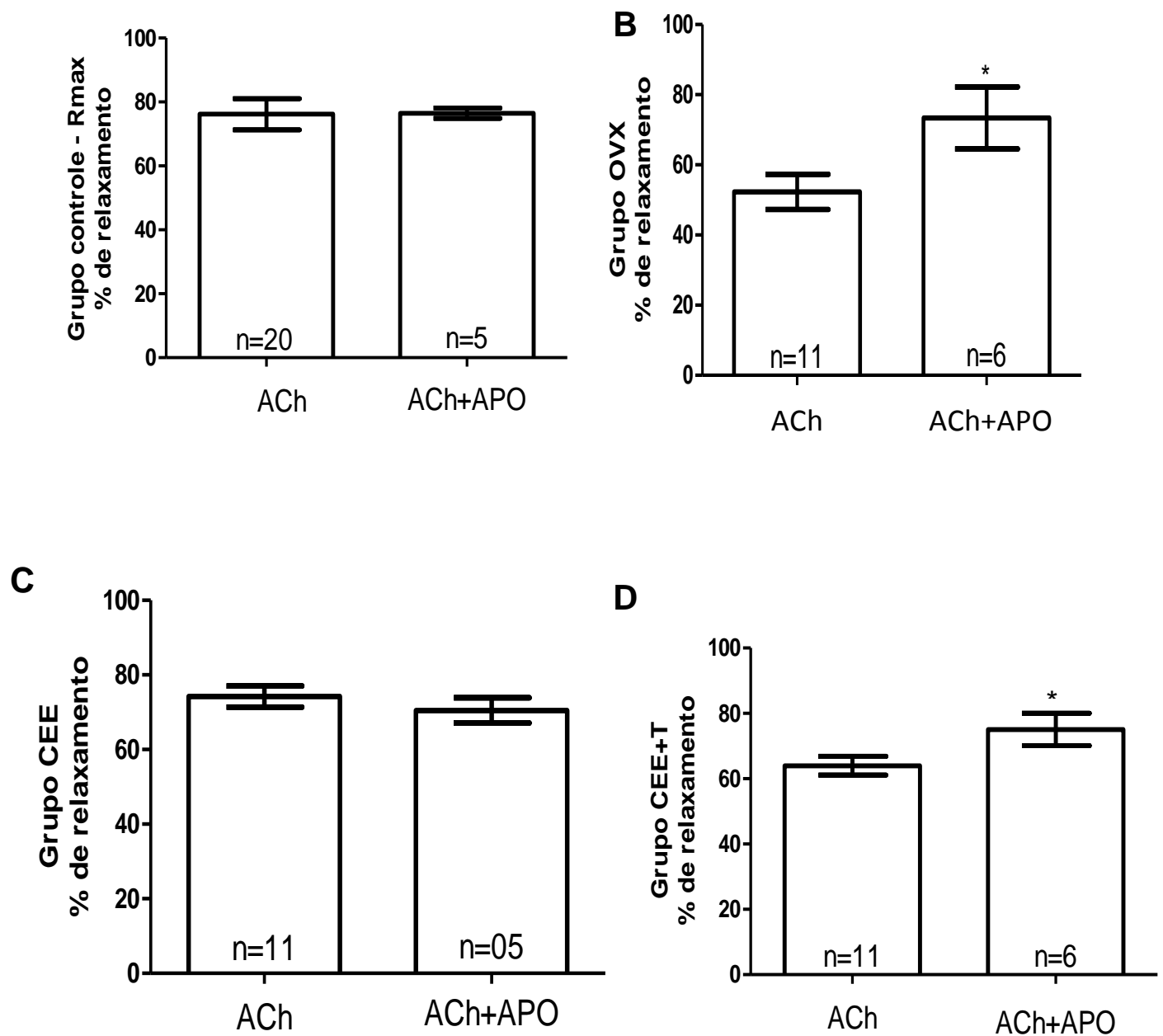

Resposta máxima (Rmax) vasodilatadora à acetilcolina na presença de apocinina, inibidor da NADPH oxidase (ACh+APO) em anéis de aorta com endotélio isolados de ratas. (A) grupo controle; (B) OVX - ovariectomizadas; (C) CEE - tratadas com Conjugado Estrogênio Equino; (D) $\mathrm{CEE}+\mathrm{T}$ - tratadas com Conjugado Estrogênio Equino associado à testosterona. $O$ número de animais utilizados por grupo encontra-se dentro das barras. Os valores foram expressos como média \pm EPM. Foi utilizado teste t para comparação entre as Rmax. ${ }^{*} p<0,05$ vs ACh.

Fonte: Costa, 2012. 
Figura 14 - Efeito da ovariectomia e dos tratamentos hormonais (CEE e CEE+T) sobre a resposta máxima vasodilatadora a ACh em anéis de aorta, com endotélio, na presença de Apocinina, inibidor da NADPH oxidase.

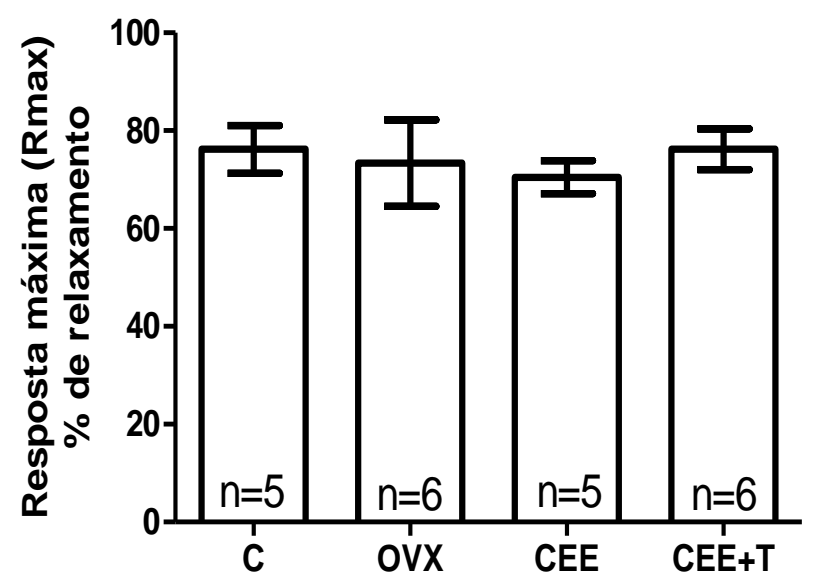

Resposta máxima (Rmax) vasodilatadora à acetilcolina na presença da apocinina, inibidor da NAD(P)H oxidase. C - representa o grupo SHR controle; OVX ovariectomizadas; CEE -tratadas com Conjugado Estrogênio Equino; $C E E+T$ tratadas com Conjugado Estrogênio Equino associado à testosterona. O número de animais utilizados por grupo encontra-se dentro das barras. Os valores foram expressos como média \pm epm. Foi utilizado o teste ANOVA de uma via para análise. Fonte: Costa, 2012. 


\subsection{Avaliação da resposta à ACh na presença do inibidor da NOS, L-NAME em anéis de aorta isolados de fêmeas SHR}

A incubação com L-NAME nos anéis de aorta com endotélio aboliu a resposta vasodilatadora para ACh em todos os grupos experimentais estudados e a fase contrátil permaneceu inalterada (Figura 15). Não houve diferença na Rmax vasoconstritora induzida pela ACh na presença do L-NAME quando comparados os quatro grupos experimentais.

Figura 15 - Efeito da ovariectomia e dos tratamentos hormonais (CEE e CEE+T) sobre a resposta vasodilatadora a ACh em anéis de aorta, com endotélio, na presença de L-NAME, inibidor da óxido nítrico sintase.

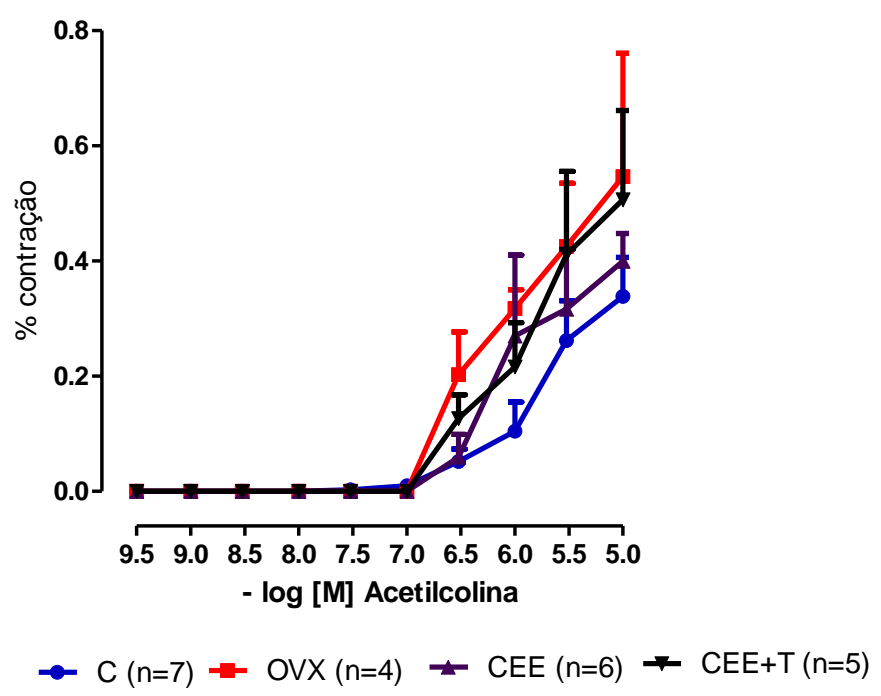

CurvaS concentração-efeito cumulativaS para acetilcolina na presença de L-NAME, inibidor da óxido nítrico sintase (NOS).C - representa o grupo SHR controle; OVX ovariectomizadas; CEE - tratadas com Conjugado Estrogênio Equino; CEE+T tratadas com Conjugado Estrogênio Equino associado à testosterona. $\mathrm{O}$ número de animais utilizados por grupo encontra-se entre parênteses. Os valores foram expressos como média \pm EPM.

Fonte: Costa, 2012 


\subsection{Avaliação da geração de espécies reativas de oxigênio (EROs) aortas isoladas de fêmeas SHR}

Os cortes de aorta dos quatro grupos experimentais estudados apresentaram geração de EROs demonstrada pela emissão de fluorescência a partir do núcleo das células vasculares e detectada no comprimento de onda da rodamina (Figura 16, painel inferior). A geração de EROs foi maior nos cortes de aorta das OVX quando comparada com as aortas do grupo C. O tratamento com CEE reduziu a geração de EROs para níveis semelhantes aos observados nas aortas do grupo $\mathrm{C}$. Entretanto, no grupo $\mathrm{CEE}+\mathrm{T}$ a geração de EROs foi semelhante ao grupo OVX e superior aos dos grupos $\mathrm{C}$ e CEE+T (Figura 16). 
Figura 16 - Efeito da ovariectomia e dos tratamentos hormonais (CEE e CEE+T) sobre a geração de EROs em anéis de aorta com endotélio.
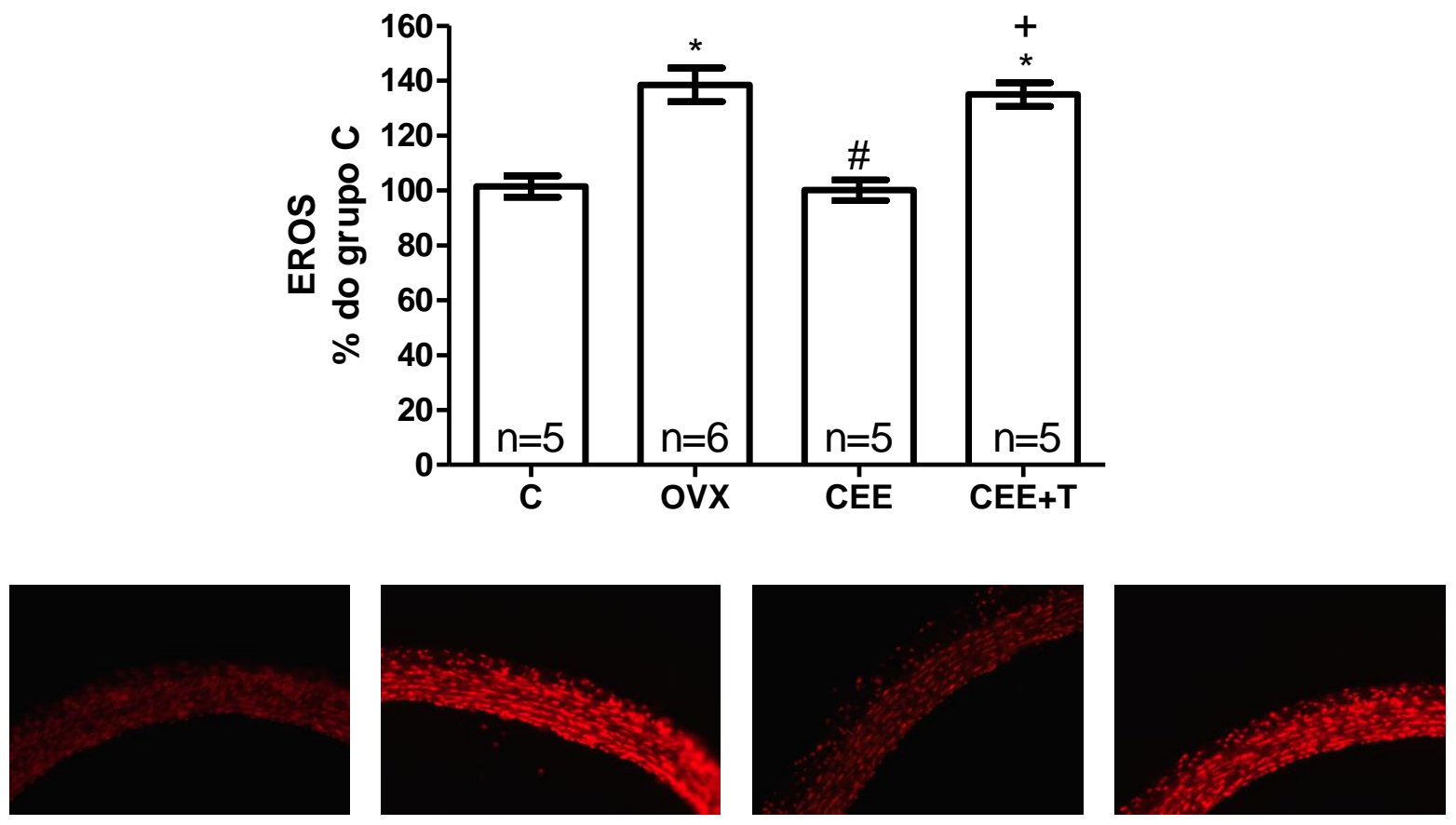

Geração de espécies reativas de oxigênio em aortas com endotélio de fêmeas SHR. C - representa o grupo SHR controle; OVX - ovariectomizadas; CEE - tratadas com Conjugado Estrogênio Equino; $\mathrm{CEE}+\mathrm{T}$ - tratadas com Conjugado Estrogênio Equino associado à testosterona. O número de animais utilizados por grupo encontra-se dentro das barras. Os valores foram expressos como média tepm. Foi utilizado o teste ANOVA de uma via para análise ${ }^{*} p<0,05$ vs $C$. \# $p<0,05$ vs OVX. $+p<0,05$ vs CEE.

Fonte: Costa, 2012. 


\subsection{Avaliação da geração de espécies reativas de oxigênio (EROs) na presença do antagonista do AT1R, losartan, em anéis de aorta isolados de fêmeas SHR}

Os cortes de aorta dos quatro grupos experimentais estudados apresentaram geração de EROs, na presença ou não de losartan, demonstrada pela emissão de fluorescência a partir do núcleo das células vasculares e detectada no comprimento de onda da rodamina .

A incubação com losartan reduziu a geração de EROs nas aortas das ratas C, OVX e CEE+T, porém não exerceu efeito sobre a geração de EROs nas aortas do grupo CEE em comparação com seus respectivos controles (Figura 17). 
Figura 17 - Efeito da ovariectomia e dos tratamentos hormonais (CEE e CEE+T) sobre a geração de EROs em anéis de aorta, com endotélio, na presença do losartan, antagonista do AT1R.
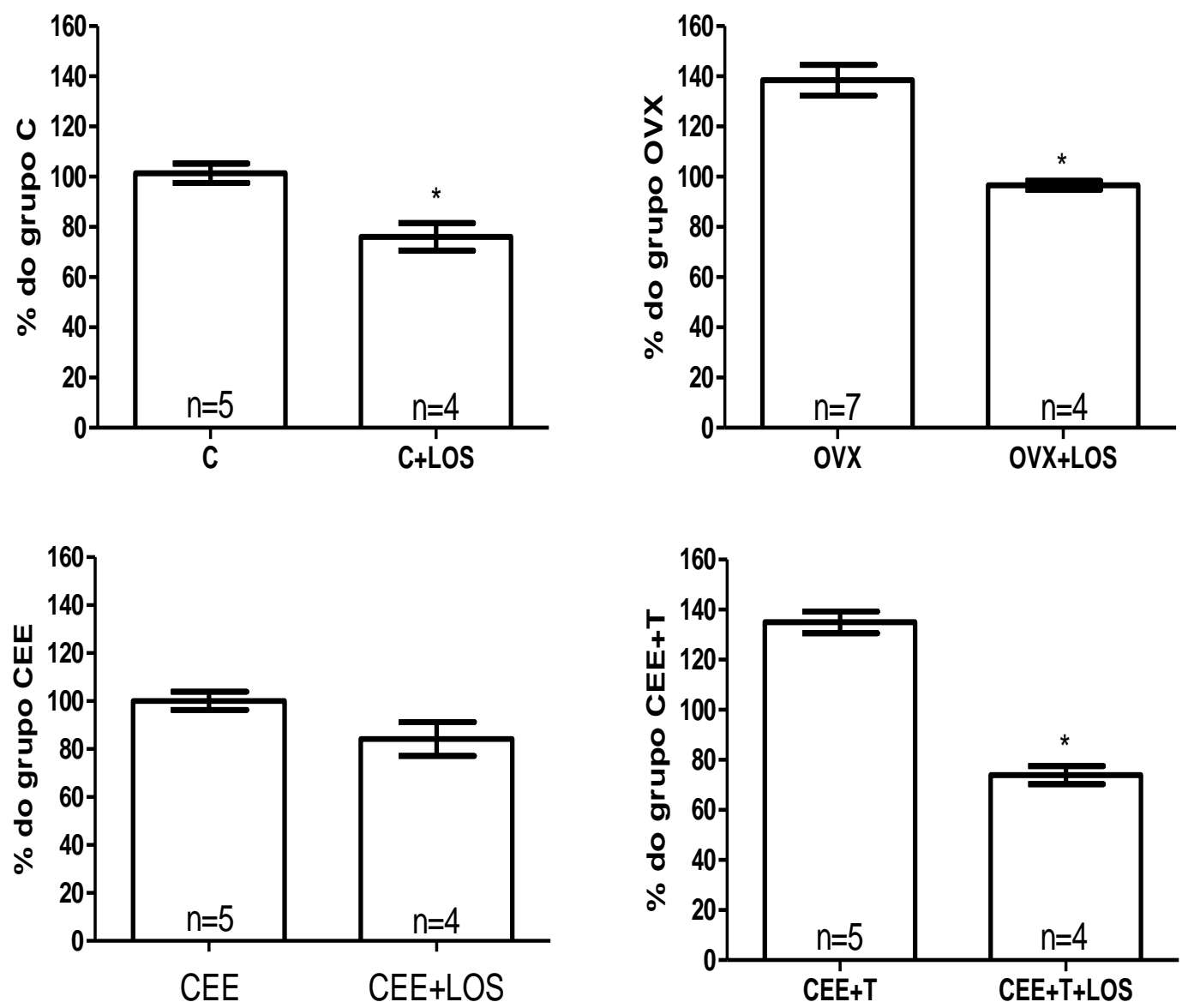

Geração de espécies reativas de oxigênio em cortes de aortas com endotélio, tradadas (+LOS) ou não com losartan antagonista do AT1R. C - representa o grupo SHR controle; OVX - ovariectomizadas; CEE - tratadas com Conjugado Estrogênio Equino; $\mathrm{CEE}+\mathrm{T}$ - tratadas com Conjugado Estrogênio Equino associado à testosterona. $O$ número de animais utilizados por grupo encontra-se dentro das barras. Os valores foram expressos como média tepm. Foi utilizado o teste t para análise. ${ }^{*} p<0,05$ em relação ao respectivo controle sem losartan.

Fonte: Costa, 2012 
4.10 Avaliação da geração de espécies reativas de oxigênio (EROs) na presença do inibidor da NADPH oxidase, apocinina, em anéis de aorta isolados de fêmeas SHR

Os cortes de aorta dos quatro grupos experimentais estudados apresentaram geração de EROs, na presença ou não do apocinina, demonstrada pela emissão de fluorescência a partir do núcleo das células do músculo liso vascular e detectada no comprimento de onda da rodamina .

No grupo C e CEE a apocinina não alterou a geração de EROs nas aortas. Porém, no grupo OVX e CEE+T houve redução na geração de EROs quando comparado com seus respectivos controles sem apocinina (Figura 18). 
Figura 18 - Efeito da ovariectomia e dos tratamentos hormonais (CEE e CEE+T) sobre a geração de EROs em anéis de aorta, com endotélio, na presença de apocinina, inibidor da NADPH oxidase.
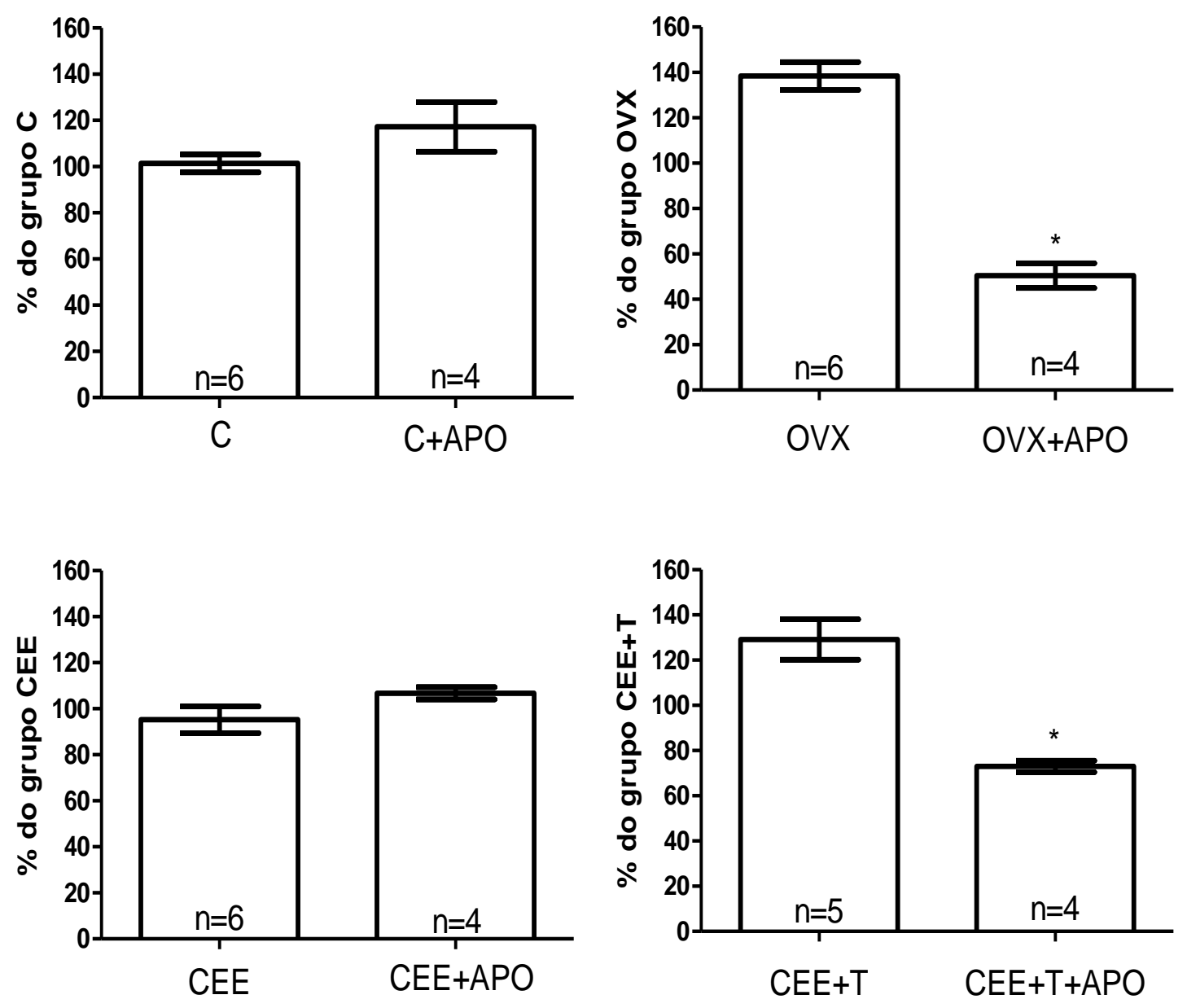

Geração de espécies reativas de oxigênio em aortas com endotélio, tradadas (+APO) ou não com apocinina, inibidor da NAD(P)H oxidase. C - representa o grupo SHR controle; OVX - ovariectomizadas; CEE - tratadas com Conjugado Estrogênio Equino; $\mathrm{CEE}+\mathrm{T}$ - tratadas com Conjugado Estrogênio Equino associado à testosterona. O número de animais utilizados por grupo encontra-se dentro das barras. Os valores foram expressos como média tepm. Foi utilizado o teste t para análise. ${ }^{*} p<0,05$ vs seu respectivo controle sem apocinina.

Fonte: Costa, 2012 
4.11 Avaliação da geração de espécies reativas de oxigênio na presença do 0016HET, inibidor do 20-HETE, em anéis de aorta de fêmeas SHR.

Os cortes de aorta dos quatro grupos experimentais estudados apresentaram geração de EROs, na presença ou não do 1600HET, demonstrada pela emissão de fluorescência a partir do núcleo das células do músculo liso vascular e detectada no comprimento de onda da rodamina .

Nos grupos C, OVX e CEE, o inibidor do 20-HETE não alterou a geração de EROs nos cortes de aorta, porém este bloqueio reduziu a geração no grupo $C E E+T$ (Figura 19). 
Figura 19 - Efeito da ovariectomia e dos tratamentos hormonais (CEE e CEE+T) sobre a geração de EROs em anéis de aorta, com endotélio, na presença do 0016HET, inibidor do 20-HETE.
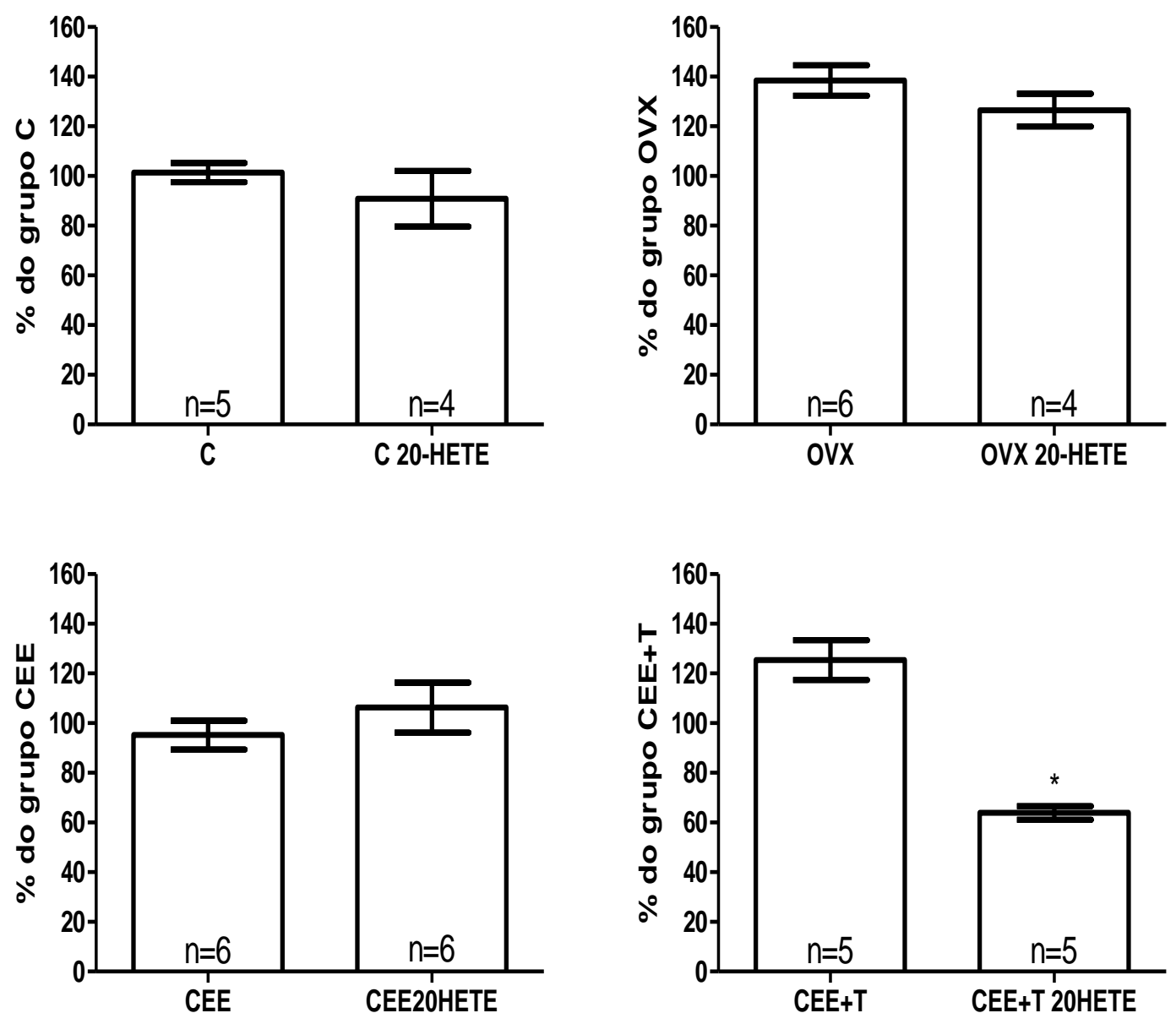

Geração de espécies reativas de oxigênio em cortes de aortas com endotélio tratada com 0016HET, inibidor do 20-HETE. C - representa o grupo SHR controle; OVX ovariectomizadas; CEE - tratadas com Conjugado Estrogênio Equino; CEE+T tratadas com Conjugado Estrogênio Equino associado à testosterona. $\mathrm{O}$ número de animais utilizados por grupo encontra-se dentro das barras. Os valores foram expressos como média \pm epm. Foi utilizado teste t para análise. ${ }^{*} p<0,05$ em relação ao respectivo controle sem $0016 \mathrm{HET}$.

Fonte: Costa, 2012 


\subsection{Análise da expressão protéica da eNOS total em aortas de fêmeas SHR}

As aortas das SHR dos diferentes grupos experimentais estudados apresentaram expressão protéica da enzima eNOS. A expressão da eNOS foi semelhante nas aortas de ratas OVX e CEE quando comparada a expressão nas aortas de ratas $\mathrm{C}$. $\mathrm{O}$ tratamento com $\mathrm{CEE}+\mathrm{T}$ reduziu a expressão de eNOS para níveis inferiores aos observados nas aortas das ratas C, OVX e CEE. (Figura 20).

Figura 20 - Efeito da ovariectomia e dos tratamentos hormonais (CEE e CEE+T) sobre a expressão proteica da eNOS em anéis de aorta com endotélio.

eNOStotal (140KDa)

a-actina (40KDa)
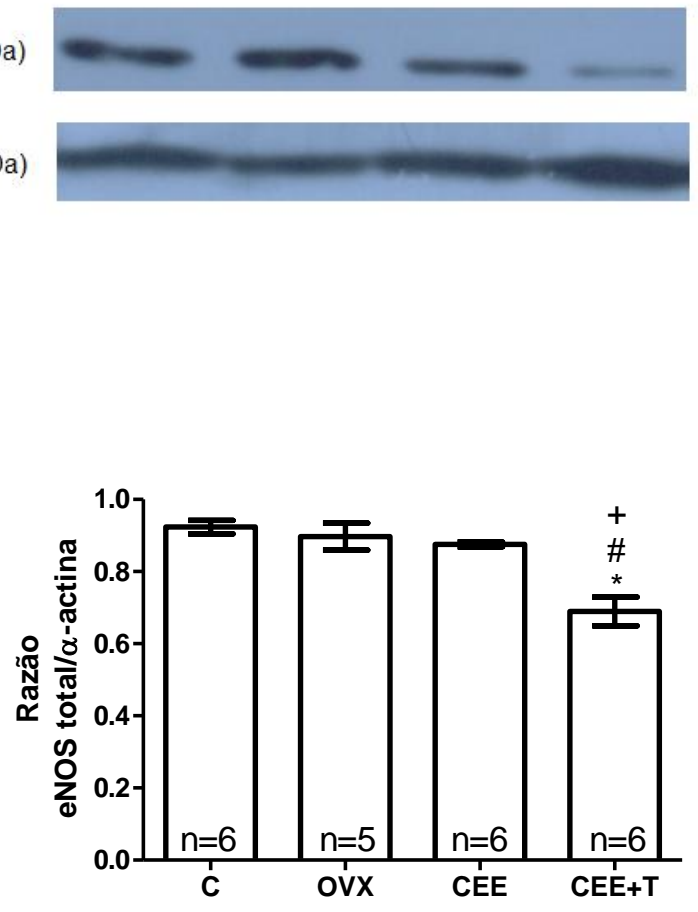

Western blot para eNOS em aortas com endotélio isoladas de fêmeas SHR. Valores normalizados pela expressão de $\alpha$-actina Painel superior: imagens representativas dos imunoblots para eNOS (140kDa) e a-actina (40kDa). C - representa o grupo SHR controle; OVX - ovariectomizadas; CEE - tratadas com Conjugado Estrogênio Equino; $\mathrm{CEE}+\mathrm{T}$ - tratadas com Conjugado Estrogênio Equino associado à testosterona. $O$ número de animais utilizados por grupo encontra-se dentro das barras. Os valores foram expressos como média \pm epm. Foi utilizado o teste ANOVA de uma via para análise. ${ }^{*} p<0,05$ vs $C$. $\# p<0,05$ vs OVX. $+p<0,05$ vs CEE.

Fonte: Costa, 2012 


\subsection{Avaliação da expressão do RNAm dos receptores AT1 e AT2 de ANG II em aortas isoladas de fêmeas SHR.}

A aorta das ratas dos grupos $C$, OVX, CEE e CEE+T apresentam expressão de RNAm para os receptores AT1 e AT2 de ANG II e essa expressão foi semelhante entre os grupos estudados (Figura 21).

Figura 21 - Efeito da ovariectomia e dos tratamentos hormonais (CEE e CEE+T) sobre a expressão do RNAm dos receptores AT1 e AT2 de angiotensina II em anéis de aorta com endotélio.
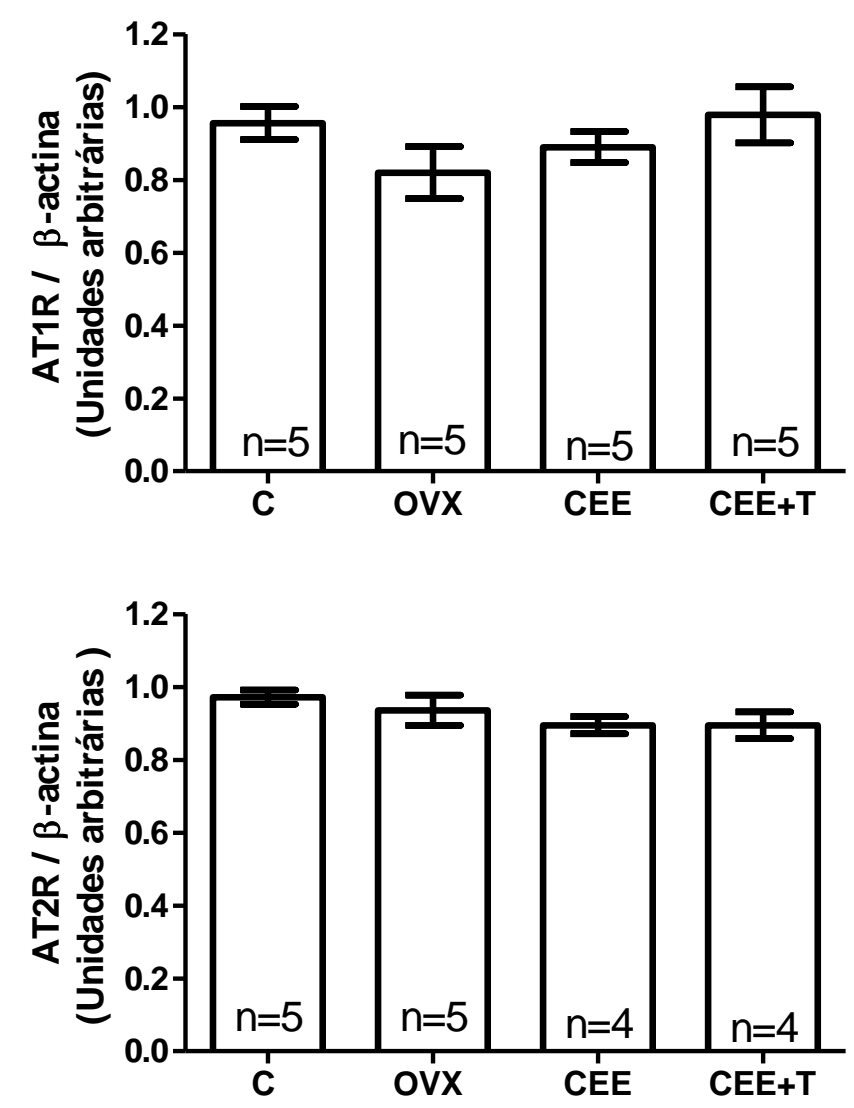

Expressão do RNAm do receptores AT1 e AT2 de angiotensina II, em aortas isoladas de ratas SHR, utilizando a técnica de RT-PCR em tempo real. Valores normalizados pela expressão do RNAm da $\beta$-actina. C - representa o grupo controle; OVX ovariectomizadas; CEE - tratadas com Conjugado Estrogênio Equino; CEE+T tratadas com Conjugado Estrogênio Equino associado à testosterona. $O$ número de animais utilizados encontra-se dentro das barras. Os valores foram expressos como média \pm epm. Foi utiliado o teste ANOVA de uma via para análise.

Fonte: Costa, 2012 
4.14 Expressão do RNAm das subunidades da NADPH oxidase: $g p 91^{\text {phox }}$, p47 ${ }^{\text {phox }}$ e p22 ${ }^{\text {phox }}$ em aortas isoladas de fêmeas SHR

As aortas das fêmeas hipertensas dos diferentes grupos experimentais estudados apresentaram expressão de RNAm para as subunidades gp91 ${ }^{\text {phox }}, \mathrm{p} 47^{\text {phox }}$ e p22 ${ }^{\text {phox }}$. No grupo OVX foi observado aumento na expressão do RNAm para as subunidades gp91 ${ }^{\text {phox }}$ e p22 ${ }^{\text {phox }}$ quando comparadas com as do grupo C. Os tratamentos com CEE e CEE+T reduziram a expressão da gp91 ${ }^{\text {phox }}$ e p22 ${ }^{\text {phox }}$ (Figura 22A e 22B para níveis semelhantes ao do grupo $C$. Não foi observada diferença na expressão do RNAm da subunidade $\mathrm{p} 47^{\text {phox }}$ entre os grupos experimentais (Figura 22B). 
Figura 22 - Efeito da ovariectomia e dos tratamentos hormonais (CEE e CEE+T) sobre a expressão do RNAm das subunidades da NADPH oxidase $\left(\mathrm{gp} 91^{\text {phox }}, \mathrm{p} 47^{\text {phox }}\right.$ e p22 ${ }^{\text {phox }}$ ) em anéis de aorta com endotélio.

A

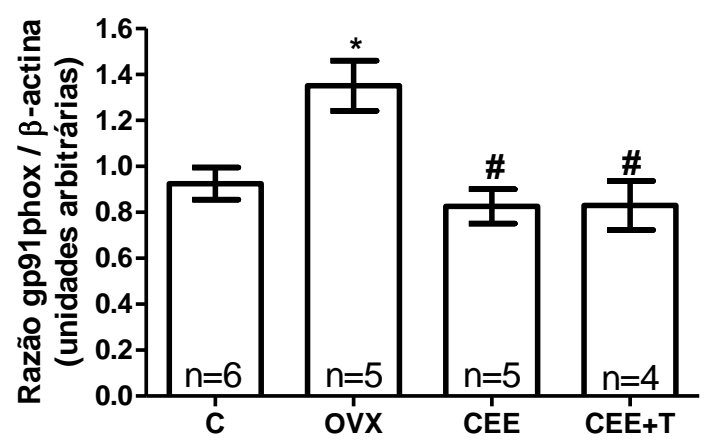

B

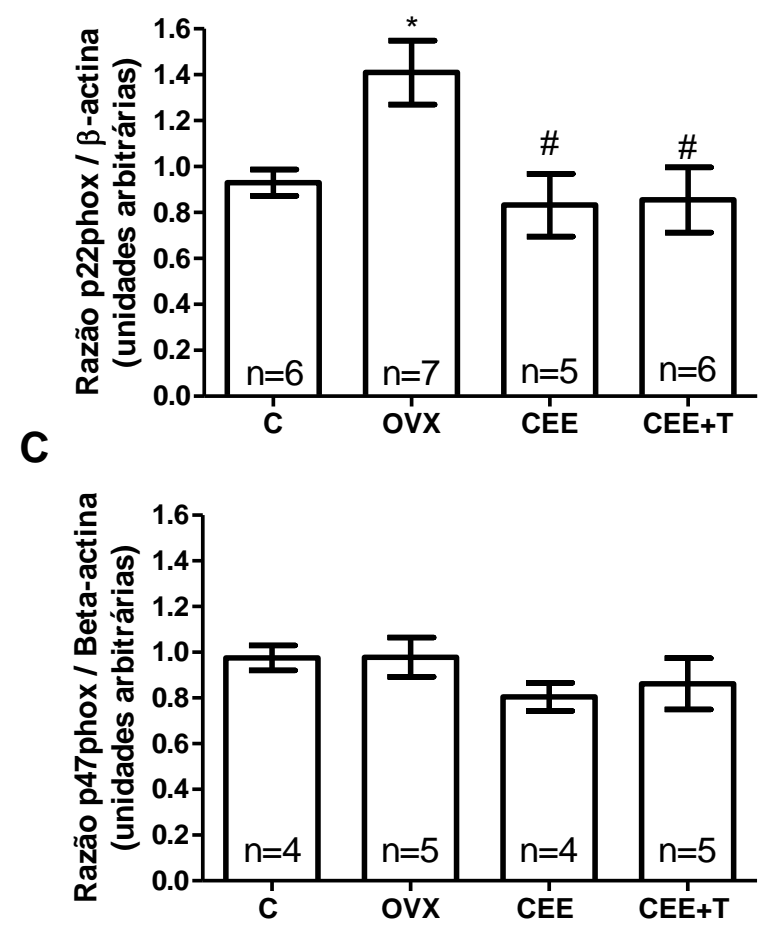

Expressão do RNAm das subunidades da NADPH oxidase, gp91 ${ }^{\text {phox }}(\mathrm{A}), \mathrm{p} 47^{\text {phox }}(\mathrm{B}) \mathrm{e}$ p22 ${ }^{\text {phox }}(\mathrm{C})$ em aorta isoladas de ratas SHR, utilizando a técnica de RT-PCR em tempo real. Valores normalizados pela expressão do RNAm da $\beta$-actina. C representa o grupo SHR controle; OVX - ovariectomizadas; CEE - tratadas com Conjugado Estrogênio Equino; $\mathrm{CEE}+\mathrm{T}$ - tratadas com Conjugado Estrogênio Equino associado à testosterona. O número de animais utilizados por grupo encontra-se dentro das barras. Os valores foram expressos como média \pm epm. Foi utilizado 0 teste ANOVA de uma via para análise. ${ }^{*} p<0,05$ vs $C$.; $\# p<0,05$ vs OVX.

Fonte: Costa, 2012. 


\title{
4.15 Análise da expressão protéica das enzimas antioxidantes: $\mathrm{Cu} / \mathrm{Zn}$ superóxido dismutase (SOD) e catalase (CAT) em aortas isoladas de fêmeas SHR.
}

As aortas das ratas hipertensas dos diferentes grupos experimentais estudados apresentaram expressão das enzimas antioxidantes SOD (Figura 23) e CAT (Figura 24). A expressão da SOD no grupo OVX não foi diferente quando comparada com as ratas do grupo $\mathrm{C}$. $\mathrm{O}$ tratamento com $\mathrm{CEE}$ ou $\mathrm{CEE}+\mathrm{T}$ aumentou a expressão protéica da SOD em comparação com as dos grupos C e OVX.

Figura 23 - Efeito da ovariectomia e dos tratamentos hormonais (CEE e CEE+T) sobre a expressão proteica da superóxido dismutase em anéis de aorta com endotélio.

\author{
Cu/Zn SOD (16kDa) \\ B-actina (42kDa)
}
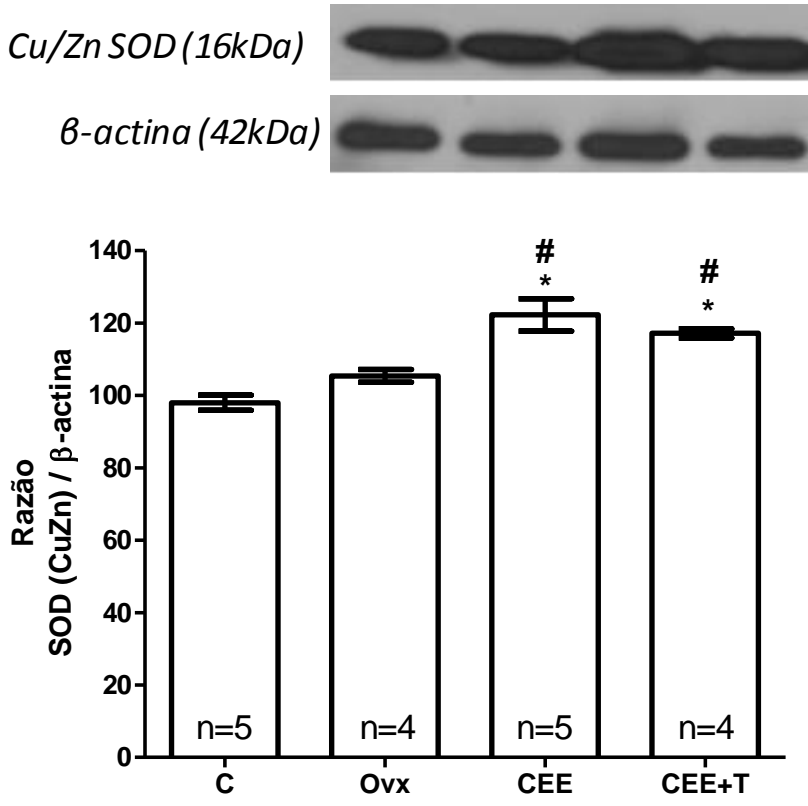

Western blot para a Cu/Zn-SOD em aortas com endotélio isoladas de ratas SHR. Valores normalizados pela expressão de $\beta$-actina. Painel superior: imagens representativas dos imunoblots para SOD (16kDa) e $\beta$-actina $(42 \mathrm{kDa}) \mathrm{C}$ - representa o grupo SHR controle; OVX - ovariectomizadas; CEE - tratadas com Conjugado Estrogênio Equino; $\mathrm{CEE}+\mathrm{T}$ - tratadas com Conjugado Estrogênio Equino associado à testosterona. $O$ número de animais utilizados por grupo encontra-se dentro das barras. Os valores foram expressos como média tepm. Foi utilizado o teste ANOVA de uma via para análise. ${ }^{*} p<0,05$ vs $C$. \# $p<0,05$ vs OVX.

Fonte: Costa, 2012 
As aortas das SHR OVX apresentaram redução na expressão de CAT em relação ao grupo $\mathrm{C}$. Os tratamentos hormonais com CEE e CEE+T corrigiram a expressão da CAT para níveis semelhantes aos do grupo C.

Figura 24 - Efeito da ovariectomia e dos tratamentos hormonais (CEE e CEE+T) sobre a expressão proteica da catalase em anéis de aorta com endotélio.
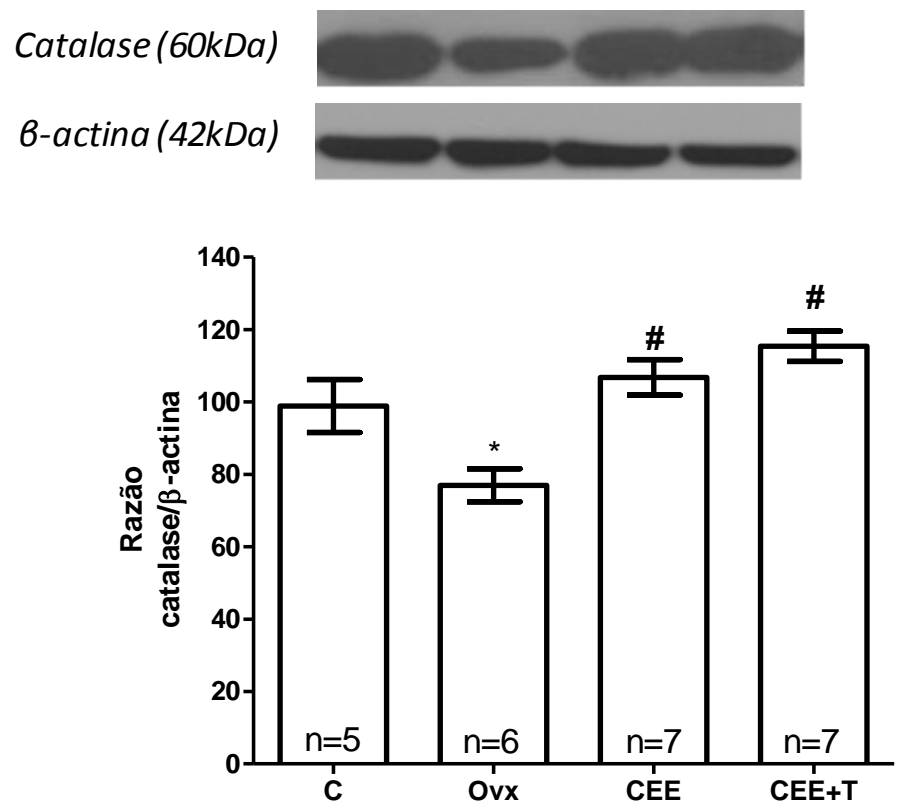

Western blot para a Catalase em aortas com endotélio isoladas de ratas SHR. Valores normalizados pela expressão de $\beta$-actina. Painel superior: imagens representativas dos imunoblots para CAT $(60 \mathrm{kDa})$ e $\beta$-actina $(42 \mathrm{kDa}) . C$ - representa o grupo SHR controle; OVX - ovariectomizadas; CEE - tratadas com Conjugado Estrogênio Equino; $\mathrm{CEE}+\mathrm{T}$ - tratadas com Conjugado Estrogênio Equino associado à testosterona. $O$ número de animais utilizados por grupo encontra-se dentro das barras. Os valores estão expressos como média tepm. Foi utilizado o teste ANOVA de uma via para análise . ${ }^{*} p<0,05$ vs. $C \# p<0,05$ vs OVX.

Fonte: Costa, 2012 


\subsection{Expressão do RNAm dos ERa e ERß e de receptor de andrógeno em aortas isoladas de fêmeas SHR}

As aortas das ratas dos grupos experimentas estudados apresentaram expressão de RNAm para ERa e ERß e para receptor de andrógeno (Figura 25). Houve aumento da expressão de RNAm para ERa (Figura 25A) e ERß (Figura 25B) nas aortas do grupo OVX quando comparadas com as do $\mathrm{C}$, o que foi corrigido pelos tratamentos com CEE ou CEE+T. Não houve diferença na expressão dos receptores de andrógeno nos grupos experimentais estudados (Figura 25C). 
Figura 25 - Efeito da ovariectomia e dos tratamentos hormonais (CEE e CEE+T) sobre a expressão do RNAm dos receptores de estrógeno ( $\alpha$ e $\beta$ ) e andrógeno.

A

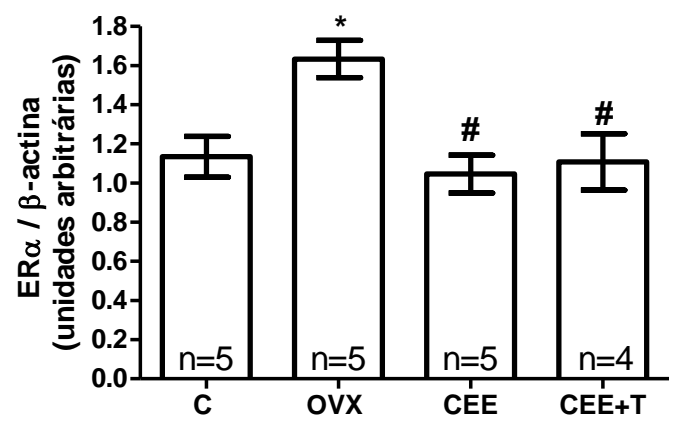

B

C
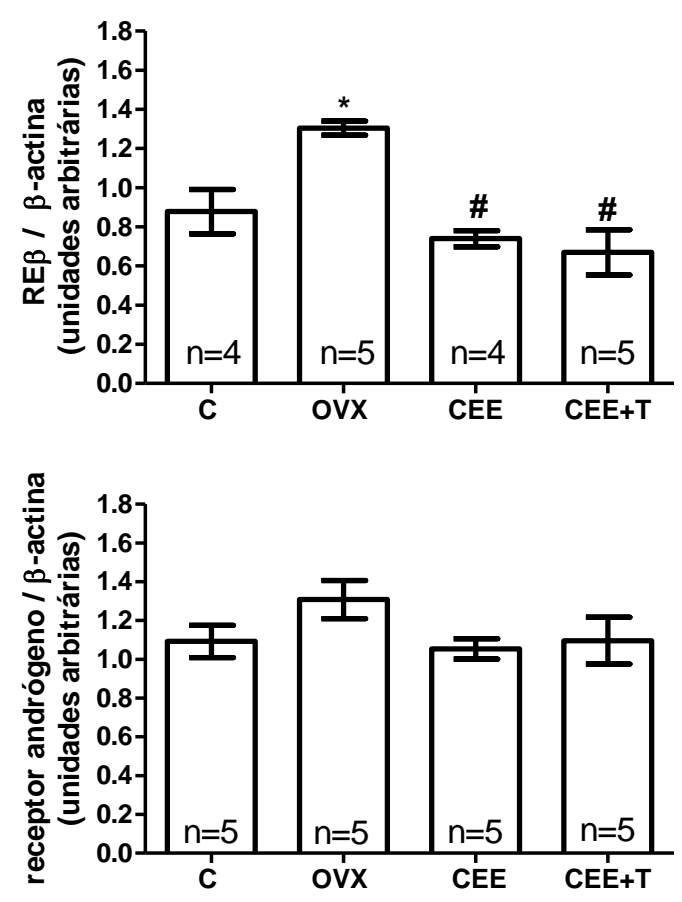

Expressão do RNAm do receptor de estrógeno $\alpha(E R-\alpha)(A)$, receptor de estrógeno $\beta$ $(E R-\beta)(B)$ e do receptor de andrógeno (C), avaliada em aortas isoladas de ratas SHR com a técnica de RT-PCR em tempo real. Valores normalizados pela expressão do RNAm de $\beta$-actina. C - representa o grupo SHR controle; OVX ovariectomizadas; CEE - tratadas com Conjugado Estrogênio Equino; CEE+T tratadas com Conjugado Estrogênio Equino associado à testosterona. $\mathrm{O}$ número de animais utilizados por grupo encontra-se dentro das barras. Os valores foram expressos como média \pm epm. Foi utilizado o teste ANOVA de uma via para análise ${ }^{*} p<0,05$ vs $C$. \# $p<0,05$ vs OVX.

Fonte: Costa, 2012 


\section{DISCUSSÃO}

Os dados do presente trabalho demonstraram que a ovariectomia apesar de não alterar a pressão arterial agrava a disfunção endotelial em ratas SHR. O tratamento das SHR-OVX com CEE promove melhora da função endotelial por mecanismos que envolvem a redução do estresse oxidativo e aumento no mecanismo antioxidante celular, sem alterar a pressão arterial. O tratamento com $\mathrm{CEE}+\mathrm{T}$ aumentou a pressão arterial e inibiu os efeitos vasculoprotetores do CEE sobre o endotélio, promovendo o aumento na geração de EROs e alteração nas respostas vasculares endotélio-dependentes. Além disso, diminuiu a expressão da eNOS, contribuindo ainda mais para o agravamento da disfunção endotelial. Porém, diferente do observado nas fêmeas SHR-OVX, a geração de EROs neste grupo ocorreu independente do aumento na expressão de subunidades da NADPH oxidase, mas devido a participação do metabólito 20-HETE.

A remoção cirúrgica dos ovários, ovariectomia, em ratas é uma estratégia experimental bastante utilizada para simulação dos baixos níveis estrogênicos observados na pós-menopausa e após histerectomia de mulheres jovens (Waynfoth, 1980). A eficácia da ovariectomia nas fêmeas SHR foi demonstrada pela redução acentuada dos níveis plasmáticos de $17 \beta$-estradiol, estrona e progesterona e do peso uterino. Observamos também que a ovariectomia aumentou o peso corpóreo das SHR, que pode ser considerado como um parâmetro indireto da redução dos níveis estrogênicos (Heine et al., 2000). Esses resultados, tanto dos níveis hormonais e peso uterino quanto do peso corpóreo das SHR, estão em concordância com o que vem sendo demonstrado por nosso grupo (Dantas et al., 1999; Tostes et al., 2000) e também por outros autores (Wayntorth,1980; Torres et al., 2008).

O CEE é uma terapia hormonal utilizada em larga escala no mundo, principalmente nos EUA, em mulheres na pós-menopausa e histerectomizadas, a fim de restabelecer os níveis estrogênicos e evitar os efeitos indesejáveis da redução desse hormônio (Fernandes et al., 2004). A dose de CEE utilizada para o tratamento das SHR-OVX, neste trabalho, restaurou os níveis plasmáticos de estrona e aumentou os de $17 \beta$-estradiol para valores suprafisiológicos, entretanto não alterou os níveis de progesterona e testosterona, que permaneceram semelhantes aos das 
SHR-OVX. É importante ressaltar que a dose utilizada para o tratamento das SHROVX foi equivalente à dose para tratamento hormonal em humanos $(0,625 \mathrm{mg} / \mathrm{dia})$, sendo que as mulheres que fazem esse tipo de terapia hormonal também apresentam níveis plasmáticos de $17 \beta$-estradiol suprafisiológicos (Sarrel et al., 1998). Portanto, há similaridade entre os estudos clínicos e o nosso trabalho experimental. O mesmo pode ser descrito para as SHR-OVX que receberam testosterona associada ao CEE, que, além de níveis suprafisiológicos de 17ß-estradiol, apresentaram aumento suprafisiológico de testosterona plasmática, o que também vem sendo demonstrado em estudos clínicos (Shifren et al., 2000). Dessa forma, podemos sugerir que ambos os tratamentos foram eficazes em simular os níveis plasmáticos hormonais observados em mulheres na pós-menopausa que recebem terapia hormonal estrogênica associada ou não à testosterona.

A queda dos níveis estrogênicos ocasiona a perda da função uterina e, com isso, há queda drástica do peso desse órgão (Utian et al., 1987). De fato, a ovariectomia reduziu o peso uterino seco e úmido nas SHR e o tratamento com CEE restaurou esse parâmetro. Foi demonstrado por Utian et al. (1987) e Gruber et al. (2002) que a ação estrogênica via ER-a, presente no útero, promove aumento do fluxo sanguíneo local, da absorção de água e proliferação celular, tornando o endométrio mais espesso. Adicionalmente, nossos resultados concordam com trabalhos anteriores que demonstram que o tratamento com $17 \beta$-estradiol subcutâneo (Dantas et al.,1999; Dantas et al., 2004) ou estrona (Washburn et al., 2003) corrige o peso uterino de ratas ovariectomizadas, porém essa correção não é observada quando as ratas são tratadas apenas com 17a-Dihidroequilenin (Washburn et al., 2003).

A testosterona quando associada ao CEE corrigiu apenas o peso seco do útero. A testosterona per se pode promover hiperplasia no útero de ratas adultas (Laqueur, Fluhmann, 1942) e a associação de estrógeno e testosterona pode causar metaplasia endometrial em ratas não castradas (Shifren et al., 2000). Porém, não há relatos dos efeitos uterinos dessa associação em ratas SHR-OVX. Observamos em outra série de experimentos do nosso grupo que o tratamento de ratas SHR-OVX com apenas testosterona não restaura o peso uterino seco e úmido (dados não 
publicados). Portanto, ainda não é possível descartar que a testosterona possa estar interferindo diretamente sobre os efeitos dos estrogênios neste parâmetro.

O estrógeno é um importante modulador da deposição de adipócitos abdominais em mulheres e em ratas (Wade et al., 1985; Cooke et al., 2001), principalmente via ERa. O ERa pode modular a lipogênese no tecido adiposo, diminuindo a atividade da lípase, uma lipoproteína que regula a captação de lipídeos pelos adipócitos, reduzindo o acúmulo de gordura (Gentry et al., 1976; Heine et al., 2000; Torrezan et al.,2008). Por isso, a redução estrogênica no organismo pode ocasionar aumento do número e tamanho dos adipócitos (Gentry et al., 1976), ocasionando aumento no peso corpóreo. O aumento do peso das SHR-OVX parece estar relacionado com o aumento de gordura retroperitonial e no peso dos músculos, induzido pelo decréscimo dos níveis estrogênicos.

O tratamento com CEE reduziu o delta de peso das SHR-OVX, sugerindo a importante participação dos estrógenos no ganho de peso ao longo do tratamento. Complementar a esses achados, sugerimos que o tempo de tratamento é um importante parâmetro a ser considerado, uma vez que verificamos em nosso laboratório que o tratamento por 30 dias com CEE foi eficaz em corrigir o peso das fêmeas SHR-OVX para níveis semelhantes aos das SHR controle em estrofisiológico (dados não publicados) e no presente trabalho as ratas foram tratadas por 15 dias. Em estudos clínicos Chumlea et al., (1981) e Ley et al., (1992) demonstraram que mulheres na idade reprodutiva apresentam menor deposição de gordura abdominal quando comparadas com mulheres na pós-menopausa, sendo esse aumento de gordura abdominal um fator que contribui para o desenvolvimento de resistência à insulina, diabetes tipo II e síndrome metabólica na pós-menopausa (Wade et al., 1985).

O tratamento com estrógeno associado à testosterona em SHR-OVX, por 15 dias, não alterou o efeito do CEE sobre o peso corpóreo e delta de peso, apesar de aumentar a deposição de gordura retroperitonial e o peso muscular dessas fêmeas. Estes resultados estão em concordância com aqueles demonstrados por Reckelhoff et al. (2004) onde ratas SHR tratadas apenas com testosterona apresentam aumento na deposição de gordura retroperitonial levando ao aumento no peso corpóreo 
desses animais. Além disso, mulheres com síndrome do ovário policístico, síndrome essa relacionada com hiperandrogenismo, apresentam obesidade e acúmulo de gordura (Diament-Kabdarikis, 2006) o que contribui para um futuro quadro de resistência à insulina (Diament-Kabdarikis, 2008). Dessa forma podemos sugerir que o tratamento com $\mathrm{CEE}+\mathrm{T}$ não exerceu nenhum efeito adicional sobre o peso corpóreo das ratas, apesar de aumentar a gordura retroperitonial e massa muscular.

Avaliamos também os efeitos da ovariectomia e dos tratamentos hormonais na pressão arterial. Está bem estabelecido que mulheres na idade fértil apresentam menor risco de desenvolvimento de hipertensão e doenças cardiovasculares quando comparadas com homens da mesma idade e mulheres na pós-menopausa. Esse fato também é observado em diferentes modelos animais, sugerindo então que os hormônios sexuais femininos podem exercer efeito protetor no sistema cardiovascular e na regulação dos níveis pressóricos (Maas et al., 2009).

Apesar dessas evidências, o papel efetivo dos estrogênios no controle da pressão arterial ainda é assunto controverso. Em nosso trabalho a ovariectomia não agravou a pressão arterial das fêmeas SHR. Outros autores já haviam descritos que a ovariectomia não altera a pressão arterial em ratas Wistar (Goldstein, 1988; PérezTorres et al., 2008), Sprague-Dawley (Yung et al., 2011) e SHR (Reckelhoff et al 1998). Por outro lado, Dantas et al. (1999) demonstraram que a ovariectomia aumenta os níveis pressóricos de SHR, provavelmente por alterar a resposta vascular (aumento na resistência vascular) em microvasos (arteríolas), o que pode ser decorrente da queda dos níveis estrogênicos. Complementar a esse achado, foi observado por Reckelhoff et al. (1998) que ratas SHR velhas (na "pós-menopausa"; com 16 meses de idade) apresentam aumento nos níveis pressóricos. Esses trabalhos nos sugerem que a queda nos níveis plasmáticos de estrógeno pode ocasionar o aumento da pressão arterial.

É importante salientar que o estudo clínico denominado NHANESIII observou que o aumento da pressão arterial em mulheres na pós-menopausa (negras e brancas não-hispânicas e mexicanas) ocorre entre 5 e 20 anos após a menopausa. Isso é importante e sugere que a queda dos níveis estrogênicos iniciada no climatério não é o fator determinante para o aumento na pressão arterial no início da 
pós-menopausa (Burnl et al., 1995; Calhoum et al., 1998; August et al., 1999). Portanto, o tempo permanente de ovariectomia pode ser decisivo para o aumento da pressão arterial.

O tratamento com o CEE não exerceu nenhum efeito sobre a pressão arterial das fêmeas SHR-OVX. Esses resultados são semelhantes aos observados em estudos clínicos em mulheres que utilizam CEE oral (Harvey et al., 2000; Kornhauser et al., 1997). Em contraposição, outros autores demonstraram aumento na pressão arterial de mulheres que utilizaram CEE associado à progesterona (Crane et al.,1978; Wren et al., 1981). Além disso, em modelos animais, o tratamento com CEE (Dubey et al., 2002) ou pellets subcutâneos de 17ß-estradiol (Seely et al.,1999; Dantas et al., 1999) reduzem a pressão arterial, o que pode estar correlacionado com a diminuição na resistência vascular em microvasos. Num estudo recente envolvendo mulheres Koreanas na pós-menopausa foi demonstrado que a terapia oral com CEE associado à progesterona aumentou a pressão arterial em normotensas e reduziu em hipertensas (Lee et al., 2011). Essas discrepâncias de resultados podem ocorrer devido aos diferentes tratamentos utilizados, via de administração do fármaco, tempo de tratamento, associação ou não com progesterona, dose utilizada, linhagem dos animais e etnia das mulheres.

O tratamento associando testosterona à CEE aumentou os níveis pressóricos sistólicos, diastólicos e da pressão arterial média das SHR-OVX. E, de fato, vem sendo descrito que a testosterona pode estar envolvida na regulação e manutenção da hipertensão arterial de SHR fêmeas e machos (Reckelhoff et al. 1998). Dessa forma, a remoção cirúrgica dos testículos e o tratamento com flutamida (antagonista do receptor de testosterona) em machos SHR reduz a pressão arterial e o tratamento de fêmeas SHR-OVX somente com testosterona causa elevação dos níveis pressóricos (Reckelhoff et al., 1998). Estes efeitos pressóricos da testosterona envolvem ações renais, no sistema nervoso central e nos vasos sanguíneos (Chen et al., 1992). Dentre as ações centrais destaca-se o efeito do hormônio em aumentar a atividade simpática, liberando noradrenalina e promovendo constrição em microvasos (Liu, Ely, 2011). Nos rins, os andrógenos podem elevar a reabsorção tubular de sódio pela ação em seus receptores localizados no túbulo proximal renal e 
aumentar a atividade do SRA intrarenal (Reckelhoff et al., 1998; Quan et al., 2004). De fato, em animais SHR machos há o aumento do RNAm de angiotensinogênio, ECA e na atividade da renina no túbulo proximal (Quigley et al., 2008) e a castração desses animais leva a diminuição do RNAm do angiotensinogênio que é restabelecido com a administração de testosterona (Ellison et al., 1989), confirmando a hipótese da testosterona como reguladora do SRA intrarenal.

Nos vasos, um destaque importante, é no papel do metabólito 20-HETE, um potente vasoconstritor. Em fêmeas com síndrome do ovário policístico foi observado aumento da pressão arterial associado a maior produção do 20-HETE, sugerindo então uma importante correlação entre andrógeno, 20-HETE e pressão arterial. Esse aumento vascular do 20-HETE na artéria renal, promove vasoconstrição, aumento da PA e hipertensão (Yanes, Reckelhoff et al., 2011), conforme observados em nosso modelo. Além disso, não podemos descartar também a ação deste metabólito em outros vasos sanguíneos, como microvasos e aorta.

Avaliamos também, em outra série de experimentos, o efeito da OVX e dos tratamentos hormonais sobre alguns parâmetros vasculares, importante para responder o nosso objetivo. Observamos que as aortas das SHR-OVX são hiperreativas à ANG II e hiporreativas à $A C h$, o que nos permite sugerir que a ovariectomia agrava a disfunção endotelial em SHR. A ovariectomia e consequentemente o decréscimo dos níveis plasmáticos de estrógenos pode alterar a liberação de fatores contráteis e relaxantes derivados do endotélio, favorecendo o desenvolvimento de disfunção endotelial em macro e microvasos de ratas normotensas Sprague Dawley (Yung et al., 2011) e o agravamento da disfunção endotelial em ratas hipertensas SHR (Dantas et al., 1999) e DOCA-sal (Tostes et al., 2000).

O agravamento da disfunção endotelial na ovariectomia ocorre provavelmente pelo aumento na geração de EROs, concomitantemente com o aumento da expressão do RNAm para as subunidades da NADHP oxidase (Dantas et al., 1999; Silva-Antonialli, et al.,2005; Yung et al., 2011), uma das principais fontes geradora de EROs no sistema cardiovascular 
O SRA é um dos principais sistemas envolvidos nas alterações vasculares. Está bem estabelecido que a ANGll está envolvida nas alterações funcionais/estruturais dos vasos sanguíneos, principalmente pela interação com 0 receptor do tipo AT1. Esse receptor atua sobre a NADPH oxidase, aumentando sua expressão e/ou atividade, ocasionando aumento na geração de EROs no sistema vascular que pode ter tanto efeito lesivo quanto sinalizador (Groot et al., 2004).

O aumento na expressão gênica/proteica do AT1R de ANGIl pode ser o fator que contribui para a disfunção endotelial e, de fato, Yung et al., 2011 demonstraram que a regulação positiva na expressão proteica de AT1R em aorta de ratas SD-OVX ocasiona aumento na geração de EROs neste tecido. Apesar de não termos encontrado alteração na expressão do RNAm de AT1R, o antagonismo desse receptor diminuiu a geração de EROs e aumentou a vasodilatação à ACh nas aortas das SHR-OVX. Em concordância, Dantas et al. (2003) demonstraram que o antagonismo do AT1R reduz a geração de EROs em microvasos de ratas SHR-OVX, independente de sua expressão, levando a melhora nos parâmetros vasculares como resposta à ANGII e ACh. Dessa forma, sugerimos que a ovariectomia agrava a disfunção endotelial pré- existente em fêmeas SHR.

$O$ tratamento com CEE corrigiu as alterações funcionais nas aortas das SHR-OVX, demonstrando que este fármaco exerce papel benéfico no sistema vascular. Diversos são os mecanismos descritos para explicar o papel modulador do estrógeno endógeno sobre a resposta das células do músculo liso e/ou endotélio vascular. O estrógeno endógeno é um importante modulador da função endotelial, principalmente por aumentar a produção de NO (Rosselli et al.,1994). Rosselli et al. 1994, demonstraram que a produção de NO vascular ocorre nos diversos ciclos menstruais, porém na fase folicular, fase associada a alta concentração de estrógeno, há aumento na produção de NO.

Dentro os estrogênios, o $17 \beta$-estradiol é apontado como o principal que atua no sistema vascular, promovendo efeitos favoráveis no perfil lipídico, como redução dos níveis de LDL, por sua atividade antioxidante, diminuindo a produção de EROs, e por sua ação na via do NO, que além de atuar no tônus vascular contribui inibindo a agregação plaquetária, a agregação de monócitos, de moléculas de adesão e a 
migração e proliferação celular, que são fatores importantes para inibir a formação de trombose e placas de ateroma (Leman et al., 2005). No músculo liso vascular, alguns autores propõem que o $17 \beta$-estradiol atua antagonizando os canais de cálcio sensíveis a voltagem do tipo $L$ e/ou por ativar os canais de potássio (Crews et al.; 1999). O bloqueio dos canais de cálcio inibe a entrada de cálcio para o meio intracelular e consequentemente a despolarização que origina a constrição (Jiang et al., 1991; Han et al. 1994). A ativação dos canais de potássio envolve o efluxo de potássio da célula, promovendo uma hiperpolarização e vasodilatação. Porém, é importante ressaltar que foi observado por Pinto et al. (1997) que tratamento com $17 \beta$-estradiol altera a resposta vascular ao vasodilatador dependente do endotélio, ACh, mas não ao independente, no caso o NPS. Resultado semelhante a esse foi por nós demonstrado, utilizando o tratamento com CEE. Portanto, podemos sugerir que os efeitos do CEE ocorrem por meio de modulação da função endotelial.

A modulação da função endotelial pelo $17 \beta$-estradiol envolve, principalmente, o sistema oxidante celular. Este hormônio pode atuar sobre a NADPH, regulando negativamente a expressão das suas subunidades e, assim, diminuindo a geração de EROs (Dantas et al., 2004). Com a menor geração de EROs, o NO torna-se mais biodisponível e, além disso, o 17ß-estradiol ainda aumenta a produção de NO, via modulação da eNOS (Nelson et al.; 2000).

Outra importante atuação do $17 \beta$-estradiol é sobre o mecanismo antioxidante celular, aumentando a expressão proteica e do RNAm da SOD e da CAT, diminuindo a geração de EROs. Para exercer esses efeitos, o 17 $\beta$-estradiol interage principalmente com o $\mathrm{ER \alpha}$, importante receptor mediador das ações benéficas hormonais no sistema vascular (Khalil et al., 2009). De fato, foi observado por outros autores que $\mathrm{o}$ tratamento apenas com $17 \alpha$-estradiol não exerce nenhum efeito modulador na via do NO, indicando, portanto, que o $17 \beta$-estradiol é importante nesta modulação (Khalil et al., 2009).

Há um grande número de estudos na literatura que demonstram os efeitos benéficos do $17 \beta$-estradiol endógeno e utilizado como terapia hormonal no sistema cardiovascular de mulheres e modelos animais. Entretanto, os efeitos do CEE, utilizado em nosso estudo, são escassos, mas também são alvo de estudos e suas 
ações benéficas vêm sendo descritas. Foi observado por Wingrove et al. (1999) que - CEE aumenta a produção de NO em coronárias de humanos, modulando positivamente a enzima eNOS. Essa semelhança entre os efeitos do $17 \beta$-estradiol e do CEE podem ocorrer devido a presença do $17 \beta$-estradiol no conjugado equino ( $0,68 \%$ da formulação) e pelo fato de alguns componentes, como a estrona ( $48 \%$ da composição do CEE) serem convertidos em $17 \beta$-estradiol. Entretanto, não é possível descartar que os demais componentes do conjugado atuem sobre a produção de NO. Vem sendo sugerido que a estrona, pode ter efeito protetor no sistema vascular por atividade antiproliferativa (Kikuchi et al., 2000) e por aumentar a produção de NO, apesar deste efeito ser menos pronunciado em comparação com o $17 \beta$-estradiol (Novensa et al., 2010).

Além disso, os conjugados da família do equilin também atuam no sistema vascular. Esses componentes possuem grande afinidade pelo $\operatorname{ER} \beta$, sendo que esse receptor é apontado como outra importante fonte geradora de NO nas células endoteliais (Novensa et al., 2010), contribuindo, então, para a melhora da função endotelial. Esses dados devem ser objeto de investigações mais profundas, uma vez que alguns autores demonstraram que os efeitos vasculares promovidos pelo CEE não são tão potentes quanto aos promovidos pelo 17ß-estradiol (Okano, 2006). Isso pode ocorrer, pois os componentes do CEE como a estrona e o equilin podem competir com o 17ß-estradiol em ERs o que dificultaria a ação deste em produzir NO (Novensa et al., 2010). Dessa forma, podemos sugerir que os efeitos vasculares observados no tratamento com CEE possam estar relacionados aos níveis suprafisiológicos do $17 \beta$-estradiol, entretanto, não é possível descartar a participação dos demais componentes deste conjugado e da competição entre eles.

O CEE pode atuar ainda, no sistema vascular, regulando positivamente a expressão de enzimas antioxidantes como a SOD e a CAT, fato importante para a diminuição da geração de EROs (Rao et al., 2011). De fato, nós observamos que o tratamento com CEE foi capaz de aumentar a expressão protéica da SOD e CAT nas aortas das fêmeas SHR-OVX. Esse é uma importante e pioneira descrição da ação do CEE na melhora dos parâmetros vasculares e na função endotelial. 
A modulação simpática também pode sofrer influência do estrógeno. Dantas et al., 1999 demonstraram que o tratamento de fêmeas SHR-OVX com 17ß-estradiol corrige a hiperreatvidade à NOR para níveis observados em ratas SHR em estrofisiológico. O estrógeno parece reduzir a resposta adrenérgica pela diminuição de receptores a-adrenérgicos (Roberts et al., 1979; Mishra et al., 1985). Gisclard et al. (1986) observaram em coelhas ovariectomizadas que o tratamento com $17 \beta$-estradiol reduz a vasodilatação induzida pela ativação de receptores $\alpha$-adrenérgicos.

Nosso grupo, em dados recentemente submetidos à publicação, demonstrou que a correção da resposta à NOR pelo tratamento com CEE ocorreu pela menor geração de EROs, uma vez que o tratamento com apocinina em aortas de SHROVX, corrigiu a resposta vasoconstritora à NOR. Portanto, nossa sugestão é que a correção na resposta tanto à NOR quanto a FE se dá pela modulação endotelial, com diminuição na EROs e maior biodisponibilidade do NO.

Portanto, podemos sugerir que o CEE melhora a função vascular, principalmente por ação antioxidante celular. Esses hormônios conjugados reduzem a geração EROs, pela regulação negativa do RNAm das subunidades da NADPH oxidase e por regular positivamente a expressão proteica de enzimas antioxidantes, como a SOD e a CAT. Em conjunto essa menor oxidação celular corrige as respostas vasculares à vasconstritores e vasodilatadores observadas na ovariectomia.

A associação de testosterona ao tratamento com CEE inibiu os efeitos vasculoprotetores promovidos pelo CEE. Os andrógenos podem promover aumento na resposta vasoconstritora à ANGIl em artérias renais de fêmeas SHR (Reckelhoff et al.,1998) e New Zealand Genetically Hypertensive Rats (Song et al.,2006). Esse aumento na resposta vasoconstritora à ANGIl está associado à regulação positiva na expressão do RNAm do AT1R e consequente aumento na geração de EROs nesses vasos (Reckelhoff et al.,1998; Song et al.,2006) e também por amplificação da sinalização RhoA/Rho quinase (Song et al., 2006). A testosterona pode também causar aumento na geração de EROs na medula renal (Makino et al., 2002) e em células do músculo liso vascular de ratos SHR e Wistar (Chinaglia, 2009), contribuindo para alterações no tônus vascular. Esse aumento na geração de EROs 
ocorre via $N A D(P) H$ oxidase, pela regulação positiva do RNAm das subunidades gp91 ${ }^{\text {phox }}$, p22 ${ }^{\text {phox }}$ e p47 ${ }^{\text {phox }}$ (lliesco et al., 2006), hipótese que descartamos, pois não observamos alteração na expressão do RNAm das subunidades.

A forma pela qual a testosterona modula a disfunção endotelial ainda não foi elucidada. Alteração no SRA pode ser uma das causas para a disfunção endotelial. $O$ aumento na expressão proteica ou do RNAm do AT1R pode contribuir fortemente para a disfunção endotelial, uma vez que a interação entre ANGIl e AT1R leva a geração de EROs nos vasos sanguíneos (Song et al.; 2006); porém pouco se sabe da relação entre a testosterona e a expressão do RNAm e proteica do AT1R vascular. Embora em ratas SHR-OVX e Dahl sal-sensível-OVX tenha sido observado aumento do RNAm do AT1R nos rins e que o tratamento com estrógeno diminuiu essa expressão (Hinojosa et al., 2004; Silva-Antonialli et al., 2004), em nossos modelos experimentais não houve alteração na expressão de RNAm do AT1R e AT2R de ANGII. Ressalto que o antagonismo do AT1R melhorou a vasodilatação endotélio-dependente à ACh e diminuiu a geração de EROs nos anéis de aorta do grupo CEE+T. Sugerimos então, que o SRA por meio do AT1R possui importante atividade, independente do aumento da expressão, nesse tratamento hormonal de associação, podendo ser o ponto inicial de uma cascata de sinalização.

Tem sido discutido que a testosterona pode modular a atividade da PKC e Rho-Kinase. Foi observado que em ratas o estrógeno pode suprimir a atividade e a expressão da PKC e Rho-Kinase (Chrissobolis et al., 2004) e os andrógenos podem potencializar a resposta vascular à ANGIl por aumentarem a atividade da RhoKinase (SONG et al.; 2006). Entretanto não observamos nenhuma diferença na resposta vascular à ANGIl na presença do inibidor da Rho-Kinase (fasudil), descartando, assim, mais uma hipótese para explicar o efeito da testosterona na associação com CEE (dados não mostrados).

Outro mecanismo avaliado foi a participação da enzima do metabólito 20HETE na geração de EROs e agravamento da disfunção endotelial. Observamos que inibição do 20-HETE reduz a geração de EROs nas aortas das fêmeas do grupo tratado $\mathrm{CEE}+\mathrm{T}$ e, além disso, observamos redução na expressão proteica da eNOS. 
O 20-HETE é um potente vasoconstritor e regulador da pressão arterial, por ação vascular e renal (Marji et al., 2002; Yanes et al., 2011, Ward et a., 2011). Em modelos experimentais de hipertensão genética e diabetes a produção do 20-HETE apresenta-se aumentada, assim como em ratas velhas ou na síndrome do ovário policístico (Reckelhoff et al., 2011). Vem sendo sugerido que o aumento na produção do 20-HETE se dá por ação androgênica (Roman, 2002; Yanes et al., 2011). De fato, já foi observado que a hipertensão arterial em ratas velhas ocorre devido ao aumento dos níveis androgênicos e, neste modelo, a inibição do 20-HETE foi capaz de reduzir os níveis pressóricos (Yanes et al., 2011). Nós demonstramos pela primeira vez que a testosterona quando associada a CEE aumenta a geração de EROs via 20-HETE.

Portanto, o conjunto de dados deste trabalho nos permite concluir que 0 tratamento com CEE tem efeito protetor em aortas, promovendo a melhora da função endotelial, em fêmeas SHR-OVX. Isso foi caracterizado tanto pela redução do estresse oxidativo celular quanto pela regulação positiva das enzimas antioxidantes. Entretanto, a testosterona associada a CEE aboliu os efeitos vasculoprotetores promovidos pelo CEE, principalmente por aumentar o estresse oxidativo celular e, além disso, diminuir a expressão proteica da eNOS, contribuindo ainda mais para o agravamento da disfunção endotelial. O aumento na geração de EROs ocorreu devido a participação do metabolito 20-HETE. 


\section{CONCLUSÃO}

Nossos dados permitem concluir que o tratamento de fêmeas SHR-OVX com CEE promove melhora da função endotelial por mecanismos que envolvem a redução do estresse oxidativo e aumento no mecanismo antioxidante celular. A testosterona quando associada ao CEE aumentou a geração e diminui a expressão da eNOS, contribuindo para a disfunção endotelial. Porém, diferente do observado nas fêmeas SHR-OVX, a geração de EROs neste grupo ocorreu independente do aumento na expressão da subunidades da NADPH oxidase, mas devido a participação do metabólito 20-HETE. Portanto, a associação de CEE e testosterona abole os efeitos vasculoprotetores do CEE, agravando a disfunção endotelial de fêmeas SHR-OVX

\section{PERSPECTIVA}

A associação de testosterona no tratamento com CEE deve ser realizada com cautela visto que, em modelo animal de hipertensão, este tratamento inibiu os efeitos vascular benéficos do CEE. 


\section{RERERÊNCIAS ${ }^{1}$}

Akishita M, Kozaki K, Eto M, Yoshizumi M, Ishikawa M, Toba K, et al. Estrogen attenuates endothelin-1 production by bovine endothelial cells via estrogen receptor. Biochem Biophys Res Commun. 1988; 251(1):17-21.

Alhenc-Gelas F, Tache A, Saint-Andre JP, Milliez J, Sureau C, Corvol P, Menard J. The renin-angiotensin system in pregnancy and parturition. Adv Nephrol Necker Hosp. 1986;15:25-33.

August P, Oparil S. Commentary: hypertension in women. J Clin Endocrinol Metab. 1999;84:1862-6.

Basson R. Pharmacotherapy for women's sexual dysfunction. Expert Opin Pharmacother. 2009; 10:1631-48.

Bhavnani BR, Cecutti A, Gerulath A, Woolever AC, Berco M. Comparasion of the antioxidant effects os equine estrogen, red win components, vitamin $\mathrm{E}$, and probucol on low-density lipropotein oxidation in postmenopausal women. Menopause. 2001;8(6): 408-19

Brzezinski A, Danenberg HD. Estrogen, progesterone, and cardiovascular health: when shall we complete thpuzzle? Menopause. 2005;12(5):488-91.

Borreli CL, Almeida PG. Doenças cardiovasculares e as terapias de reposição hormonal. Hipertensão. 2005; 8(3):1-5.

Burger HG. Androgen production in women. Fertil Steril. 2002; 77(4):S3-S5.

Burl VL, Whelton P, Roccella EJ, Brown C, Cutler JA, Higgins M, Horan MJ, Labarthe, D. Prevalence of hypertension in the US adult population: results from the Thrid National Health and Nutricion Examination Survey, 1988-1991. Hypertension. 1995; 25:305-13.

Broshihan KB, Senanayake PS, Li P, Ferrario CM. Bi-directional actions of estrogen on the rennin-angiotensin system. J Hypertens. 2004; 22(Suppl 1):111S.

Buster JE, Kingsberg SA, Aguirre O, Brown C, Breaux JG, Buch A, Rodenberg $\mathrm{CA}$, Wekselman K, Casson $\mathrm{P}$, et al. Testosterone patch for low sexual desire in surgically menopausal women: a randomized trial. Obstet Gynecol. 2005;105:944-52.

1 De acordo com: International Commitee of Medical Journal Editors. Uniform requirements for manuscripts submited to Biomedical Journal: sample references. Available from: http://www.icmje.org [2007 May 22]. 
Brown NJ, Vaughan DE. The Renin-Angiotensin and fibrinolytic systems coconspirators in the pathogenesis of ischemic cardiovascular disease. Trends Cardiovasc Med. 1996; 6(7):239-43.

Cai $\mathrm{H}$, Griendling KK, Harrison DG. The vascular $\mathrm{NAD}(\mathrm{P}) \mathrm{H}$ oxidases as therapeutic targets in cardiovascular diseases. Trends Pharmacol Sci. 2003;24:471-8.

Calhoum DA, Oparil, S. The sexual dimorphism of high blood pressure. Cardiol Rev. 1988; 6:356-63.

Carvalho MHC, Scivoletto R, Fortes ZB, et al. Reactivity of aorta and mesenteric microvessels to drugs in spontaneously hypertensive rats: role of the endothelium. $J$ Hypertens. 1987; 5(3):377-82.

Chen YF, Meng QM. Sexual dimorphism of blood pressure in spontaneously hypertensive rats is androgen dependent. Life Sci. 1991;48:85-96.

Chen YF, Naftilan AJ, Oparil S. Androgen dependent angiotensinogen and rennin messenger RNA expression in hypertensive rats. Hypertension.1992;19:456-63.

Chignalia AZ. Testosterona induz migração de células da musculatura lisa vascular de ratos espontaneamente hipertensos por mecanismos dependentes de EROs e ativação da NADPH oxidase via c- Src. [tese (Doutorado em Farmacologia)]. São Paulo: Instituto de Ciências Biomédicas da Universidade de São Paulo; 2009.

Christian RC, Harrington S, Edwards WD, et al. Estrogen status correlates with the calcium content of coronary atherosclerotic plaques in women. J Clin Endocrinol Metab. 2002;87:1062-7.

Chrissbois S, Budzyn, K. Marley, PD, Sobey CG. Evidence that estrogen suppresses rho-kinase function in the cerebral circulation in vivo. Stroke. 2004;35:2200-5.

Chumlea WC, Roche AF, Siervogel RM, Knittle JL, Webb P. Adipocytes and adiposity in adults. Am J Clin Nutr.1981;34(9):1798-803.

Clarkson TB, Appt SE. Controversies about HRT-lessons from monkey models. Maturitas. 2005; 51(1):64-74.

Colburn P, Buonassisi V, Estrogen binding sites in endothelial cell cultures. Science. 1978;201:817-9.

Crane MG, Harris JJ, Winsor W 3rd. Hypertension and oral contraceptives. Br Med J. $1978 ; 21 ; 2(6145): 1165$. 
Crews JK, Khalili, RA. Gender-especific of $\mathrm{Ca} 2+$ entry mechanisms of arterial vasoconstriction by sex hormones. Clin Exp Pharmacol Physiol.1999;26(9):707-15.

Croft KD, McGiff JC, Sanchez-Mendoza A, Carroll MA. Angiotensin II releases 20HETE from rat renal microvessels. Am J Physiol Renal Physiol. 2000; 279:F544-F51.

Dantas APV, Tostes RC, Fortes ZB, Carvalho MHC, et al. In vivo evidence for antioxidant potential of estrogen in microvessels of female spontaneously hypertensive rats. Hypertension. 2002; 39:405-11.

Dantas APV, Franco MCP, Silva-Antonialli MM, Tostes RC, Fortes ZB, Nigro D, Carvalho MHC et al. Gender differences in superoxide generation in microvessels of hypertensive rats: role of $\mathrm{NAD}(\mathrm{P}) \mathrm{H}$-oxidase. Cardiovasc Res. 2004; 61(1):22-9.

Dantas APV, Scivoletto R, Fortes ZB, Nigro D, Carvalho MHCC. Influence of female sex hormones on endotheliumderived vasoconstrictor prostanoid generation in microvessels of spontaneously hypertensive rats. Hypertension.1999;34:914-9.

Diczfalusy E. [In search of human dignity: gender equality, reproductive medicine and aging in good health]. Contracept Fertil Sex.1997;25(12):885-93.

Dubey RK, Jackwson E, Keller P, Imthurm B, Rosselli M. Estradiol metabolites inhibit endothelin synthesis bya an estrogen receptor-independent mechanism. Hypertension. 2001;37:640-4.

Dubey RK, Oparil S, Imthurn B, Jackson EK. Sex hormones and hypertension . Cardiovasc Res. 2002;53(3):688-708.

El-Alfy M, Luu-The V, Huang XF, Berger L, Labrie F, Pelletier G. Localization of type 5 17beta-hydroxysteroid dehydrogenase, 3beta-hydroxysteroid dehydrogenase, and androgen receptor in the human prostate by in situ hybridization and immunocytochemistry. Endocrinology. 1999; 140(3):1481-91.

Farhat, MY, Abi-Younes S, Ramwell PW. Non-genomic effects of estrogen and the vessel wall. Biochem Pharmacol. 1996; 51(5):571-6.

Fernandes CE, Ferreira JAS, Melo NR, Peixoto S. Terapêutica hormonal no climatério feminino: onde estamos e para onde vamos? São Paulo: Editora Segmento;2009.160p.

Fernandes CE, Pinho-Neto JSL, Gebara OCV, et al. I Diretriz Brasileira sobre Prevenção de Doenças Cardiovasculares em Mulheres Climatéricas e a Influência da Terapia de Reposição Hormonal (TRH) da Sociedade Brasileira de Cardiologia (SBC) e da Associação Brasileira do Climatério (SOBRAC). Arq Brás Cardiol, 2008. 91(1 supl.1):1-23 
Fernandes DC, Wosniak J, Pescatore LA, Bertoline MA, Liberman M, Laurindo FRM, Santos CX. Analysis of dihydroethdium-derived oxidation products by HPLC in the assessment of superoxide production and NADPH oxidase activity in vascular systems. Am J Physiol Cell Physiol. 2007;292:C413-C22.

Ferrario CM. Role of angiotensin II in cardiovascular disease therapeutic implications of more than a century of research. J. Renin Angiotensin Aldosterone Syst. 2006; 7(1):3-14.

Fisher $M$, Baessler A, Schunkert $H$. Renin angiotensina system and gender differences in the cardiovascular system. Cardiovasc Res.2002;53:672-7.

Grady D, Herrington D, Bittner V, et al. Cardiovascular disease outcomes during 6.8 years of hormone therapy: Heart and Estrogen/progestin Replacement Study followup (HERS II). JAMA. 2002;288(1):49-57.

Greene JG. Constructing a standard climacteric scale. Maturitas.1998;29(1):25-31.

Gentry RT, Wade GN. Sex differences in sensitivity of food intake, body weight, and running-wheel activity to ovarian steroids in rats. J Comp Physiol Psychol. 1976; 90(8):747-54.

Goldstein RS, Tarloff, JB, Hook, JB. Age-related nephropathy in laboratory rats. FASEB J. 1998; 2:2241-51.

Groot AA, Zwieten PA, Peter SLM. Involvement of Reactive Oxyen Species in Angiotensin II-induced vasconstriction. J Cardiovasc Pharmacol. 2004; 43 (1):154-9.

Hames SR, Levin ER. Extranuclear steroid receptors: nature and actions. Endocr. Rev. 2007; 28(7):726-41.

Hanke $\mathrm{H}$, Kamenz $\mathrm{J}$, Hanke S, et al. Effect of 17-beta estradiol on pre-existing atherosclerotic lesions: role of the endothelium. Atherosclerosis. 1999; 147(1): 12332.

Harrap SB. Public health, cardiovascular disease and molecular biology. Kidney Int. 1994; 46(6):1546-9.

Harvey PJ, Molloy D, Upton J, Wing LM. Dose response effect of conjugated equine oestrogen on blood pressure in postmenopausal women with hypertension. Blood Press. 2000;9(5):275-82.

Heinlein CA, Chang, C. The roles of androgen receptors and androgen-binding proteins in nongenomic androgen actions. Mol. Endocrinol. 2002; 16(10):2181-2187. 
Heine PA, Taylor JA, Iwamoto GA, Lubahn DB, Cooke PS. Increased adipose tissue in male and female estrogen receptor- $\alpha$ knockout mice. Proc Natl Acad Sci U S A. 2000;97:12729-34.

Hinojosa L, Craig T, Zheng W, Ji H, Haywood JR, Sandberg K. Ovariectomy augments hypertension in aging female Dahl-salt-sensivite rats. Hypertension. 2004; 44:405-9.

Hishikawa K, Nakaki T, Marumo T, Suzuki H, Kato R, Saruta T. Up-regulation of nitric oxide synthase by estradiol in human aortic endothelial cells. FEBS Lett. 1995; 360:291-3.

Honda $\mathrm{H}$, Unemoto $\mathrm{T}$, Kogo $\mathrm{H}$.. Different mechanisms for testosterone-induced relaxation of aorta between normotensive and spontaneously hypertensive rats. Hypertension. 1999; 34:1232-6.

Hulley S, Grady D, Bush T, et al. Randomized trial of estrogen plus progestin for secondary prevention of coronary heart disease in postmenopausal women. Heart and Estrogen/progestin Replacement Study (HERS) Research Group. JAMA. 1998; 280(7): 605-13.

Irigoyen MC, Consolim-Colombo FM, Krieger Em. Controle cardiovascular: regulação reflexa e papel do sistema nervoso simpático. Ver Bras Hipertens. 2001; 8:55-62.

Jiang CW, Sarrel PM, Linday DC, Poole-Wilson PA, Collins P. Endotheliumindependent relaxation of rabbit coronary artery by 17 beta estradiol in vitro. $\mathrm{Br} \mathrm{J}$ Pharmacol. 1991;104:1033-37.

Jones R, Hugh JT, Channer KS. The influence of testosterone upon vascular reactivity. Eur J Endocrinol. 2004;151(1):29-37.

Judd HL, Judd, GE, Lucas WE, Yen SS Endocrine function of the postmenopausal ovary: concentracion of androgens and estrogens in ovarian and peripheral vein blood. J Clin Endocrinol Metab.1974;39(6):1020-4.

Jun SS, Chen Z, Pace MC, Shaul PW. Estrogen upregulates cyclooxygenase-1 gene expression in ovine fetal pulmonary artery endothelium. J Clin Invest.1998; 102(1):176-83.

Khalil RA, Smiley DA. Estrogenic compounds, estrogen receptors and vascular cell signaling in the aging blood vessels. Curr Med Chem.2009;16(15):1863-87.

Kearney PM, Whelton M, Reynolds K, Muntner P, Whelton PK, He J. Global burden of hypertension: analysis of worldwide data. Lancet. 2005;365(9455):217-23.

Keating NL, Clery PD, Rossi AS, et al. Use of hormone replacement therapy by postmenopausal women in the United States. Ann Inter Med.1999;130:545-53. 
Kornhauser C, Malacara JM, Garay ME, Pérez-Luque E.L. The effect of hormone replacement therapy on blood pressure and cardiovascular risk factors in menopausal women with moderate hypertension. J Hum Hypertens. 1997;11(7):405-11.

Kuiper GG, Carlosson B, Grandien, K, et al. Comparison of the ligand binding specificity and transcript tissue distribution of estrogen receptors ERa and ER $\beta$. Endocrinology.1997;138:863-70.

Krieger EM, Franchini KG, Krieger JE.Fisiopatogenia da hipertensão arterial. Medicina. 1996; (29):181-92.

Krieger EM, Irygoen MC, Krieger JE. Fisiopatologia da hipertensão. Ver Soc Cardiol Estado de São Paulo. 1999; (9):1-7

Krapf JM, Simon JA. The role of testosterone in the management of hypoactive sexual desire disorder in postmenopausal women. Maturitas. 2009; 20;63(3):213-9.

Lassegue $\mathrm{B}$, Clempus RE. Vascular $\mathrm{NAD}(\mathrm{P}) \mathrm{H}$ oxidase: specific features, expression and regulation. Am. J. Physiol. Regul. Intregr. Comp. Physiol. 2003; 285(2): R277R97.

Lassegue B, Griendling KK. NADPH oxidase: functions and pathologies in the vasculature. Aterioscler Thromb Vasc Biol. 2010;30:653-61.

Lee JH, Yang DH, Park HS, Cho Y, Jun JE, Park WH, Chun BY, Shin JY, Shin DH, Lee KS, Kim KB, Kim YJ, Chae SC. Incidence of hypertension in Korea: 5 year followup study. J Korean Med Sci. 2011;26(10):1286-392.

Levin ER. Etrongen- $\beta$ and the cardiovascular system. Endocrinol metab. 2002; 13(5):184-5.

Lerman A, Zeiher AM. Endothelial function: cardiac events. Circulation. 2005; 111(3):363-68.

Liu B, Ely D. Testosterone increases: sodium reabsorption, blood pressure, and renal pathology in female spontaneously hypertensive rats on a high sodium diet. Adv Pharmacol Sci. 2011; (2011):817835.

Limacher MC. Hormones and heart disease: what we thought, what we have learned, what we still need to know. Trans Am Clin Climatol. Assoc.2002;113:31- 40.

Lin AL, Schultz JJ, Brenner RM, Shain, SA. Sexual dimorphism characterizes baboon myocardial androgen receptors but not myocardial estrogen and progesterone receptors. J Steroid Biochem Mol Biol.1990; 37(1):85-95. 
Lindheim SR, Buchanan TA, Duffy, et al. Comparison of estimates of insulin sensitivity in preand postmenopausal women using the insulin tolerance test and frequently sampled intravenous glucose tolerance test. J Soc Gynecol Investig. 1994; $1: 150-4$.

Littleton-Kearney M, Hurn PD. Testosterona as a modulator of vascular behavior. Biol. Res. Nurs. 2004;5(4):276-285.

Marcondes FK, Bianchi FJ, Tanno AP. Determination of the estrous cycle phases of rats: some helpful considerations. Braz. J. Biol. 2002. 62(4): 609-14

Mass A, Franke HR. Women's health in menopause with a focus on hypertension. Neth J.2009; 2:68-72.

Marji JS, Wang MH, Laniado-Schwartzman M. Cytochrome P-450 4A isoform expression and 20-HETE synthesis in renal preglomerular arteries. Am J Physiol Renal Physiol. 2002; 283(1):F60-F7.

Meyer MR, Baretella O, Prossnitz ER, Barton M. Dilation of epicardial coronary arteries by the $\mathrm{G}$ protein-coupled estrogen receptor agonists G-1 and ICI 182,780. Pharmacology. 2010;86(1):58-64.

Meyer MR, Haas E, Prossnitz ER, Barton M. Non-genomic regulation of vascular cell function and growth by estrogen. Mol Cell Endocrinol. 2009; 24(1-2):9-16.

McGiff, JC, Quilley, J. 20-HETe and the kidney: resolution of old problems and new beginnings. Am J Physiol (Reg Integr Com Physiol). 1999; 227:R607-R23.

Novensa L, Selent J, Pastor M, Sandberg K, Heras M, Dantas AP. Equine estrogens impair nitric oxide production and endothelial nitric oxide synthase transcriptional in human endothelial cells compared with the natural 17b-estradil. Hypertension. 2010; 56:405-11.

Okano HMD, Jayachandran MP, Yoshikawa, AWD, Miller VMP. Differential effects of chronic treatment with estrogen receptor ligants on regulation of nitric oxide synthase in porcine aortic endothelial cells. J Cardiovasc Pharmacol. 2006; 47:621-28.

Orimo A, Inoue S, Ikegami A, et al. Vascular smooth cells are targets for estrogen. Biochem Byophis Res Commun. 1993;195:730-36.

Ouchi Y, Share L, Crofton JT, et al. Sex difference in the development of deoxycorticosterone-salt hypertension in the rat. Hypertension. 1987;9:172-7.

Pasqualini C, Leviel V.; Guibert B, Faucon-Biguet N.; Kerdelhui B. Inhibitory action of acute estradiol treatment on the activity and quantity of tyrosine hydroxylase in the median eminence of ovariectomized rats. J Neuroendocrinol.1991;3:575-80. 
Paech K, Webb P, Kuiper GG, Nilsson S, Gustafsson J, Kushner PJ, et al. Differential ligand activation of estrogen receptors ERalpha and ERbeta at AP1 sites. Science. 1997;277(5331):1508-10.

Park JW, Hoyal, CR, Benna J, Baior, BM. Kinase-dependent activation of the leukocyte NADPH Oxidase in a cell-free system. J Biol Chem.1997;272(17):1103543.

Pérez-Torres I, El Hafidi M, Infante O, Baños G. Effects of sex hormone levels on aortic vascular reactivity and variables associated with the metabolic syndrome in sucrose-fed female rats. Can J Physiol Pharmacol. 2008; 86(1-2): 25-35.

Pinto S, Virdis A, Ghiadoni L, et al. Endgenous estrogen and acetylcholine-induced asodilation in normotensive women. Hypertension. 1997; 29 (1,pt2):268-73.

Price MO, McPhail LC, Lambeth D, Han CH, Knaus UG, Dinauer MC. Creation of a genetic system for analysis of the phagocyte respiratory burst: high-level reconstitution of the NADPH oxidase in a nonhematopoietic system. Blood. 2002; 99(8): 2653-61.

Raisz LG, Wiita B, Artis A, Bowen A, et al. Comparison of the effects of estrogen alone and estrogen plus androgen on biochemical markers of bone formation and resorption in postmenopausal women. J Clin Endocrinol Metab. 1996; 81:37-43.

Ramos AM, Camargos AF, Pereira FE. Effects of simultaneous treatment with estrogen and testosterone on the uterus of female adult rats. Clin Exp Obstet Gynecol. 2007; 34:52-4.

Rao AK, Dietrich AK, Ziegle YS, Nardulli AM. 17ß-Estradiol-mediated increase in $\mathrm{Cu} / \mathrm{Zn}$ superoxide dismutase expression in the brain: $\mathrm{A}$ mechanism to protect neurons from. J Steroid Biochem Mol Biol. 2011; 127(3-5):382-9.

Reckelhoff, JF, Zhang H, Granger JP. Testosterone exacerbates hypertension and reduces pressure-natriuresis in male spontaneously hypertensive rats. Hypertension. 1998; 31:435-9.

Reckelhoff JF. Sex Steroids, Cardiovascular disease, and hypertension. Hypertension. 2004; 45:170-4.

Resta, TC, Kanagy NL, Walker BR. Estradiol-induced attenuation of pulmonary hypertension is not associated with altered eNOS expression. AM J Physiol Lung Cell Mol Physiol. 2001; 280:L88-L97. 
Revankar CM, Cimino DF, Sklar LA, Arterburn JB, Prossnitz ER. A transmembrane intracellular estrogen receptor mediates rapid cell signaling. Science. 2005;307(5715):1625-30.

Rigatto KV, Bohlke M, Irigoyen MC. Sistema renina-angiotensina: da fisiologia o tratamento. Rev Soc Cardiol Rio Grande do Sul. 2004;3:1-5.

Rosenfeld ME, Kauser K, Martin-McNullty B, et al. Estrogen inhibits the initiation of fatty streaks throughout the vasculature but does not inhibit intra-plaque hemorrhage and the progression of established lesions in apolipoprotein $\mathrm{E}$ deficient mice. Atherosclerosis. 2002; 164(2):251-9.

Roman RJ. P-450 metabolites of arachidonic acid in the control of cardiovascular function. Physiol Rev. 2002;82:131-85.

Rosselli M, Imthurm B, Macas E, Keller PJ, Dubey RK. Circulating nitrite/nitrate levels increase with follicular development: indirect evidence for estradiol mediated NO release. Biochem Biophys Res Commun. 1994; 202(3):1543-52.

Rossi R, Grimald T, Origliani G, Fantini G, Coppi F, Modena MG. Menopause and cardiovascular risk. Pathophysiol Haemost Thromn. 2002 (32):325-28.

Rossouw JE, Anderson GL, Prentice RL, LaCroix AZ, Kooperberg C, Stefanick ML, et al. Risks and benefits of estrogen plus progestin in healthy postmenopausal women: principal results From the Women's Health Initiative randomized controlled trial. JAMA. 2002;288(3):321-33

Rowland NE, Fregly MJ. Role of gonadal hormones in hypertension in the Dahl saltsensitive rat. Clin. Exp. Hypertens.1992;14:367-75.

Roman RJ. P-450 metabolites of arachidonic acid in the control cardiovascular function. Physiol Rev. 2002; 82:131-85.

Roger VL, Go AS, Lloyd-Jones DM, et al. Heart disease and stroke statistics - 2012 update: a report from the American Heart Association. Circulation. 2012;125:e2-e220

Rubanyi GM, Freay AD, Kauser K, Sukovich D, Burton G, Lubahn, DB, et al. estrogen receptors and endothelium-derived nitric oxide production in the mouse aorta. Gender difference and effect of estrogen receptor gene disruption. J Clin Invest. 1997; 99(10):2429-37 .

Sarrel P, Dobay B, Wiita B. Estrogen and estrogen-androgen replacement in postmenopausal women dissatisfied with estrogen-only therapy. Sexual behavior and neuroendocrine responses. J Reprod Med. 1998; 43(10): 847-56.

Seely EW. Hypertension in pregnancy: a potential window into long-term cardiovascular risk in women. J Clin Endocrinol Metab. 1999;84(6):1858-61. 
Sewer MB, Koop DR, Morgan ET. Endotoxemia in rats is associated with induction of the P4504A subfamily and suppression of severalother forms of cytochrome P450. Drug Metb Dispos 1996; 24:401-7.

Schmidt CW. Sexual and gender identity disorders. In: First MB, Ross R, (eds.) Diagnostic and statistical manual of mental disorders, 4.ed. Washington, DC: American Psychiatric Association; 1994. p.496-8.

Schmidt-Nielsen K. Fisiologia Animal. São Paulo: Editora Santos; 2007. 609p.

Shifren JL. Androgen deficiency in the oophorectomized woman. Fertil Steril. 2002;77 (Suppl 4):S60-S2.

Sinha-Hikim I.; Taylor, W. E.; Gonzalez-Cadavid, N.F.; Zheng, W.; Bhasin, S. Androgen receptor in human skeletal muscle and cultured muscle satellite cells: upregulation by androgen treatment. J Clin Endocrinol Metab. 2004; 89,(10):5245-55.

Simoncini T, Hafezi-moghadam A, Brasil DP, Ley K, Chin WW, Liao JK. Interaction ooestrogen receptor with the regulatory subunit of phosphatidylinositol-3-OH kinase. Nature. 2000; 407(6803):538-41.

Silva-antonialli MM, Fortes ZB, Carvalho MHC, Scivoletto R, Nigro D. et al. Sexual dimorphism in the response of thoracic aorta from SHRs to losartan. Gen Pharmacol. 2000; 34(5):329-35.

Sociedade Brasileira de Cardiologia / Sociedade Brasileira de Hipertensão / Sociedade Brasileira de Nefrologia. VI Diretrizes Brasileiras de Hipertensão. Arq Bras Cardiol 2010; 95(1 supl.1): 1-51

Schiffrin EL. Vascular and cardiac benefits of angiotensin receptor blockers. Am. J. Med. 2002; 113(5):409-418.

Smith CL, O'Malley BW Coregulator function: a key to understanding tissue specificity of selective receptor modulators. Endocr Rev. 2004; 25:45-71.

Stewart KG, Zhang Y, Davidge ST.Estrogen decreases prostaglandin H synthase products from endothelial cells. J Soc Gynecol Investig. 1999; 6(6):322-7.

Stewart KG, Zhang Y, Davidge ST. Estrogen decreases prostaglandin H synthase products from endothelial cells. J Soc Gynecol Investig. 1999;6(6):322-7.

Soules MR, Sherman S, Parrot E, Rebar R, Santoro N, Utian W, Woods N. Stages of reproductive aging workshop (STRAW). J Womens Health Gend. Baesd. Med. 2001; 10 (9): 843-8. 
Spyridopoulos I, Sullivan AB, Keanery M, Isner JM, Losordo DW. Estrogen-receptormediated inhibition of human endothelial cell apoptosis. Estradiol as a survival factor. Circulation. 1997; 95(6):1505-14.

Silva-Antonialli MM, Tostes RC, Fernandes L, Fior-Chadi DR, Akamine EH, Carvalho $\mathrm{MH}$, Fortes ZB, Nigro D. A lower ratio of AT1/AT2 receptors of angiotensin II is found in female than in male spontaneously hypertensive rats. Cardiovasc. Res. 62(3):58793, 2004.

Simon J, Braunstein G, Nachtigall L, et al. Testosterone Patch Increases Sexual Activity and Desire in Surgically Menopausal Women with Hypoactive Sexual Desire Disorder. J Clin End Metab. 2005; 90:5226-33.

Tatchum-Talom R, Martel C, Marette A. Effects of ethinyl estradiol, estradiol, and testosterone on hindlimb endothelial function in vivo. J Cardiovasc Pharmacol. 2002; 39:496-502.

Teoh H, Quan A, Leung SW, Man Y. Differential effects of 17beta-estradiol an testosterone on the contractile responses of porcine coronary arteries. B J. Pharmacol. 2000. 129 (7): p.1301-08.

Thompson J, Khalil RA. Gender differences in the regulation of vascular tone. Clin Exp Pharmacol Physiol. 2003; 30(1-2):1-15.

Torrezan R. O tratamento com isoflavonas mimetiza a ação do estradiol no acúmulo de gordura em ratas ovariectomizadas. Arq Bras Endocrinol Metab . 2008; 52(9): 1489-96.

Tostes RC, Nigro D, Fortes ZB, Caravalho MHC.Effects of estrogen on the vascular system. Braz J Med Biol Res. 2003; 36(9):1143-58.

Tostes RCA, David FL, Carvalho MHC, Nigro D, Scivoletto R, Fortes ZB. Gender differences in vascular reactivity to endothelin-1 in deoxycortiscosterone-salt hypertensive rats. J Cardiovasc Pharmacol. 2000; 36(1):S99-S101.

Thompson J, Khalil R. A. Gender differences in the regulation of vascular tone. Clin Exp Pharmacol Physiol. 2003; 30(1-2):1-15.

Touyz RM, Tabet F, Schiffrin EL. Redox-dependent signalling by angiotensin II and vascular remodelling in hypertension. Clin Exp Pharmacol Physiol. 2003; 30(11):8606.

Utian WH. Overiew on menopause. Am J Obstet Gynecol. 1987;156(5):1280-3. 
VanBuren GA, Yang DS, Clarck KE. Estrogen-induced uterine vasodilatation is antagonized by Lnitroarginine methyl ester; an inhibitor of nitric oxide synthesis. Am J Obstet Gynecol. 1992; 167:828-33.

Vasconcelos SML, Goulart MOF, Moura JBF, Benfato VMMS, Kubota LT. Espécies reativas de oxigênio e de nitrogênio, antioxidantes e marcadores de dano oxidativo em sangue humano: principais métodos analíticos para sua determinação. Quim Nova. 2007; 30(5):1323-38.

Vedernikov YP, Liao QP, Jain V, et al. Effects of chronic treatment with $17 \beta$-estradiol and endothelium-dependent and -independent relaxation in isolated aortic rings from ovariectomized rats. Am J Obstet Gynecol. 1999;176:603-8.

Walter P, Green S, Greene G, Krust A, Bornert JM, Jeltsch JM, et al. Cloning of the human estrogen receptor cDNA. Proc Natl Acad Sci U S A. 1985; 82(23):7889-93.

Ward NC, Chen K, Li C, Croft KD, Keaney JFJr. Chronic activation of AMP-activated protein kinase prevents 20-hydroxyeicosatetraenoic acid-induced endothelial dysfunction. Clin Exp Pharmacol Physiol. 2011; 38(5):328-33.

Washburn SA, Adams MR, Clarkson TB, Adelman SJ. A conjugated equine estrogen with differential effects on uterine weight and plasma cholesterol in the rat. Am J Obstet Gynecol.1993;169(2 Pt 1):251-6.

Watts NB, Notelovitz M, Timmons MC, et al. Comparison of oral estrogens and estrogens plus androgen on bone mineral density, menopausal symptoms and lipidlipoprotein profiles in surg ical menopause. Obstet Gynecol 1995; 85:529-37.

Xing D, Nozell S, Chen YF. Estrogen and mechanisms of vascular protection. Arterioscler Thromb Vasc Biol. 2009; 29:289-95.

Wajchenberg BL. Disfunção endothelial no diabetes tipo 2. Arq Bras Endocrinol Metab. 2002; 46(5):1-6.

Waynforth HB. Experimental and surgical technique in the rat. 1980. London ; Uk. Academic press. p.161

Webb CM, McNeill JG, Hayward CS, Zeigler DE, Collins P. Effects of testosterone on coronary vasomotor regulation in men with coronary heart disease. Circulation. 1999; 100:1690-6.

Windler E, Zyriax BC, Eidenmuller B, et al. Hormone replacement therapy and risk for coronary heart disease Data from the CORA-study-A case-control study on women with incident coronary heart disease. Maturitas. 2007; 57(3): 239-46. 
Wingorve CS, Garr E, Pickar JH, Dey M, Stevenson JC. Effects of equine oestrogens on markers of vasoactive function in human coronary artery endothelial cells. Mol Cell Endocrinol. 1999; 150:33-37.

Winters SJ. Androgens and antioandrogens. In: Brody TM, Larner J, Minnerman KP. Human pharmacology: molecular to clinics. St Louis: Mosby, 1999; p.519-31.

Yue P, Chatterjee K, Beale C, Poole-Wilson PA, Collins P. Testosterone relaxes rabbit coronary arteries and aorta. Circulation. 1995; 91:1154-60.

Yung LM, Wing TW, Xiao YT, Fung PL, Lai HY, et al. Inhibition of Renin-angiotensin system reverses endothelial dysfunction and oxidative stress in estrogen deficient rats. Plos one. $2011 ; 29 ; 6(3): \mathrm{e} 17437$.

Ylikorkala O, Orpana A, Puolakka J, Pyorala T, Viinikka L. Postmenopausal hormonal replacement decreases plasma levels of endothelin-1. Clin Endocrinol Metab. 1995; 80: 3384-87.

Zhang QC, Raz L, Wang GR, et al. Estrogen attenuates ischemic oxidative damage via an estrogen receptor alpha-mediated inhibition of NADPH oxidase activation. J Neurosci. 2009; 29:13823-36.

Yanes LL, Rormare DG, Cucchiarelli VE, Fortepiani LA, Gomez-Sanchez CE, Santacruz F, Reckelhoff JF. . Role of endothelin in mediating postmenopausal hypertension in a rat model. Am J Physiol Regul Integr Comp Physiol 2005; 288: R229-R33.

Yanes LL, Romero DG, lles JW, lliescu R, Gomez-Sanchez C, Reckelhoff JF. Sexual dimorphism in the renin-angiotensin system in aging spontaneously hypertensive rats. Am J Physiol Regul Integr Comp Physiol. 2006; 291: R383-R90.

Yanes LL, Romero G, lliesco R, Zhang H, Davis D, Reckelhoff JF. Postmenopausal hypertension: role of the renin-angiotensin system. Hypertension. 2010;56(3):359-63.

Yanes LL, Reckelhoff JF. Postmenopausal hypertension. Am J Hypertens. $2011 ; 24(7): 740-9$. 